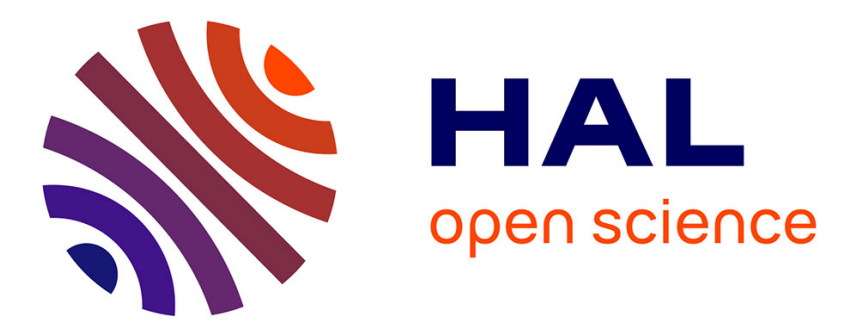

\title{
State of the art in large-scale soil moisture monitoring
}

E. Ochsner, M.H. Cosh, Richard Cuenca, H. Dorigo R., S. Draper C., Y.

Hagimoto, Yann H. Kerr, M. Larson K., E.G. Njoku, E. Small E., et al.

\section{To cite this version:}

E. Ochsner, M.H. Cosh, Richard Cuenca, H. Dorigo R., S. Draper C., et al.. State of the art in largescale soil moisture monitoring. Soil Science Society of America Journal, 2013, pp.1-32. 10.2136/sssaj2013.03.0093 . ird-00913404

\section{HAL Id: ird-00913404 https://hal.ird.fr/ird-00913404}

Submitted on 9 Dec 2013

HAL is a multi-disciplinary open access archive for the deposit and dissemination of scientific research documents, whether they are published or not. The documents may come from teaching and research institutions in France or abroad, or from public or private research centers.
L'archive ouverte pluridisciplinaire HAL, est destinée au dépôt et à la diffusion de documents scientifiques de niveau recherche, publiés ou non, émanant des établissements d'enseignement et de recherche français ou étrangers, des laboratoires publics ou privés. 


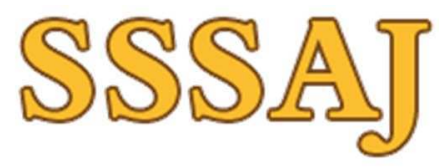

\section{STATE OF THE ART IN LARGE-SCALE SOIL MOISTURE MONITORING}

\begin{tabular}{|r|l|}
\hline Journal: & Soil Science Society of America Journal \\
\hline Manuscript ID: & S-2013-03-0093-IR.R1 \\
\hline Manuscript Type: & Invited Review \\
\hline Keywords: & soil moisture, monitoring \\
\hline & \\
\end{tabular}

SCHOLARONE $^{\text {I" }}$

Manuscripts 


\section{STATE OF THE ART IN LARGE-SCALE SOIL MOISTURE MONITORING}

Formatted: Indent: First line: $0.5^{\prime \prime}$

\begin{abstract}
Soil moisture is an essential climate variable influencing land_-_atmosphere interactions, an essential hydrologic variable impacting rainfall___runoff processes, an essential ecological variable regulating net ecosystem exchange, and an essential agricultural variable constraining food security. Large-scale soil moisture monitoring has advanced in recent years creating opportunities to transform scientific understanding of soil moisture and related processes. These advances are being driven by researchers from a broad range of disciplines, but this complicates collaboration and communication. And, for some applications, the science required to utilize large-scale soil moisture data is poorly developed. In this review, we describe the state of the art in large-scale soil moisture monitoring and identify some critical needs for research to optimize the use of increasingly available soil moisture data. We review representative examples of 1) emerging in situ and proximal sensing techniques, 2) dedicated soil moisture remote sensing missions, 3) soil moisture monitoring networks, and 4) applications of large-scale soil moisture measurements. Significant near-term progress seems possible in the use of large-scale soil moisture data for drought monitoring. Assimilation of soil moisture data for meteorological or hydrologic forecasting also shows promise, but significant challenges related to spatial variability and model structures-and model errors remain. Little progress has been made yetin the use of large-scale soil moisture observations within the context of ecological or agricultural modeling. Opportunities abound to advance the science and practice of large-scale soil moisture monitoring for the sake of improved Earth system monitoring, modeling, and forecasting.
\end{abstract}


The science and practice of large-scale soil moisture monitoring has entered a stage of unprecedented growth with the potential to transform scientific understanding of the patterns and dynamics of soil moisture and soil moisture-related processes. Large-scale soil moisture monitoring may lead to improved understanding of soil moisture controls on water, energy, and carbon fluxes between the land and atmosphere, resulting in improved meteorological forecasts and climate projections. Soil moisture measurements are also key in assessing flooding and monitoring drought. Knowledge gained from large-scale soil moisture observations can help mitigate these natural hazards, yielding potentially great economic and societal benefits. Here large-scale refers to spatial support scales of $>1^{2} \mathrm{~m}^{2}$ for an in situa sensor or spatial extents of $>100^{2} \mathrm{~km}^{2}$ for an in situa sensor network (Crow et al., 2012; Western and Blöschl, 1999). In this review areas are often enumerated in the $\mathrm{XX}^{2}$ format to indicate the length of one side of a square of the given area, e.g. $10,000 \mathrm{~km}^{2}=100^{2} \mathrm{~km}^{2}$. New developments continue within the realm of in situ sensors which monitor soil moisture at the point-scale, i.e.i.e., $<1^{2} \mathrm{~m}^{2}$ support. These point-scale sensors have been reviewed recently (Dobriyal et al., 2012; Robinson et al., 2008) and will not be considered here except within the context of large-scale networks. Rather, this review aims to broadly describe the state of the art in large-scale soil moisture monitoring. Airborne and satellite remote sensing approaches for soil moisture are also-considered largescale monitoring techniques in this review.

To provide context, it is helpful to begin with a brief historical overview of soil moisture monitoring in general. The first major technological advance in modern soil moisture monitoring can be traced to the development of the neutron probe after World War II (Evett, 2001). The measurement of soil moisture based on neutron thermalization first appeared in peerreviewed literature in a paper by Iowa State College (now University) soil physicists, Gardner 
and Kirkham (1952). This technology was soon commercialized under a contract between the US Army Corps of Engineers and Nuclear-Chicago Corporation, and by 1960 hundreds of neutron probes were in use around the world (Evett, 2001). The neutron probe remained the de facto standard for indirect soil moisture measurement until a soil physicist and two geophysicists working for the Government of Canada made a key breakthrough in using dielectric properties to measure soil water (Topp et al., 1980). Despite initial skepticism from the soil science and remote sensing communities (Topp, 2006), the time domain reflectometry (TDR) approach of Topp et al. (1980) eventually became a dominant technology for soil moisture monitoring, and created for the first time, the possibility of automated, multiplexed, unattended, in situ monitoring (Baker and Allmaras, 1990). By the 1990s, the TDR technology had proven the value of electromagnetic methods for monitoring soil moisture, and an avalanche of impedance or capacitance type probes followed (Robinson et al., 2008). These capacitance probes typically operate at frequencies much lower than the effective frequency of TDR. As a result these probes are simpler and less expensive, but also less accurate than TDR (Blonquist et al., 2005). Much effort has also been devoted to the development of heat dissipation (Fredlund and Wong, 1989; Phene et al., 1971; Reece, 1996) and heat pulse sensors (Bristow et al., 1993; Campbell et al., 1991; Heitman et al., 2003; Ochsner et al., 2003; Song et al., 1999; Tarara and Ham, 1997) for soil moisture measurement with reasonable success.

While Canadian researchers were beginning to develop the groundbreaking TDR method, scientists in the US were pioneering remote sensing of soil moisture from tower, aircraft, and satellite platforms using microwave radiometers (Schmugge et al., 1974), scatterometers (Dickey et al., 1974), synthetic aperture radar (Chang et al., 1980), and combined radar/radiometer systems (Ulaby et al., 1983). A variety of $\underline{\text { Various }}$ other techniques were also introduced during 
the same time, including methods based on polarized visible light (Curran, 1978), thermal inertia (Pratt and Ellyett, 1979), and terrestrial gamma radiation (Carroll, 1981). Satellite remote sensing approaches in particular have engendered much enthusiasm and interest with their promise of global data coverage ${ }_{2}$ leading Vinnikov et al. (1999) to speculate that, in regards to long-term soil moisture monitoring, "The future obviously belongs to remote sensing of soil moisture from satellites..- And, in fact, the intervening decades of research on remote sensing of soil moisture are now beginning to bear fruit in terms of operational satellites for large-scale soil moisture monitoring.

Not everyone has been content to wait for the arrival of operational soil moisture satellites; rather, some have envisioned and created large-scale in situ monitoring networks for soil moisture. The earliest organized networks were in the Soviet Union and used repeated gravimetric sampling (Robock et al., 2000). The Illinois Climate Network was the first largescale network to use a nondestructive measurement device, the neutron probe (Hollinger and Isard, 1994), while the US Department of AgricultureDA (USDA) Natural Resources Conservation Service (NRCS) Soil Climate Analysis Network (SCAN) (Schaefer et al., 2007) and the Oklahoma Mesonet (McPherson et al., 2007) pioneered the use of automated, unattended sensors in large-scale soil moisture networks during the 1990s. Since then numerous networks have emerged around the world, and have come to play vital roles in the science and practice of large-scale soil moisture monitoring, not the least of which is their role in calibrating and validating satellite remote sensing techniques.

The past ten years have witnessed the emergence of potentially transformative new soil moisture technologies which are beginning to fundamentally alter the possibilities for large-scale monitoring. These new methods include the cosmic-ray soil moisture observing system 
(COSMOS), global positioning system (GPS) based techniques, and fiber optic distributed temperature sensing (DTS) approaches (Larson et al., 2008; Sayde et al., 2010; Steele-Dunne et al., 2010; Zreda et al., 2008). Meanwhile, the number and scope of large-scale automated soil moisture monitoring networks has been steadily increasing, both in the US and around the world. And, in 2009, the European Space Agency (ESA) launched the Soil Moisture Ocean Salinity (SMOS) satellite, the first one designed specifically for soil moisture monitoring (Kerr et al., 2010).

Despite these developments, many challenges remain within the realm of large-scale soil moisture monitoring. The recent progress in this field has been enabled by contributions from many different disciplines, and future progress will likely be interdisciplinary, as well. But, staying informed about new developments can be challenging when the research is spread across a broad range of science disciplines from soil science to remote sensing to geodesy to meteorology. Contemporary soil physicists, whose predecessors were instrumental in birthing the modern era of soil moisture monitoring, have been largely focused on development and testing of point-scale measurement techniques and have perhaps not been adequately engaged in advancing the science of large-scale monitoring. Great advances have been made in satellite remote sensing approaches for estimating surface soil moisture, but the coarse horizontal $\underline{\text { resolution and the shallow sensing depth are significant limitations for many applications }}$ (Wagner et al., 2007). Most impertantlyFurthermore, the basic-science and technology required to actually use large-scale soil moisture data is relatively under-developed. There has been a dearth of research investment in developing modeling and forecasting tools informeddriven by large-scale-soil moisture data-especially data from large-scale in situ networks. There has also $\underline{\text { been little research on the use of remotely sensed soil moisture products for applications beyond }}$ 
weather forecasting or streamflow prediction.-_This was understandable in previous decades when the widespread availability of such data was a distant prospect, but the circumstances have changed. Soil moisture data are now common and may be ubiquitous in the near future.

In light of these circumstances, we seek to meet the need for a cross-disciplinary state of the art review for the sake of improving communication and collaboration. We further seek to engage and mobilize the expertise of the international soil science, and specifically soil physics, community in advancing the science and practice of large-scale soil moisture monitoring. Also, we seek to highlight the pressing need to accelerate the pace of progress in the area of using large-scale soil moisture observations for advanced Earth systems monitoring, modeling, and forecasting applications. Our objectives are 1) to succinctly review the state of the art in largescale soil moisture monitoring and 2) to identify some critical needs for research to optimize the use of increasingly available soil moisture data.

This review does not aim to be comprehensive. Rather we have selected specific topics which are illustrative of the opportunities and challenges ahead. This review is organized in four primary sections: 1) emerging in situ and proximal sensing techniques, 2) dedicated soil moisture remote sensing missions, 3) soil moisture monitoring networks, and 4) applications of large-scale soil moisture measurements. In this context, "in situ" techniques are those using sensors embedded in the soil, and "proximal" techniques are those using sensors which are in close proximity to the soil, but not embedded in it. Some observations regarding primary challenges and opportunities for large-scale soil moisture monitoring are provided at the end of the review. 
Area-average soil moisture can be measured in the field using cosmic-ray neutron background radiation whose intensity in air above the land surface depends primarily on soil moisture. The cosmic-ray probe integrates soil moisture over an area hundreds of meters in diameter, something that would require an entire network of point measurement devices. Measurements can be made using stationary probes, which provide an hourly time series of soil moisture, or mobile probes, which provide snapshots in time over an area or along a line. Cosmic-ray protons that impinge on the top of the atmosphere create secondary neutrons that in turn produce additional neutrons, thus forming a self-propagating nucleonic cascade (Simpson, 2000; Desilets and Zreda, 2001). As the secondary neutrons travel through the atmosphere and then through the top few meters of the biosphere, hydrosphere and lithosphere, fast neutrons are created (Desilets et al., 2010). Because fast neutrons are strongly moderated by hydrogen present in the environment (Zreda et al., 2008, 2012), their measured intensities reflect variations in the soil moisture (Zreda et al., 2008) and other hydrogen present at and near the Earth's surface (Zreda et al., 2012; Franz et al., 2013).

The process of neutron moderation depends on three factors that together define the neutron stopping power of a material (Zreda et al., 2012): (1) the elemental scattering cross section or probability of scattering; hydrogen has a high probability of scattering a neutron; (2) the logarithmic decrement of energy per collision, which characterizes how efficient each collision is; hydrogen is by far the most efficient element; and (3) the number of atoms of an element per unit mass of material, which is proportional to the concentration of the element and to the inverse of its mass number. Because of the abundance of water in soils and hydrogen's low atomic mass, hydrogen, next to oxygen and silicon, makes up a significant fraction of all 
atoms in many soils. The extraordinarily high stopping power of hydrogen makes the cosmicray soil moisture method work.

The fast neutrons that are produced in air and soil travel in all directions within and between air and soil and in this way an equilibrium concentration of neutrons is established. The equilibrium is shifted in response to changes in the hydrogen content of the media, which in practice means changes in the amount of water on or in the soil. Adding water to soil results in more efficient moderation of neutrons by the soil, causing a decrease of fast neutron intensity above the soil surface. Removing water from the soil has the opposite effect. Thus, by measuring the fast neutron intensity in the air the moisture content of the soil can be inferred, for example using the equation of Desilets et al. (2010):

$$
\theta=\frac{a_{0}}{\left(N / N_{0}\right)-a_{1}}-a_{2}
$$

which is plotted in Fig. 1. In the equation $\theta$ is the neutron-derived moisture content, $N$ is the measured neutron intensity, $N_{0}$ is the neutron intensity in air above a dry soil (this is a calibration parameter obtained from independent in situ soil moisture data), and $a_{0}, a_{1}$, and $a_{2}$ are fitted constants that define the shape of the calibration function. Neutron transport modeling shows that the shape of the calibration function is similar for different chemical compositions of soil and soil textures (Zreda et al., 2008; Desilets et al., 2010) and in presence of hydrogen pools other than pore water, for example vegetation or water vapor (Franz et al., 2013; Rosolem et al., 2012). Therefore, the same function can be used under different field conditions once corrections are made for all pools of hydrogen (Franz et al., 2013).

The probe senses all hydrogen present within the distance that fast neutrons can travel in soils, water, air and other materials near the land surface. That distance varies with the chemical 
composition and density of the material, from centimeters in water through decimeters in soils to hectometers in air. The support volume can be visualized as a hemisphere above the soil surface placed on top of a cylinder in the soil (Fig. 2). For soil moisture measurements the diameter and height of the cylinder are important. The horizontal footprint, which is defined as the area around the probe from which $86 \%\left(1-\mathrm{e}^{-2}\right)$ of counted neutrons arise, is a circle with a diameter of $660 \mathrm{~m}$ at sea level (Zreda et al., 2008). It decreases slightly with increasing soil moisture content and with increasing atmospheric water vapor content, and it increases with decreasing air density (decreasing atmospheric pressure or increasing altitude)(Zreda et al., 2012). The horizontal footprint has been verified by field measurements (Zweck et al., 2011).

The effective depth of measurement, which is defined as the thickness of soil from which $86 \%\left(1-\mathrm{e}^{-2}\right)$ of counted neutrons arise, depends strongly on soil moisture (Zreda et al., 2008). It decreases non-linearly from about $70 \mathrm{~cm}$ in soils with no water to about $12 \mathrm{~cm}$ in saturated soils and is independent of air density. The effective depth of measurement decreases with increasing amount of hydrogen in other reservoirs, such as lattice water, soil organic matter or vegetation.

The decrease in the vertical support volume is more significant at the dry end (on the order of 10 $\mathrm{cm}$ ) than at the wet end (on the order of $1 \mathrm{~cm}$ ). The vertical footprint has not been verified empirically.

Neutrons react with any hydrogen present near the Earth's surface. Therefore, the measured neutron intensity reflects the total reservoir of neutrons present within the sensing distance of the probe (Fig. 2), and hence the probe can be viewed as the total surface moisture probe. The greater the concentration of hydrogen, the greater is its impact on the neutron intensity. Large near-surface reservoirs of hydrogen, roughly in order of decreasing size, are: (1) surface water (including snow), (2) soils, (3) lattice water and water in soil organic matter; (4) 
vegetation, and (5) atmospheric water vapor. Because the neutron signal integrates all these factors, isolation of one of these components, for example soil moisture, requires that the others be: (a) constant in time, (b) if not constant, assessed independently, or (c) negligibly small. In addition, the support volume (or the measurement volume) will be affected by these other sources of hydrogen.

Calibration requires simultaneous measurements of area-average soil moisture $(\theta)$ and neutron intensity $(N)$, and solving Eq. [1] for the calibration parameter $N_{0}$. Area-average soil moisture representative of the cosmic-ray footprint is obtained by collecting numerous soil samples around the cosmic-ray probe and measuring moisture content by the oven-drying method (Zreda et al., 2012); other methods, such as time-domain reflectometry $\underline{\text { TDR, }}$ can be used as well. The measured neutron intensities must be corrected for atmospheric water vapor and pressure variations. Soil samples must be analyzed for chemical composition to correct the calibration function for any additional water in mineral grains (lattice water) and in organic matter present in the soil (Zreda et al., 2012). The presence of that extra water shifts the position of the calibration point to the left on the calibration function (Fig. 1), which results in steeper curve and thus in reduced sensitivity of neutrons to changes in soil moisture. Other sources of water have a similar effect on the calibration function.

Measurement precision of soil moisture determination is due to neutron counting statistics. The counts follow the Poisson distribution (Knoll, 2000) in which for the total number of counts, $N$, the standard deviation is $N^{0.5}$. Thus, more counts produce better precision (i.e.i.e., lower coefficient of variation), provided that the neutron intensity remains stationary over the counting time. High counting rates are expected under these conditions: (1) high altitude and high latitude, because the incoming cosmic-ray intensity, which is the precursor to fast neutrons, 
increases with both (Desilets and Zreda, 2003; Desilets et al., 2006); (2) dry soil, because of the inverse relation between soil moisture and neutron intensity (Fig. 1); (3) dry atmosphere, because of the inverse relation between atmospheric moisture and neutron intensity (Rosolem et al., 2012); (4) no vegetation; (5) low lattice and organic matter content of soil. Opposite conditions will result in lower counting rates and poorer precision.

The accuracy of soil moisture determination depends on a few factors related to calibration and the presence of other pools of hydrogen within cosmic-ray probe support volume. The calibration uncertainty is due to two factors: (1) the accuracy of the independent measure of area-average soil moisture, which is usually below $0.01 \mathrm{~m}^{3} \mathrm{~m}^{-3}$; (2) the accuracy of neutron count rate at the time of calibration, which is usually around $2 \%$. (These calibration data sets can be viewed at cosmos.hwr.arizona.edu.) If these were the only contributing factors, the accuracy would be better than $0.01 \mathrm{~m}^{3} \mathrm{~m}^{-3}$. But there are a few complicating factors that may lead to an increase of the uncertainty. They include atmospheric water vapor, infiltration fronts, changing horizontal correlation scale of soil moisture, variable vegetation, and variations in the incoming cosmic-ray intensity. Corrections have been developed for these factors, but their contributions

to the overall uncertainty of soil moisture determination have not been assessed rigorously. At a desert site near Tucson, Arizona, Franz et al. (2012) found a root mean square error (RMSE) of $0.017 \mathrm{~m}^{3} \mathrm{~m}^{-3}$ between the soil moisture estimates from a well-calibrated cosmic-ray probe and the depth-weighted soil moisture average from a network of point-scale sensors distributed across the probe footprint.

Cosmic-ray soil moisture probes are used as stationary or roving devices. Stationary probes are installed above the land surface to measure and transmit neutron intensity and ancillary data at user-prescribed time intervals (Zreda et al., 2012). These measurements are then 
used, together with cosmic-ray background intensity data, to compute soil moisture. A network of stationary probes, called the COsmic-ray Soil Moisture Observing System (COSMOS), is beinghas been installed in the USA, with the main aim to provide area-average soil moisture data for atmospheric applications (Zreda et al., 2012). Data are available with one hour latency at http://cosmos.hwr.arizona.edu. Other networks or individual probes are being installed in Australia (the network named CosmOz), Germany (Rivera Villarreyes et al., 2011) and elsewhere around the globe.

A mobile version of the cosmic-ray soil moisture probe, called COSMOS rover, is under development. Its main application is mapping soil moisture over large areas from a car or an aircraft; a backpack version is possible as well. The vehicle-mounted instrument is approximately ten times larger than the stationary cosmic-ray probe to provide more counts (better statistics) in short time as the vehicle progresses along the route. The measured neutron intensity is converted to soil moisture using the usual calibration equation (Desilets et al., 2010). Transects (Desilets et al., 2010) or maps (Zreda et al., 2011) of soil moisture can be produced within hours or days. Such maps are-may prove useful for many applications, including calibration and validation of satellite soil moisture missions like SMOS. SMOS (Kerr et al., 2010) and SMAP (Entekhabiet al., 2010).

\section{Soil Moisture Monitoring Using Global Positioning System Signals}

While the cosmic ray probe utilizes an existing natural "signal,", the ambient fast neutron intensity, to infer soil moisture, new methods employing global pesitioning system (GPS) receivers utilize existing anthropogenic signals. The GPS signals follow two types of paths between the satellites that transmit GPS signals and the antennas that receive them (Fig. 3).

Some portion of GPS signals travel directly from satellites to antennas. These direct signals are 
optimal for navigation and geodetic purposes. Antennas also receive GPS signals that reflect off the land surface-, referred to as multipath by the geodetic community (Georgiadou and Kleusberg, 1988). GPS satellites transmit microwave (L-band) signals (1.57542 and 1.22760 GHz) that are optimal for sensing water in the environment (Entekhabi et al., 2010). For bare soil conditions, the reflection coefficients depend on permittivity of the soil, surface roughness, and elevation angle of the reflections. Therefore, reflected GPS signals can be used to estimate soil moisture, as well as other environmental parameters. GPS antennas and receivers can also be mounted on satellites (Lowe et al., 2002) or on planes (Katzberg et al., 2005). The data collected by these instruments are considered remote sensing observations. Alternatively, GPS reflections can also be measured using antennas mounted fairly close to the land surface (Larson et al., 2008; Rodriguez-Alvarez et al., 2011a), yielding a hybrid remote sensing in sitt ebservationproximal sensing technique. Ground-based GPS studies use the interference of the direct and reflected GPS signals, and thus the method is often called GPS interferometric reflectometry (GPS-IR).

For GPS-IR systems, the sensing footprint depends on (1) the height of the antenna above the ground and (2) the range of satellite elevation angles used in the analysis. As satellite elevation angle $(E)$ increases, the portion of the ground that yields specular (i.e.i.e.. mirror-like) reflections both shrinks and moves closer to the antenna. For the case of a typical geodetic antenna height of $2 \mathrm{~m}$, the center of the area sensed varies from $25 \mathrm{~m}$ at an elevation angle of $E=5_{-}^{\circ}$ degrees to $5 \mathrm{~m}$ at an elevation angle of $E-30_{-}^{\circ}$-degrees. Larger sampling areas can be achieved by raising the antenna to heights of $\sim 100 \mathrm{~m}$, above which observations are complicated by the GPS code lengths (Rodriguez-Alvarez et al., 2011a). As GPS is a constellation of more than 30 satellites, different GPS satellites rise and set above a GPS soil moisture site throughout 
the day. These reflections are measured from different azimuths depending on the orbital characteristics of each satellite. For the best sites, more than 60 soil moisture estimates can be made per day. So, the soil moisture data estimated from GPS reflections should be considered as daily in temporal frequency, once averaged over an area of $\sim 1000 \mathrm{~m}^{2}$ for antenna heights of $2 \mathrm{~m}$ (Larson et al., 2008).

\section{Two methods of GPS soil moisture sensing are currently beinghave been developed. The} first is based on using GPS instruments designed for geodesists and surveyors. These GPS instruments traditionally measure the distance between the satellites and antenna in order to estimate position. However these GPS instruments also measure signal power, or signal-to-noise ratio (SNR). Embedded on the direct signal effect are interference fringes caused by the reflected signal being in or out of phase with respect to the direct signal. The SNR frequency is primarily driven by the height of the antenna above the ground. As permittivity of the soil changes, the amplitude, phase, and frequency of the SNR interferogram varies. (Larson et al., 2010;

Zavorotny et al., 2010). Of the three parameters, the phase of the SNR interferogram is the most useful for estimating soil moisture.

Chew et al (2013) demonstrated theoretically that phase varies linearly with surface soil moisture. For the soils described by Hallikainen et al. (2005), the slope of this relationship does not vary with soil type. For most conditions, phase provides a good estimate of average soil moisture in the top $5 \mathrm{~cm}$. The exception is when very wet soil overlies dry soil, for example immediately following short-duration rainstorms when the wetting front has not propagated to $\sim 5$ cm (Larson et al., 2010). Estimates of soil moisture from phase have been compared to in situ soil moisture measurements (Fig. 4). At grass-dominated sites with relatively low vegetation water content $\left(<0.5 \mathrm{~kg} \mathrm{~m}^{-2}\right)$, SNR phase varies linearly with in situ soil moisture $\left(\mathrm{r}^{2}>0.8 \underline{76}\right)$ 
(Larson et al., 2008; and unpublished dataLarson et al., 2010), consistent with the theoretical analysis by-as predicted by Chew et al. (2013). The vegetation at these sites is typical of many rangeland areas in the western U.S.US A SNR interferogram is also affected by higher water content vegetation, for example that which exists in irrigated agricultural fields (Small et al., 2010). Methods are being developed to retrieve surface soil moisture from SNR interferograms under these conditions.

One advantage to using geodetic GPS equipment to measure soil moisture is that existing geodetic networks can provide much needed hydrologic information. The National Science Foundation's Plate Boundary Observatory (PBO)network has more than 1100 stations with effectively identical GPS instrumentation. Many of the stations are located amidst complex topography, which does not facilitate estimation of soil moisture via GPS-IR. However, soil moisture is being estimated at 59 stations with relatively simple topography. The data is are updated daily and is-are available at http://xenon.colorado.edu/portal/.

A second GPS soil moisture sensing method is also under development (RodriguezAlvarez et al., 2009). Similar to Larson et al. (2008), this system measures the interference pattern resulting from the combination of direct and reflected GPS signals. A dual polarization antenna measures power of the vertically- and horizontally-polarized signals separately, which is not possible using standard geodetic instrumentation. The satellite elevation angle at which reflectivity of the vertically-polarized signal approaches zero, i.e.i.e., the Brewster angle, varies with soil moisture (Rodriguez-Alvarez et al., 2011a). The existence of this Brewster angle yields a notch in the interference pattern. The position of the notch is then used to infer soil moisture. 
Over a bare soil field, this technique yielded 10 soil moisture estimates over a one month period; they show good agreement with those measured in situ at a depth of $5 \mathrm{~cm}(\mathrm{RMSE}$-error $<$ $0.03 \mathrm{~m}^{3} \mathrm{~m}^{-3}$ ) (Rodriguez-Alvarez et al.,,2009). A vegetation canopy introduces additional notches to the observed interference pattern. The position and amplitude of these notches can be used to infer both vegetation height and soil moisture. This approach yielded excellent estimates of corn height throughout a growing season $($ RMSE $\underline{\text {-error }}=6.3 \mathrm{~cm})$ (Rodriguez-Alvarez et al., 2011b). Even beneath a 3_m tall corn canopy, soil moisture estimates typically differed by $<0.04$ $\mathrm{m}^{3} \mathrm{~m}^{-3}$ from those measured with in situ probes at $5 \mathrm{~cm}$. The main difference between these two approaches is that the approach of Larson et al. (2008) uses commercially-available geodetic instrumentation - which typically already exists - and can be simultaneously used to measure position. The approach of Rodriguez-Alvarez et al. (2009) uses a system specifically designed for environmental sensing, but it is not yet commercially-available-, (1)

Soil Moisture Monitoring Using Distributed Temperature Sensing

Much as the Larson et al. (2008) GPS-IR method repurposes commercially available GPS receivers to monitor soil moisture, other researchers have sought to develop new soil moisture monitoring methods using commercially available distributed temperature sensing (DTS) systems. In a DTS system, an optical instrument is used to observe temperature along a continuum of points within an attached optical fiber cable, typically by the principle of Raman scattering (Selker et al., 2006). The spatial location corresponding to each temperature measurement is determined based on the travel time of light in the fiber in a manner analogous to TDR. Weiss (2003) pioneered the use of DTS systems for soil moisture monitoring by successfully demonstrating the potential use of fiber optics to detect the presence of moisture in a 
landfill cover constructed from sandy loam soil. A $120-\mathrm{V}$ generator supplied current to the stainless steel sheath of a buried optical fiber cable for $\sim 626 \mathrm{~s}$ at a rate of $18.7 \mathrm{~W} \mathrm{~m}^{-1}$, and the corresponding spatially variable temperature rise of the cable was observed at 40-s temporal resolution and 1-m spatial resolution. Analysis of the temperature rise data using the single probe method (Carslaw and Jaeger, 1959) resulted in satisfactory estimates of the spatial variability of soil thermal conductivity along the cable, which in turn reflected the imposed spatial variability of soil moisture. However, the temperature uncertainty achieved was $\sim 0.55^{\circ} \mathrm{C}$, and Weiss concluded that without improvements in signal-to-noise ratio, that system would not be able to resolve small changes in soil moisture above $0.06 \mathrm{~m}^{3} \mathrm{~m}^{-3}$ for the sandy loam soil used in that study.

The potential of using passive (unheated) DTS methods for soil moisture estimation was explored by Steele-Dunne et al. (2010). Optical fiber cable was installed in a tube on the soil surface and at depths of 8 and $10 \mathrm{~cm}$. The soil texture was loamy sand, and the vegetation cover was sparse grass. With temperatures from the upper and lower cables as time-dependent boundary conditions, the temperature at the middle cable was modeled by numerical solution of the 1-D heat conduction equation. A numerical search routine was used to find the thermal diffusivity which produced the best agreement between the simulated and observed temperatures at the $8 \mathrm{~cm}$ depth. The results demonstrated that the passive DTS system could detect temporal changes in thermal diffusivity associated with rainfall events, but the accuracy of the diffusivity estimates was hindered by uncertainties about the exact cable depths and spacings. Furthermore, deriving soil moisture estimates was complicated by uncertainty and nonuniqueness in the diffusivity—soil moisture relationship. 
Sayde et al. (2010) modified the active DTS approach of Weiss (2003) by interpreting the temperature rise data in terms of cumulative temperature increase, i.e.i.e., the integral of the temperature rise from the beginning of heating to some specified time limit. Based on a laboratory sand column experiment with 2-min, $20 \mathrm{~W} \mathrm{~m}^{-1}$ heat pulses, they developed an empirical calibration function which fit the observed cumulative temperature increase ( 0 to 120 s) versus soil moisture data. Based on that function and the observed uncertainty in the cumulative temperature increase data, the uncertainty in the soil moisture estimates would increase approximately linearly from $0.001 \mathrm{~m}^{3} \mathrm{~m}^{-3}$ when soil moisture is $0.05 \mathrm{~m}^{3} \mathrm{~m}^{-3}$ to $0.046 \mathrm{~m}^{3}$ $\mathrm{m}^{-3}$ when soil moisture is $0.41 \mathrm{~m}^{3} \mathrm{~m}^{-3}$. Gil-Rodríguez et al. (2012) used the approach of Sayde et al. (2010) to satisfactorily monitor the dimensions and evolution of the wetted bulb during infiltration beneath a drip emitter in a laboratory column of sandy loam soil.

Striegl and Loheide (2012) used an active DTS approach to monitor spatial and temporal dynamics of soil moisture along a 130-m transect associated with a wetland reconstruction project (Fig. 5). They used a $10-\mathrm{min}, 3 \mathrm{~W} \mathrm{~m}^{-1}$ heat pulse, a lower heating rate than used in previous active DTS studies. They followed Sayde et al. (2010) in adopting a primarily empirical calibration approach, but rather than cumulative temperature increase, they related soil moisture to the average temperature rise observed from 380 to $580 \mathrm{~s}$ after the onset of heating. A calibration function was developed by relating the observed temperature rise data to independent soil moisture measurements at three points along the transect, and the resulting function had a RMSE $=0.016 \mathrm{~m}^{3} \mathrm{~m}^{-3}$ for soil moisture $<0.31 \mathrm{~m}^{3} \mathrm{~m}^{-3}$ but $\mathrm{RMSE}=0.05 \mathrm{~m}^{3} \mathrm{~m}^{-3}$ for wetter conditions. Their system successfully monitored field scale spatiotemporal dynamics of soil moisture at 2-m and 4-h resolution across a 2-month period consisting of marked wetting and drying cycles (Fig. 6). 

unmatched spatial resolution $(<1 \mathrm{~m})$ in long-term soil moisture monitoring on field scale $(>100$ m) transects. These methods may in the near future greatly impact our understanding of the finescale spatiotemporal structure of soil moisture and shed new light on the factors influencing that structure. Thus far, the active DTS methods have shown more promise than passive DTS, but more sophisticated data assimilation approaches for interpreting passive DTS data are in development. The active DTS method is still in its infancy, and many key issues remain to be addressed. None of the active DTS methods developed to date involve spatial variability in the soil moisture calibration function, so heterogeneity in soil texture and bulk density could give rise to appreciable uncertainties in field settings. Field installation of the optical fiber cables at the desired depths with good soil contact and minimal soil disturbance is also a significant challenge. Custom designed cable plows (Steele-Dunne et al., 2010) and commercial vibratory plows (Striegl and Loheide, 2012) have been used with some success. The active DTS methods have demonstrated good precision for low to moderate soil moisture levels, but further improvements in measurement precision are needed for wet conditions. Obtaining good quality temperature measurements using a DTS instrument in the field requires that thermally-stable calibration baths be included in the system design. The instrument itself must also be in a thermally-stable environment because sizeable errors can result from sudden changes in the instrument temperature (Striegl and Loheide, 2012). The measurement principles behind DTS are discussed in more detail by Selker et al. (2006), and practical aspects of DTS, including key limitations and uncertainties, are described by Tyler et al. (2009). 
Remote sensing approaches for soil moisture monitoring have been investigated since the 1970 s, although but the first dedicated soil moisture satellitemission, -measuring in the Lband range (1-2 GHz), SMOS, was not launched until 2009. However, sSoil moisture estimates have been are also being, nonetheless, derived retrieved from other-satellite instruments not specifically designed for sensing soil moisture, most notably from microwave sensors operating at sub-optimal frequencies.not specifically optimized for soil moisture monitoring. The Advanced Microwave Scanning Radiometer for EOS (AMSR-E) instrument was carried into orbit aboard the US National Aeronautics and Space Administration (NASA) Aqua satellite in 2002 and provided passive measurements in the $\mathrm{C}$ band range $(-4 \mathrm{GHz})$ at six dual-polarized frequencies until October 2011 when a problem with the rotation of the antenna ended the data stream (Njoku et al., 2003). Several different retrieval algorithms have been developed to retrieve soil moisture from the lowest two frequencies $(6.9,10.6 \mathrm{GHz})$ observed by AMSR-E (e.g., Owe et al, 2001; Njoku et al 2003). Soil moisture information is also being retrieved from active microwave sensors, specifically from Following the launch of AMSR-E, theESA's taunched the-Advanced Scatterometer (ASCAT), which was launched in in 2006 aboard the MetOp-A meteorological satellite (and before that from ASCAT's predecessors, the ERS satellites): The ERS and The-ASCAT instruments areis aC-band radar scatterometers designed for measuring wind speed; however soil moisture retrievals have also been developed (Bartaliset al., 2007Wagner et al., 1999). An operationally-supported, remotely-sensed soil moisture product derived from the ASCAT instrument is currently available (Wagner et al., 2013). Wagner et al. (2007) provided an excellent review of then-existing satellite remote sensing approaches for soil moisture; here we focus on two newer satellite approaches and one airborne approach. 


\section{Soil Moisture and Ocean Salinity Mission (SMOS)}

The Soil Moisture and Ocean Salinity mission (Kerr et al., 2010), an Earth Explorer

Opportunity mission, was successfully-launched on November 2, 2009, and successfully econcluded its commissioning phase in May 2010. It was developed under the leadership of the European Space Agency (ESA) with the Centre National d'Etudes Spatiales (CNES) in France and the Centro para el Desarrollo Teccnologico Industrial (CDTI)-in Spain.

Microwave radiometry at low frequencies is an established technique for estimating surface soil moisture with an adequate sensitivity. The choice of L-band as the spectral range in which to operate was determined from a large number of studies that demonstrated L-band has high sensitivity to changes of moisture in the soil (Schmugge and Jackson, 1994) and salinity in the ocean (Lagerloef, 2001). Furthermore, observations at L-band are less susceptible to attenuation due to the atmosphere or the vegetation than measurements at higher frequencies (Jackson and Schmugge, 1989; Jackson and Schmugge, 1991). L-band also enables a larger penetration depth into the surface soil layer than is possible with shorter wavelengths (Escorihuela et al., 2010).

Even though the L-band radiometry concept was demonstrated early by a space experiment (SKYLAB) back in the 1970's, no dedicated space mission followed because achieving a suitable-ground resolution $(\leq 50-60 \mathrm{~km})$ required a prohibitive antenna size $(\geq 4 \underline{8}$ $\mathrm{m})$. The so-called interferometry design, inspired from the very large baseline antenna concept (radio astronomy), made such a venture possible. Interferometry was first put forward in the $\underline{1980 \text { 's (Levine, 1988) and validated with an airborne prototype (Levine et al., 1994; Levine et }}$

al., 1990). The idea consists of deploying an array of small receivers in space (located 
endistributed along a a deployable-structure) that folds for launch then unfolds in orbit. This approach enables reconstruction of, then reconstructing a brightness temperature $\left(T_{B}\right)$ field with a resolution corresponding to the spacing between the outmost receivers. The two-dimensional interferometer allows measuring $T_{\underline{B}}$ at several incidence angles, with full polarization. Such an instrument instantaneously records a whole scene; as the satellite moves, a given point within the 2D field of view is observed from different view angles. The series of independent measurements allows retrieving surface parameters with much improved accuracy.

The baseline SMOS payload is thus an L-band $(1.413 \mathrm{GHz}, 21 \mathrm{~cm}$ - located within the protected 1400-1427 MHz band) 2D interferometric radiometer designed to provide accurate soil moisture data with moderate spatial resolution. The radiometer that is $\mathrm{Y}$ shaped with three $4.5 \mathrm{~m}$ arms as shown in Figure 7. SMOS is on a sun--synchronous (6 a.m. ascending) circular orbit and measures the $\underline{T}_{\underline{B}}$ brightness temperature emitted from the Earth at L-band over a range of incidence angles ( 0 to $55^{\circ}$ ) across a swath of approximately $1000 \mathrm{~km}$ (covering the globe twice in less than 3 days)-with a spatial resolution of 35 to $50 \mathrm{~km}$ (average is $43 \mathrm{~km}$ ) and a maximum revisit time of three days for both ascending and descending passes (Kerr et al., 2001; Kerr et al., 2010). A retrieval algorithm incorporating an L-band microwave emission forward model is applied to the $T_{\underline{B}}$ data to estimate soil moisture (Kerr et al., 2012).).

The SMOS mission originated from recognition of the need for accurate, global, soil

moisture monitoring from space. Short wave radiation instruments were quickly discarded because of poor sensitivity and the negative impact of cloud cover (Kerr, 2007). Use of thermat infra-red also-suffered complications due to the need for accurate knowledge of forcings (Kerr, 2007). Radars and synthetic aperture radar (SAR) typically suffer from low temporal resolution, often compensated by a high spatial resolution. Another limitation of these active techniques is
Formatted: Font: Italic

Formatted: Font: Italic 
linked to the difficulty in separating the surface roughness contribution from that of soil moisture, often requiring the "change detection approach" (Moran et al., 1998; Moran et al., 2002). Another possibility is to use scatterometers which are characterized by a lower spatial resolution but higher temporal resolution adequate for water budget monitoring. The European Remote Sensing Satellite 1 (ERS-1), European Remote Sensing Satellite 2(ERS 2), and then MetOp scatterometers offered such opportunities (Magagi and Kerr, 1997a; Magagi and Kerr, 1997b; Magagi and Kerr, 2001; Wagner et al., 2007) relying on a change detection appreach, and thus not delivering absolute values. Consequently, it seemed logical to investigate passive microwaves at low frequencies as the ultimate approach to infer soil moisture from space with the caveat of lower spatial resolution. Interferometry was first put forward by D. LeVine et al. in the 1980's (the ESTAR project) and validated with an airborne prototype (Le Vine et al., 1994; Le Vine et al., 1990). In Europe, an improved concept was next proposed to the European Space Agency (ESA): the Microwave Imaging Radiometer using Aperture Synthesis (MIRAS) concept (Goutoule, 1995). This concept has now materialized into the SMOS mission.

The SMOS data have demonstrated good sensitivity and stability. The data-quality was sufficient to allow the production - from an interferometer - of prototype global surface soil moisture maps within one year after launch. It was the first time ever such maps were obtained. Initially, the accuracy was relatively poor and many retrievals were not satisfactory. The data were much impaired by radio frequency interference (RFI) leading to degraded measurements in several areas including parts of Europe and China (Oliva et al., 2012). With the help of the SMOS team, ESA and CNES took actions to reduce RFI.Actions have since been taken by ESA and CNES to reduce RFI. Specific RFI sources are now identified and localized thentheir locations are provided to ESA personnel who interact directly with the appropriate national 
agencies. These efforts have resulted in over 215 powerful and persistent RFI sources disappearing, including the US Defense Early Warning System in Northern Canada and many sources in Europe. Unfortunately, the remaining number of sources in some countries is large. While RFI reduction and retrieval algorithm improvements efforts-were ongoing, first attempts to use SMOS data in a variety of applications were investigated. The first topic wasefforts to validate the SMOS soil moisture retrievals began-against in situ measurements, model outputs or other remote sensing platforms. In one of the first SMOS validation studies,

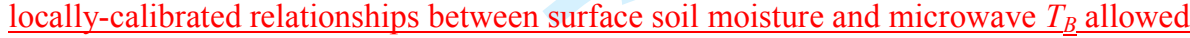
estimation of surface soil moisture from SMOS $T_{\underline{B}}$ with RMSE values ranging from 0.03 to 0.12 $\mathrm{m}^{3} \mathrm{~m}^{-3}$ when compared to the $5 \mathrm{~cm}$ soil moisture data from eleven stations of the SMOSMANIA in situ network in France (Albergel et al., 2011). A subsequent study using 16 stations in the $\underline{\text { SMOSMANIA network and a different SMOS soil moisture retrieval produced RMSE values }}$ ranging from 0.03 to $0.08 \mathrm{~m}^{3} \mathrm{~m}^{-3}$ (Parrens et al., 2012). Across four in situ networks in the US $\underline{\text { that are approximately the size of the SMOS footprint, Jackson et al. (2012) found RMSE values }}$ for SMOS ranging from 0.03 to $0.07 \mathrm{~m}^{3} \mathrm{~m}^{-3}$. Collow et al. (2012) evaluated SMOS soil moisture retrievals against in situ soil moisture observations in Oklahoma and in the northern US and found a consistent dry bias, with SMOS soil moisture values ranging from 0.00 to $0.12 \mathrm{~m}^{3} \mathrm{~m}^{-3}$ lower than the in situ data from the $5 \mathrm{~cm}$ depth. In the northern US, RFI from the Defense Early Warning System contributed to the bias. A dry bias for SMOS was also found by Al Bitar et al. (2012) using data from NRCS SCAN and SNOTEL in situ networks and by Albergel et al. (2012a) using data from in situ stations around the world. U-nderstanding the causes of the apparent underestimation of surface soil moisture by SMOS These efforts showed that SMOS 
room for improvements (A1 Bitar et al., 2012; Albergel et al., 2012a; Bircher et al., 2012;

Jackson et al., 2012; Kerr et al., 2012; Leroux et al., 2012; Mecklenburg et al., 2012; Rahmoune et al., 2012; Schwank et al., 2012). in these studies is an important area of ongoing research.

Floods in Pakistan occurring just after the end of the commissioning phase proved that SMOS was able to track such events in spite of the complex topography. The floods in the US during spring 2011 were clearly seen in the SMOS data, as well as the related human activities such as levee bursting. Most of the large flood events oceurring since launch have been monitored, and SMOS has shown its ability to provide information quickly and regularly, not being hindered by either cloud cover or revisit time, at the cost of a spatial resolution which is tower than optimal for this application. In several cases, the arrival of intensive rains (Yasi Huricane in Australia for instance) SMOS data enabled anticipation of flooding risks as a function of soil wetness prior to the rains.

Currently intensive work is underway to improveOne of the primary challenges in using $\underline{\text { SMOS soil moisture data is that the spatial support volume, roughly } 40 \mathrm{~km} \mathrm{X} 40 \mathrm{~km} \mathrm{X} 5 \mathrm{~cm} \text {, is }}$ not ideal for some applications. Significant horizontal spatial variability in soil moisture is likely to occur within a SMOS footprint. This sub-footprint scale soil moisture variability can significantly influence catchment runoff responses (e.g. Zehe et al., 2005) and simulation of latent heat flux in a land surface model (e.g. Alavi et al., 2010; Li and Avissar, 1994). Some progress has been made toward deriving accurate soil moisture estimates with higher spatial resolution by using SMOS data together with other data sources. the spatial resolution of the SMOS retrievals_By combining SMOS data with data from the Moderate Resolution Imaging $\underline{\text { Spectroradiometer, surface soil moisture estimates with 4-km resolution (Merlin et al., 2010) and }}$

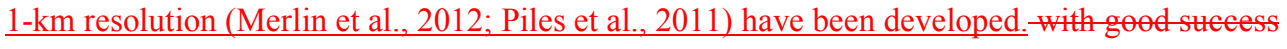


using disaggregation techniques (Merlin et al., 2010; Merlin et al., 2012). Further work is $\underline{\text { needed to refine and validate these higher resolution surface soil moisture estimates and to }}$ expand their spatial coverage beyond limited test areas.

Current activities are also devoted to the estimation of water in the entire root zone with some

Formatted: Indent: First line: $0^{n}$ success, to inferring a drought index, as well as to the possibilities of using SMOS for routing modeling (Pauwels et al., 2012) and for correcting space estimates of rainfall over land. Work to address seience challenges affecting the SMOS data is also ongeing (Kerr et al., 2012). One may cite for instance improving knowledge of water bodies and their temporal evolution, modeling of forests, improving knowledge of soil texture on a global basis and of course general instrument calibration issues. Other current efforts are devoted to improving the auxiliary data sets used in retrievals (e.g. snow and frozen soils) as well as improving underlying models (e.g. dielectric permittivity, forest emissions, etc...).

Currently,SMOS data is freely available from different sources, depending on the type (or

Level) of data required. Level 1 ( $\underline{T}_{\underline{B}}$ brightness temperatures) and Level 2 (ocean salinity over oceans or soil moisture/ vegetation opacity over land) data are available from ESA. The data is provided in swath mode (half orbits from pole to pole) in BinHex format and on the ISEA 49H grid. These Levels are available-through the ESA (-(https://earth.esa.int/web/guest/missions/esaoperational-eo-missions/SMOS). Level 3 data consist of composited data over either one day (i.e.i.e., all the Level 2 data of one day in the same file), three days, ten days, or one month and over the globe (either morning or afternoon passes) for soil moisture and vegetation opacity.

Over oceans the sampling is either daily or monthly. Level 3 data are available from the Centre Aval De Traitement des données SMOS (CATDS) through an ftp site (ftp://eftp.ifremer.fr/catds/cpdc; write to support@catds.fr to get access)._The data is provided in 
NetCDF format on the EASE grid (25km sampling). Other soil moisture products (root zone soit moisture, drought indices, etc...) will soon be available from the same site. Finally, the The implementation of these Level 3 products is expected temay bring significant improvements, particularly in the vegetation opacity retrieval using temporal information (Jacquette et al., 2010). Figure 8 shows a typical monthly Level 3 soil moisture product. Note that the SMOS $\underline{\text { surface soil moisture maps are global in extent but contain gaps where no soil moisture retrieval }}$ is currently possible. These gaps are associated with RFI, steep topography, dense vegetation, $\underline{\text { snow cover, or frozen soils. }}$

After the successful launch of SMOS, Aquarius was successfully launched on June 10

2011 and SMAP (see below) is scheduled to launch in 2014. These NASA missions are in a way complementary to SMOS and should also bring their yield of good results. New breakthroughs are expected either using single instrument measurements or, more likely, through synergisms with other sensors either in the optical/thermal infra-red range or with active/ passive microwave sensers. But, a lingering challenge remains. How to achieve better temporal and spatial sampling of the globe for soil moisture? The simplest approach relies on dis-aggregation techniques.

These techniques use data from high resolution sensors to distribute soil moisture as measured by an interferometer, and successful results have been already obtained (Merlin et al., 2010; Merlin et al., 2005; Merlin et al., 2012). Recognizing the challenge of improving spatial resolution, CNES has initiated research activities whose goal is to develop a new mission which would fulfill all the SMOS requirements but with a ten times better spatial resolution and an improved sensitivity (factor of three for salinity applications), paving the way to more applications in water resources management, coastal area monitoring, basin hydrology or even thin sea ice monitoring 
(Kaleschke et al., 2012). The concept, named SMOSNEXT, is based of merging spatial and temporal 2D interferometry and is currently undergoing phase 0 at CNES with a proof of concept experiment funded by the R\&D program.

\section{Soil Moisture Active_Passive Mission (SMAP)}

The NASA Soil Moisture Active Passive (SMAP) mission (Entekhabi et al., 2010) is scheduled to launch in October 2014. Like SMOS, the SMAP mission will utilize L-band measurements to determine surface soil moisture conditions, but SMAP will feature both active and passive L-band instruments, unlike SMOS which relies on passive measurements alone. The SMAP measurement objective is to provide frequent, high-resolution global maps of nearsurface soil moisture and freeze/thaw state. These_measurements willwill greatly improve play a role in improving_estimates of water, energy and carbon fluxes between the land and atmosphere. Observations of the timing of freeze/thaw transitions over boreal latitudes will may help reduce major uncertainties in quantifying the global carbon balance. The SMAP soil moisture mission requirement is to provide estimates of soil moisture at $10 \mathrm{~km}$ spatial resolution in the top $5 \mathrm{~cm}$ of soil with an error of no greater than $0.04 \mathrm{em}^{3} \mathrm{em}^{-3}$ at three-day average intervals over the global land area, excluding regions of snow and ice, frozen ground, mountainous topography, open water, urban areas, and vegetation with water content greater than $5 \mathrm{~kg} \mathrm{~m}^{-2}$ (averaged over the spatial resolution scale). This level of performance will enable SMAP to meet the needs of hydrometeorology and hydroclimate applications.

The SMAP spacecraft (Fig. 9) will carry two L-band microwave instruments: a nonimaging synthetic aperture radar operating at $1.26 \mathrm{GHz}$ and a digital radiometer operating at 1.41 GHz. The instruments share a rotating 6-meter offset-fed mesh reflector antenna that sweeps out a $1000 \mathrm{~km}$-wide swath. The spacecraft will operate in a $685-\mathrm{km}$ polar orbit with an 8 -day 
repeating ground track. The instrument is designed to provide high-resolution and high-accuracy global maps of soil moisture at $10 \mathrm{~km}$ resolution and freeze/thaw state-at $3 \mathrm{~km}$ resolution, every towith a maximum revisit time of three days using combined active (radar) and passive (radiometer) instruments. The radiometer incorporates radio-frequency interference (RFI) mitigation features to protect against RFI from man-made transmitters. The radiometer is

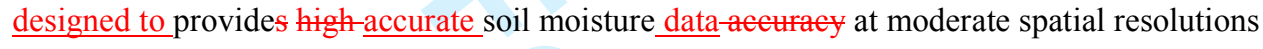
$(40 \mathrm{~km})$ by measuring microwave emission from the surface. The emission is relatively insensitive to surface roughness and vegetation-as compared to the radar. The radar measures backscatter from the surface with high spatial resolution (1-3 $\mathrm{km}$ in high resolution mode), but is more influenced by roughness and vegetation than the radiometer. The combined radar and radiometer measurements are expected to provide soil moisture accuracy approaching radiometer-based retrievals but with intermediate spatial resolution approaching radar-based resolutions. Thus, the driving aspects of SMAP's measurement requirements include simultaneous measurement of L-band $\underline{T}_{\underline{B}}$ brightness temperature and backscatter with a three-day revisit and high spatial resolution (40 km and $3 \mathrm{~km}$, respectively). The combined SMAP soil moisture product will be produced at $10-\mathrm{km}$ resolutionoutput on a 9-km grid. Significant progress has been made towards developing a suitable soil moisture retrieval algorithm for

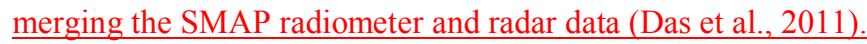

\section{The planned data products for SMAP are being developed by the SMAP project and}

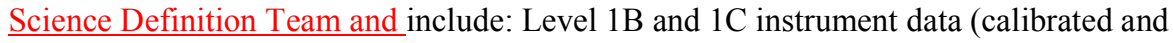
geolocated radar backscatter cross sections and radiometer $\underline{T}_{\underline{B}}$ brightness temperatures); Level 2 geophysical retrievals of soil moisture; Level 3 daily composites of Level 2 surface soil moisture and freeze/thaw state data; and Level 4 value-added data products that are based on assimilation 
of SMAP data into land surface models. The SMAP Level 1 radar data products will be archived and made available to the public by the Alaska Satellite Facility in Fairbanks, AK, while the Level 1 radiometer and all higher level products will be made available by the National Snow and Ice Data Center in Boulder, CO.

The Level 4 products will support key SMAP applications and address more directly the driving science questions of the SMAP mission. SMAP L-band microwave measurements will provide direct sensing of surface soil moisture in the top $5 \mathrm{~cm}$ of the soil column. However, several of the key applications targeted by SMAP require knowledge of root zone soil moisture (RZSM) in the top $1 \mathrm{~m}$ of the soil column, which is not directly measured by SMAP. The SMAP Level 4 data products are designed to fill this gap and provide model-based estimates of root zone soil moistureRZSM that are informed by and consistent with assimilated SMAP surface observations. The Level 4 algorithm will use an ensemble Kalman filter to merge SMAP data with soil moisture estimates from the NASA Catchment land surface model (Reichle et al., 2012).- Error estimates for the Level 4 soil moisture product will be generated as a by-product of the data assimilation system. A Level 4 carbon product will also be produced that utilizes daily soil moisture and temperature inputs with ancillary land cover classification and vegetation gross primary productivity (GPP) inputs to compute the net ecosystem exchange (NEE) of carbon dioxide with the atmosphere over northern $\left(>45^{\circ} \mathrm{N}\right.$ latitude) vegetated land areas. The NEE of earbon dioxide with the atmosphere is a fundamental measure of the balance between carbon uptake by vegetation GPP and carbon losses through autotrophic and heterotrophic respiration. The SMAP Level 4 carbon product will provide regional mapped measures of NEE and component carbon fluxes that are within the accuracy range of tower-based eddy covariance measurement approaches. 


\section{Airborne Microwave Observatory of Subcanopy and Subsurface Mission (AirMOSS)}

Current estimates of NEE at regional and continental scales contain such important uncertainties that amongst the 11 or so models tested there could be differences of 100 percent or more, and it is not always clear whether the North American ecosystem is a net sink or source for carbon (Denning et al., 2005; Friedlingstein et al., 2006). Root zone soil moisture(RZSM) is widely accepted to have a first-order effect on NEE (‥g. Law et al., 2002 Suyker et al.,2003), yet RZSM measurements are not often available with spatial or temporal extent necessary for input into regional or continental scale NEE models. Unlike the L-band missions, SMOS and SMAP, which measure surface soil moisture, the AirMOSS mission is designed to measure RZSM directly. The hypothesis of the NASA-funded AirMOSS project is that integrating spatially and temporally resolved observations of root zone soil moistureRZSM into ecosystem dynamics models can significantly reduce the uncertainty of NEE estimates and carbon balance estimates. The AirMOSS plan is to provide measurements to estimate RZSM using an ultra-high frequency (UHF - also referred to as P-band) airborne radar, over representative sites of the nine major North American biomes (Fig. 10). These include: boreal forest (Biome 1); temperate grassland and savanna shrublands (Biome 5); temperate broadleaf and mixed forest (Biome 2); temperate conifer forest east (Biome 3); temperate conifer forest west (Biome 4); Mediterranean woodlands and shrublands (Biome 6); arid and xeric shrublands (Biome 7); tropical and subtropical dry forest (Biome 8); and tropical and subtropical moist forest (Biome 9). These

radar observations will be used to retrieve root zone soil moistureRZSM, which along with other ancillary data, such as topography, land cover, and various in-situ flux and soil moisture observations, will provide the first comprehensive data set for understanding the processes that 
control regional carbon and water fluxes. The public access web site for the AirMOSS project is http://airmoss.jpl.nasa.gov/.

The airborne P-band radar system, flown on a NASA Gulfstream III aircraft, has a flight configuration over the experimental sites of typically $100 \mathrm{~km}$ by $25 \mathrm{~km}$ made up of four flight lines (Fig. 11). This represents an intermediate footprint between the flux tower observations (on the order of $1 \mathrm{~km}$ ) and regional to continental scale model simulations. It should be noted that each-Each AirMOSS flux site also has a hydrologic modeling domain of on the order of $100 \mathrm{~km}$ by $100 \mathrm{~km}$ that will be populated with the corresponding ancillary data sets to allow flexibility in the flight line design. The hydrologic simulation domain is determined based on maximizing the overlap of full watersheds with the actual flight domain. These watersheds are to be simulated using the fully distributed, physically-based finite element model PIHM (Penn State Integrated Hydrologic Model) (Qu and Duffy, 2007; Kumar et al., 2010). Carbon dioxide modeling will be performed using the Ecosystem Demography (ED2) model (Moorcroft et al., 2001). Each AirMOSS site has flux tower measurements for water vapor and carbon dioxide made using an eddy covariance system.

The P-band radar operates in the 420 to $440 \mathrm{MHz}$ frequency range $(70 \mathrm{~cm})$, with a longer wavelength than typically used in the L-band missions such as SMOS or the upcoming U.S.US SMAP mission(next section). Previous studies using similar wavelengths have shown that RZSM can be computed with an absolute accuracy of better than $0.05 \mathrm{~m}^{3} \mathrm{~m}^{-3}$ and relative accuracy of 0.01 to $0.02 \mathrm{~m}^{3} \mathrm{~m}^{-3}$ through a canopy of up to $120 \mathrm{Mg} \mathrm{ha}^{-1}$ and to soil depths of 50 to $100 \mathrm{~cm}$, depending on the vegetation and soil water content (Moghaddam et al., 2000;

Moghaddam 2009). This P-band radar system has evolved from the existing Uninhabited Aerial Vehicle Synthetic Aperture Radar(UAVSAR) subsystems, including the radio frequency 
electronics subsystem-(RFES), the digital electronics subsystem-(DES), the power subsystem, and the differential GPS subsystem. In fact, the P-band radar system is mounted within the UAVSAR platform pod on the NASA Gulfstream III thereby negating the requirement for additional air-worthiness trials. The radar backscatter coefficients are available at both 0.5 arcsecond (approximately $15 \mathrm{~m}$, close to the fundamental spatial resolution of the radar) and at 3 arc-second (approximately $100 \mathrm{~m}$ ), and the retrieved root zone soil moistureRZSM maps will be at 3 arc-second resolution.

AirMOSS flight operations began in Fall of 2012, and all sites in North America except the tropical sites (Chamela, Mexico and La Selva, Costa Rica) and the woody Savanna site (Tonzi Ranch, CA) were flown. These P band data are currently undergoing initial calibration. However, aA three-band raw data image showing the spatial variation of soil moisture over the Metolius, Oregon site, along with soil roughness and vegetation effects which have not yet been removed, is shown in Fig. 12.

\section{LARGE-SCALE SOIL MOISTURE MONITORING NETWORKS}

Soil moisture networks with spatial extents of $>100^{2} \mathrm{~km}^{2}$ are well-suited for monitoring the meteorological scale of soil moisture spatial variability as defined by Vinnikov et al. (1999) because atmospheric forcings often exhibit spatial autocorrelation lengths of $100 \mathrm{~s}$ of $\mathrm{km}$. These large-scale networks are also appropriate for studies related to basin-scale hydrology and mesoscale meteorology. Numerous smaller networks exist worldwide with spatial extents $<100^{2} \mathrm{~km}^{2}$, both within and outside the US. For example, the USDA Agricultural Research Service (ARS) has developed several soil moisture networks to enhance their experimental watershed program. Locations include the Little Washita in Oklahoma, Walnut Gulch in Arizona, Reynolds Creek in 
Idaho, and Little River in Georgia (Jackson et al., 2010). The smaller scale networks are often well-suited for watershed-scale hydrologic studies. A recent surge in the creation of these smaller-scale networks has been driven by the need to validate soil moisture estimates from satellites such as SMOS and SMAP. A partial list of current and planned soil moisture networks with spatial extents $<100^{2} \mathrm{~km}^{2}$ was provided by Crow et al. (2012).

\section{Large-Scale Soil Moisture Networks in the United States}

Large-scale soil moisture networks in the U.S. $\underline{\mathrm{US}}$ are eurrently currently operating in a variety of configurations at both national and state levels (Fig. 13, Table 1). In 1981, the Illinois Water Survey began a long term program to monitor soil moisture in situ (Hollinger and Isard, 1994; Scott et al., 2010). This network was limited by its use of neutron probes, which required significant resources to operate and maintain. These neutron probes were used to measure soil moisture as frequently as twice a month. These stations were collocated with the Illinois Climate Network stations as the Water and Atmospheric Resources Monitoring Program and ultimately totaled 19 stations with measurements from the surface to a depth of $2 \mathrm{~m}$. Beginning in 1998, these stations were converted to continuously monitor soil moisture using dielectric sensors (Hydra Probe, Stevens Water Monitoring Systems, Inc., Portland, OR), providing regular statewide estimates of soil moisture.

The next network to develop was in Oklahoma, which has become an epicenter ofa focal point for mesoscale weather and climate research. The Oklahoma Mesonet was launched in 1991 and became fully operational in 1994, now consisting of 120 stations, with at least one station in each county of Oklahoma (Brock et al., 1995; McPherson et al., 2007). Each station hosts a suite of meteorological measurements, including air temperature, wind speed and direction, air pressure, precipitation, and soil temperature. These stations monitor soil matric potential using 
heat dissipation sensors (CS-229, Campbell Scientific, Inc., Logan, UT) at the $5 \mathrm{~cm}, 25 \mathrm{~cm}$, and $60 \mathrm{~cm}$ depths, with archived data from the $75 \mathrm{~cm}$ depth available for some sites. These matric potentials can be converted to soil moisture estimates via site- and depth-specific water retention curves (Illston et al., 2008). Recent improvement in the accuracy of the water retention curve parameters resulted in a field-validated, network-wide accuracy for the soil moisture data of $\pm 0.053 \mathrm{~m}^{3} \mathrm{~m}^{-3}$ (Scott et al., in review). Also distributed through Oklahoma is a network of stations belonging to the Southern Great Plains (SGP) site of the US Department of EnergyӨE Atmospheric Radiation Measurement (ARM) Program (Schneider et al., 2003). This network uses the same type of sensor as the Oklahoma Mesonet. This network began in 1996 and spans portions of Oklahoma and Kansas. There are a variety of facilities administered by the ARMSGP site including a large central facility, as well as extended and boundary facilities, hosting a variety of meteorological, surface, and soil profile measurements.

While the Oklahoma Mesonet was being developed, the USDA Natural Resource Conservation Service (NRCS) began a pilot soil moisture/soil temperature project to monitor these parameters on a national scale. This project developed into the Soil Climate Analysis Network (SCAN network, , which now numbers approximately 180 stations across the U.S. $\underline{\text { US }}$ (Schaefer et al., 2007). This network has a standardized depth profile of Hydra Probe sensors at 5, 10, 20, 50, and $100 \mathrm{~cm}$. A similar network to SCAN is the Climate Reference Network $(\mathrm{CRN})$, operated by the National Oceanic and Atmospheric Administration (NOAA) National Climatic Data Center (Palecki and Groisman, 2011). This network commissioned 114 stations to provide a national scale weather and climate monitoring network. Soil moisture sensors are being added to these stations eurrently based on the SCAN configuration (Hydra Probes at 5, 10, 20,50 , and $100 \mathrm{~cm}$ ), but three profiles of sensors are installed at each site providing data in
Formatted: Not Highlight

Formatted: Not Highlight

Formatted: Not Highlight

Formatted: Superscript, Not Highlight

Formatted: Not Highlight

Formatted: Superscript, Not Highlight

Formatted: Not Highlight 
triplicate for each depth. In addition to soil moisture, standard weather variables such as air temperature, solar radiation, precipitation, and wind speed are also collected.

A number of other state-wide or large-scale networks have been developed since the mid 1990s. In 1998, the High Plains Regional Climate Center added soil moisture sensors to 14 Automated Weather Data Network (AWDN) stations in Nebraska. Since then sensors have been added to other stations, so now there are 53 stations throughout the state monitoring soil moisture on an hourly basis. These stations monitor soil moisture using impedance sensors (Theta Probe ML2x, Delta-T Devices, Ltd., Cambridge, UK) at depths of $10 \mathrm{~cm}, 25 \mathrm{~cm}, 50 \mathrm{~cm}$, and $100 \mathrm{~cm}$ (Hubbard et al., 2009).

The North Carolina Environment and Climate Observing Network (ECONet) has been in operation since 1999 when 27 stations were instrumented with Decagon ECHO probes (Weinan et al., 2012). In 2003, these stations were converted to Theta Probe sensors and the network was expanded to 37 . Unlike most other networks, this network does not have a near-surface measurement depth as these data are collected only at a $20 \mathrm{~cm}$ depth. The West Texas Mesonet was initiated by Texas Tech University in 1999 and currently monitors soil moisture at 53 stations at depths of $5 \mathrm{~cm}, 20 \mathrm{~cm}, 60 \mathrm{~cm}$, and $75 \mathrm{~cm}$ using water content reflectometers $(615$, Campbell Scientific, Inc., Logan, UT) (Schroeder et al., 2005). In addition the network monitors wind information, atmospheric pressure, solar radiation, soil temperature, precipitation, and leaf wetness. The Georgia Automated Environmental Monitoring Network began in 1991 (Hoogenboom, 1993) and has since grown to include 81 stations. Soil moisture sensors have been added to these stations at a depth of $30 \mathrm{~cm}$ for the purpose of agricultural and meteorological monitoring. The newest large-scale soil moisture networks in the US are the COSMOS and GPS-IR networks described in preceding sections of this manuscript. Additional 
networks are on the horizon as well, including the National Ecological Observatory Network (NEON) which will operate study sites in 20 eco-climatic domains throughout the U.S. $\underline{\text { US }}$ in the coming years (Keller et al., 2008).

\section{Large-Scale Soil Moisture Networks Outside the United States}

In recent years, several large-scale soil moisture monitoring networks have been established outside of the US, either serving research purposes, supporting natural hazard forecasting, or being an integrative part of meteorological observing systems (e.g., Calvet et al., 2007). Table 1 gives an overview of known large-scale networks that are currently measuring soil moisture on an operational or quasi-operational basis. No active network outside the US has a spatial extent as large as that of the US national networks, but several have spatial extents and densities comparable to the state level networks in the US. Worth mentioning are theSome networks, such as those in France and Mongolia, that were installed for validating satellite soil moisture missions, and thus have a setup that allows for representing as accurately as possible soil moisture variations at the spatial scale of a satellite footprint.

The networks described in the previous section have each been designed to meet different research and operational objectives, and this has resulted in a large variety of measurement setups and techniques, available metadata, data access points, and distribution policies. The first action to offer a centralized access point for multiple, globally available in-situ soil moisture data sets was the Global Soil Moisture Data Bank (GSMDB; Robock et al., 2000; Robock et al., 2005). The GSMDB collected data sets existing at that time but did not perform any harmonization of variables or data formats. The first international initiative addressing the latter has been FLUXNET (Baldocchi et al., 2001), a "network of networks" dedicated to monitor land-atmosphere exchange of carbon, energy, and water. Unfortunately, within FLUXNET soil 
moisture is not measured at all sites while, more importantly, practical use of soil moisture data from FLUXNET is severely hampered by restricted accessibility and the large time gap between acquisition of the data and making them available to the science community.

In 2009, the International Soil Moisture Network (ISMN; http://ismn.geo.tuwien.ac.at/)

was initiated to overcome the issues of timeliness in data delivery, accessibility, and

heterogeneity of data (Dorigo et al., 2011a; Dorigo et al., 2011b). This international initiative is a

result of the coordinated efforts of the Global Energy and Water Cycle Experiment(GEWEX)_in cooperation with the Group of Earth Observation (GEO) and the Committee on Earth

Observation Satellites(CEOS) to support calibration and validation of soil moisture products from remote sensing and land surface models, and to advance studies on the behavior of soil

moisture over space and time. The decisive financial incentive was given by the European Space Agency (ESA) who considered the establishment of the ISMN critical for optimizing the soil moisture products from the SMOS mission.

The ISMN collects and harmonizes ground-based soil moisture data sets from a large variety of individually operating networks and makes them available through a centralized data portal. Currently, the database contains almost $6000 \underline{-7000}$ soil moisture data sets from almost 1500 more than 1600 - sites, distributed among $37 \underline{40}$ networks worldwide (Fig. 14). Not all the networks are still active. Also $_{2}$ the data sets contained in the former GSMDB were harmonized and transferred into the ISMN. It should be noted that not all networks are still active.

Recently, several updates of the ISMN system were performed to keep up with the increasing data amount and traffic, and to meet the requirements of advanced users. Many datasets from operational networks (e.g., SCAN, the US Climate Reference Network, SWEX Poland, and ARM) are now assimilated and processed in the ISMN on a fully automated basis in 
near-real time. In addition, an enhanced quality control system is eurrentlybeing implemented (Dorigo et al., 2013) while novel methods are being explored to obtain objective measures of reliability and spatial representativeness of the various sites (Gruber et al., 2013). Challenges and Opportunities Related to Large-Scale Soil Moisture Networks The steadily increasing number of soil moisture monitoring stations goes hand in hand with the growing awareness of the role of soil moisture in the climate system. Nevertheless, Figs. 14 and 15 show that the current stations are concentrated geographically and mainly represent a limited number of climate classes in temperate regions. The number of permanent soil moisture stations is still very limited in the tropics (A category), dry areas (Bw classes), and in high latitude areas (Dfc and E classes). Especially in the latter the hydrological cycle is not yet well understood, and these regions are expected to be particularly sensitive to climate change. Thus, international efforts should concentrate on expanding networks in these areas.

However, the major challenge is not only to setup new networks but also to keep them operational in the future. Since many networks heavily rely on project funding, their continuation is typically only guaranteed for the lifetime of the project. Thus, internationally coordinated effort should focus on developing mechanisms for continued financial and logistical support.

One efsuch mechanisms may be the development of a soil moisture component as part of $\underline{\text { is the }}$

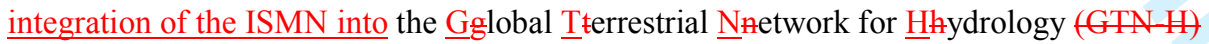
envisaged by the GCOS-Global Climate Observing System (GCOS, 2010). The task of such a network should go beyond the achievements of the ISMN and also-define standards for the measurements themselves in order to guarantee the consistency between sites.Alsoternatively, the integration of soil moisture monitoring sensors into existing operational meteorological stations would may increase the probability for continued operation.
Formatted: Font: Bold

Formatted: Centered, Indent: First line: $0 "$

Formatted: Font: Bold 


\section{- Another significant challenge for in situ networks is defining standards for the} measurements themselves in order to enhance the consistency between sites. Best practices for sensor calibration, installation, and in situ validation, as well as data quality control procedures and data archiving and retrieval standards need to be developed. The Automated Weather Data Network in Nebraska (Hubbard et al., 2009), the Oklahoma Mesonet (Illston et al., 2008), and $\underline{\text { the ISMN (Dorigo et al., 2013) have documented, automated quality control procedures in place }}$ which may prove useful for other networks. The Oklahoma Mesonet soil moisture network has $\underline{\text { also been subjected to in situ validation by soil sampling (Illston et al., 2008; Scott et al. in }}$ review), allowing quantitative estimates of the accuracy of the soil moisture data. Calibration $\underline{\text { and validation are two separate and necessary steps in measurement. Calibration here means }}$ developing a relationship between the sensor output and the true soil moisture value. Validation here means collecting independent soil moisture data in situ after sensor installation to quantify the accuracy of the calibrated and installed sensor. Such in situ validation is needed for all $\underline{\text { networks. }}$

\section{APPLICATIONS OF LARGE-SCALE SOIL MOISTURE MEASUREMENTS}

\section{Drought Monitoring}

Droughts are typically classified as-either meteorological, agricultural, or hydrological (Mishra and Singh, 2010). Meteorological drought is indicated by a lack of precipitation over a specified region during a particular period of time. Agricultural drought occurs when declining soil moisture levels negatively impact agricultural production. Some have used the term “ecological drought" to designated similar conditions which reduce primary productivity in natural ecosystems (Le Houérou, 1996). These two drought concepts are closely related and 
should perhaps be represented by the composite term "agro-ecological drought.". A third common drought classification is hydrological drought, which is a period of inadequate surface and subsurface water resources to support established water uses. Soil moisture is most directly related to agro-ecological drought ${ }_{2}$ which is often preceded by meteorological drought and comes before hydrological drought. This places soil moisture squarely in the center of the spectrum of drought classifications and drought indicators, but soil moisture measurements have been largely neglected in the science and practice of drought monitoring to date.

In earlier decades this deficiency was unavoidable because sufficient soil moisture data were simply not available to enable their use in operational drought monitoring. That situation began to change dramatically in the 1990 s with the rise of large-scale soil moisture monitoring networks in the US (Hollinger and Isard, 1994; McPherson et al., 2007; Schaefer et al., 2007), a change now spreading around the world. Even more recently, global maps of surface soil moisture based on satellite remote sensing have become available, and these could be useful in drought monitoring. The primary impediment to the use of soil moisture measurements in operational drought monitoring is no longer a lack of data, but rather a lack of scientific understanding regarding how soil moisture measurements quantitatively indicate agro-ecological drought. Strong and transparent conceptual models are needed to link soil moisture measurements with vegetation impacts in agricultural and ecological systems.

The first known attempt to use large-scale soil moisture measurements in drought monitoring was the Soil Moisture Index (SMI) introduced by Sridhar et al. (2008) based on data from the Automated Weather Data Network (AWDN) in Nebraska. Their results demonstrated that continuous soil moisture datemeasurements at 10,25,50, and $100 \mathrm{~cm}$ depths from 37 
stations in Nebraska provided-formed the basis for a strong quantitative drought indicator. The SMI was subsequently revised by Hunt et al. (2009) who proposed the following relationship

$$
S M I=-5+10 F_{A W}
$$

where $\mathrm{F}_{\mathrm{AW}}$ is the fraction of available water. Fraction of available water is calculated by

$$
F_{A W}=\left(\theta-\theta_{\mathrm{wp}}\right) /\left(\theta_{\mathrm{fc}}-\theta_{\mathrm{wp}}\right)
$$

where $\theta$ is the volumetric water content at a specified depth, $\theta_{\mathrm{fc}}$ is the volumetric water content corresponding to field capacity, and $\theta_{\mathrm{wp}}$ is the volumetric water content corresponding to

permanent wilting point. Hunt et al. (2009) calculated SMI using data from sensors at 10, 25 , and $50 \mathrm{~cm}$ depths, and then calculated the average SMI across depths.

The use of $\mathrm{F}_{\mathrm{AW}}$ as the basis for SMI is substantiated by current scientific understanding of plant water stress because water stress is more strongly related to the relative amount of plant available water in the soil than to the absolute amount of soil moisture (Allen et al., 1998).

Values of $\mathrm{F}_{\mathrm{AW}}$ are typically between 0 and 1, however both higher and lower values are possible. The scaling relationship in Eq. [2] thus causes SMI values to typically fall in the range from -5 to +5 . This scaling was perhaps-chosen to make the range of SMI comparable to the range of other drought indicators (e.g., Drought MonitorPalmer Drought Severity Index; $;$ Svoboda et al., 2002Palmer, 1965). Although stress thresholds vary somewhat with plant species and weather conditions, generally $\mathrm{F}_{\mathrm{AW}}$ values $<\_.5$ result in water stress (Allen et al., 1998). When $\mathrm{F}_{\mathrm{AW}}$ is 0.5 , the SMI value is 0 , the transition between stressed and non-stressed conditions. Again using data from the Nebraska AWDN, Hunt et al. (2009) found that the modified SMI was effective for identifying drought onset as well as soil recharge from rainfall events following significant dry periods. 
Recently, the SMI was applied using datadaily measurements of soil moisture in the 0-50

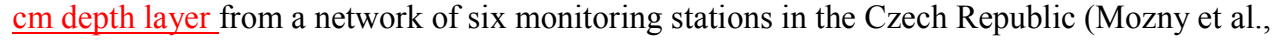
2012). That study supported the drought intensity scheme proposed by Sridhar et al. (Sridhar et al., 2008) in which SMI values <_-3 signify severe or extreme drought. Mozny et al. (Mozny et al., 2012) related the concept of "flash drought" to SMI, specifying that a flash drought occurs when SMI values decrease by at least 5 units during a period of 3 weeks. Thus, the SMI concept has shown good potential as a quantitative drought indicator based on soil moisture measurements, but some key uncertainties remain. The indicator is sensitive to the site- and depth-specific values chosen for $\theta_{\mathrm{fc}}$ and $\theta_{\mathrm{wp}}$. These critical water contents can be estimated from the in situ soil moisture time series in some cases (Hunt et al., 2009), measured directly in the laboratory, calculated using pedotransfer function models (Schaap et al., 2001), or estimated from literature values (Sridhar et al., 2008), but best practices for determining these parameters in the SMI context need to be developed.

Recently, Torres et al. (2013) introduced a method for using long-term measurements of soil water deficits (SWD) from a large-scale monitoring network to compute site-specific drought probabilities as a function of day of year. Improved quantification of seasonal patterns in drought probability may allow crop cycles to be better matched with periods when drought is less likely to occur; therefore, yield losses due to drought may be reduced. Soil water deficit for each soil layer $(D)$ is defined as

$$
D=\left(\theta_{\mathrm{fc}}-\theta\right) \Delta z
$$

where $\Delta z$ is the thickness of the soil layer, and SWD is calculated by summing $D$ over the desired soil layers. Soil moisture data from eight stations of the Oklahoma Mesonet spanning 15 years were used to calculate deficits for the $0-10 \mathrm{~cm}, 10-40 \mathrm{~cm}$, and $40-80 \mathrm{~cm}$ layers. Drought 
was defined in this context as a period when SWD is sufficient to cause plant water stress, i.e.i.e., SWD exceeds a predetermined threshold. The threshold was set for each site and layer as 0.5TAW, where TAW is the total available water calculated by substituting $\theta_{\mathrm{wp}}$ for $\theta$ in Eq. [4].

Values of SWD calculated from 0-40 cm $\left(\mathrm{SWD}_{40}\right)$ were similar to 7-d cumulative atmospheric water deficits (AWD), calculated as reference evapotranspiration minus precipitation, during much of the spring and fall, but the soil and atmospheric deficits diverged in the winter and summer months (Fig. 16).

Historical drought probabilities estimated for each day of the year using the SWD data were consistent between depths and agreed with general knowledge about the climate of the region (Fig. 17), while probabilities estimated using AWD data (Purcell et al., 2003) were substantially lower and inconsistent with general knowledge about the region and with prior drought probability estimates in nearby states. Torres et al. (2013) proposed modifications to the AWD method, either lowering the AWD threshold used to define drought or extending the summation period from 7 to 15 days, both of which resulted in drought probability estimates more consistent with the estimates from SWD method. They concluded that the new SWD method gave plausible and consistent results when applied to both the 0 - to 40 - and 0 - to $80-\mathrm{cm}$ soil layers and should be utilized when long-term soil moisture data are available.

The first known operational use of large-scale soil moisture measurements for drought monitoring involves, not SMI or SWD, but a related measure, plant available water (PAW).

Plant available water is defined as

$$
P A W=\sum_{i=1}^{n}\left(\theta_{i}-\theta_{W P i}\right) d z_{i}
$$

for soil layers $i=1 \ldots n$ of thickness $d z_{i}$. In 2012, the Oklahoma Mesonet (McPherson et al., 2007) introduced daily-updated PAW maps based on its network of $>100$ stations monitoring soil 
moisture at standard depths of 5,25, and $60 \mathrm{~cm}$. These maps are intended for use in drought monitoring and show PAW for the 0-10 cm (4-inch), 0-40 $\mathrm{cm}$ (16-inch), and 0-80 $\mathrm{cm}$ (32-inch) soil layers (http://www.mesonet.org/index.php/weather/category/soil_moisture_temperature). The depth units (e.g. $\mathrm{mm}$ or inches) of PAW make it compatible with familiar hydrologic measurements such as precipitation and evapotranspiration (ET). Figure 18 shows maps of departure from average PAW for the $0-16$ inch $(40 \mathrm{~cm})$ soil layer across Oklahoma for the months of May 2012 and May 2013. The maps show that significantly drier than average PAW $\underline{\text { conditions prevailed across large areas of central and eastern Oklahoma in May } 2012 \text { but }}$ significantly wetter than average PAW conditions covered much of the State in May 2013. $\underline{\text { These soil moisture patterns bear little resemblance to US Drought Monitor (Svoboda et al., }}$ 2002) maps from the same time periods (Fig. 18c,d), which suggest that drought conditions were substantially worse in May 2013 than May 2012 across the entire State. These maps illustrate that a drought indicator based on large-scale soil moisture monitoring can provide a dramatically $\underline{\text { different assessment of drought severity than the Drought Monitor, which blends information }}$ from meteorological indicators, streamflow percentiles, a soil moisture model, and expert opinion.

total rainfall, total short-crop reference ET based on the FAO-56 procedure (Allen et al., 1998), and average PAW across the state of Oklahoma during May 2012. Dry conditions prevailed across the state with reference ET exceeding rainfall at all measured locations. The PAW map reflects the influence of rainfall and ET with relatively high PAW values in eastern, northeastern, and central $O K$ corresponding to regions with relatively high rainfall and/or relatively low reference ET. However, the PAW maps also suggest more complex influences of vegetation, soil type, and landscape "memory". For example, note that PAW values were generally lower in 
the southwest portion of the state than in the Panhandle region even though the Panhandle region experienced lower rainfall totals and comparable reference ET. This illustrates the challenges with using atmospheric data alone to monitor agro-ecological drought and suggests a unique and complementary role for soil moisture measurements.

These recent developments in the use of soil moisture measurements for drought monitoring are encouraging; however the research needs in this area are significant. As yet, little is known regarding how soil moisture-based drought indicators relate to other widely-accepted drought indicators like the Standardized Precipitation Index (Guttman, 1999) or the Palmer Drought Severity Index. Likewise, we do not know how soil moisture-based drought indicators are related to actual drought impacts in agricultural or ecological systems. Already SMI, SWD, and PAW have demonstrated potential as soil moisture-based drought indicators driven by in situ measurements, but these three indicators all address the question, "How dry is it?" rather than the equally important question, "How much drier than average is it?". Other soil moisture-based indicators have been proposed on the basis of numerical modeling studies. These include the model-based Normalized Soil Moisture index (Peled et al., 2010) and the Soil Moisture Deficit Index (Narasimhan and Srinivasan, 2005), neither of which has been evaluated using actual soil moisture measurements.

Furthermore, most in situ soil moisture measurements are made under grassland vegetation because of problems with establishing long-term meteorological stations in cropland or forest. There is a dearth of research on how to estimate soil moisture under contrasting land use/land cover combinations based on in situ observations under grassland vegetation. This deficiency complicates the interpretation of agro-ecological drought indicators based on in situ soil moisture measurements. Clearly, there should be a role for satellite remote sensing of soil 
moisture to assist in overcoming some of the deficiencies of drought monitoring by in situ soil moisture observations. Bolten et al. (2010) showed that AMSR-E AMSR-E-surface soil moisture retrievals could add significant value to root zone soil moistureRZSM predictions in an operational drought modeling framework. Soil moisture data from AMSR-E have also shown potential as part of an integrated drought monitoring system for East Africa (Anderson et al., 2012)-. However, there are as yet no operational systems for drought monitoring that utilize satellite soil moisture measurements. We anticipate a surge in this type of research in the near future. atmospheric boundary layer $(\mathrm{ABL})$ interactions with the land surface is presented in Fig. 19.

Daytime growth of the ABL is directly affected by soil and vegetation states and processes, and these processes play a role in partitioning the energy balance which relates net radiation to soil heat flux, sensible heat flux, and latent heat flux, i.e.i.e., evapotranspiration. Root_zone soil moisture can influence the atmospheric boundary layer $\underline{\mathrm{ABL}}$ by controlling land surface energy and moisture fluxes. -For example, Basara and Crawford (2002) found that soil water content in the root-zone, particularly the 20 to $60 \mathrm{~cm}$ depths, during the summer was linearly correlated with daytime evaporative fraction and daily-maximum values of sensible heat flux and latent heat flux on days with strong radiative forcing and weak shear in the lower troposphere. Rootzone soil moisture was also linearly related to key parameters in the ABL such as the daily maximum air temperature at $1.5 \mathrm{~m}$. 
Numerous large-scale hydrologic-atmospheric-remote sensing experiments have been conducted to better understand the soil moisture-moderated interactions of the soil-vegetation system with the diurnal atmospheric boundary layerABL. Improved parameterization of general circulation models (GCMs) was one of the initial objectives of the experiments. Table 2 gives a concise overview of a few of these experiments, including HAPEX-MOBILHY which was the first experiment conducted on this scale (André et al, 1986; André et al., 1988). It should be noted $m$ Most of the experiments listed cover large geographic areas which play a-significant roles in the general circulation system of the planet.

The strong linkage of surface soil moisture and parameterization of soil hydraulic processes with ABL response was demonstrated by Ek and Cuenca (1994), based on data from the HAPEX-MOBILHY. This study found that variations in soil hydraulic process parameterization could have a clear impact on the simulated surface energy budget and atmospheric boundary layer $\mathrm{ABL}$ development. This impact was accentuated for dry to moderate soil moisture conditions with bare soils. Ek continued to do considerable work in the area of simulation of the ABL and the influence of soil moisture conditions, often using data from regional experiments such as HAPEX-MOBILHY and the Cabauw data set from the Netherlands (Monna and van der Vliet, 1987). Data from HAPEX-MOBILHY wereas used to evaluate the evolution of the relative humidity profile in the ABL in Ek and Mahrt (1994). The relationships between canopy conductance, root density, soil moisture and soil heat flux with simulation of the ABL using the Cabauw data set was investigated in Ek and Holtslag (2004). It should be noted that $\mathrm{t}$ The ABL simulation evolved from the Oregon State University 1-D planetary boundarylayer model (OSU1DPBL) (Mahrt and Pan, 1984; Pan and Mahrt, 1987) to the Coupled Atmospheric boundary layer-Plant-Soil (CAPS) model. These models in turn are the basis for 
the Noah land-surface model (Chen and Dudhia, 2001; Ek et al., 2003) which plays a major role in the Medium-Range Forecast Model for numerical weather prediction (NWP) at the NOAA National Center for Environmental Prediction.

Given its influence on ABL development, root-zone soil moistureRZSM can have a strong influence on weather forecasts. If not suitably constrained, the root zone soil moistureRZSM in a an atmosphericNWP model will drift from the true climate, resulting in erroneous boundary layer forecasts (Drusch and Viterbo, 2007). Roøt-zone seil moisture cannot currently be observed at the spatial scales required by NWP, and $\underline{S}$ since the mid 1990s, many NWP centers have been indirectly constraining their model soil moisture using methods that minimize the errors in measured screen-level $\left(1.5-2.0 \_\mathrm{m}\right)$ temperature and humidity (Best et al 2007; Hess, 2001; Mahfouf 1991; Mahfouf et al 2009). While this approach reduces boundary layer forecast errors, it does not generate realistic soil moisture since the latter is often adjusted to compensate for model errors unrelated to soil moisture (Douville et al., 2000; Drusch and Viterbo, 2007; Hess, 2001). Ultimately a model with inaccurate soil moisture cannot accurately describe the atmosphere across the full range of forecast lengths produced from NWP models. Hence, the NWP community has been working towards improving model soil moisture by assimilating remotely sensed near-surface soil moisture. Near-surface soil moisture is more directly related to root zone soil moistureRZSM than screen-level variables, and assimilating near-surface soil moisture data $(0$ to $5 \mathrm{~cm})$ has been shown to improve model reot-zone seil moistureRZSM (Calvet et al., 1998; Hoeben and Troch, 2000; Montaldo et al., 2001). Figure 20 compares several experiments constraining model root zone soil moistureRZSM by assimilating observations of near-surface soil moisture and screen-level temperature and relative humidity, highlighting the fundamental difference between these two approaches. These experiments were 
conducted with Météo-France's NWP land surface model using an Extended-extended Kalman Filterfilter and the Advanced Microwave Scanning Radiometer for the Earth Observing System (AMSR-E) Land Parameter Retrieval Model near-surface soil moisture data (Owe et al., 20082001). Refer to Draper et al. (2011) for further details.

In general, assimilating the screen-level observations (black dashed line)-improved the fit between the mean forecast and observed screen-level variables, compared to the open loop (ne assimilation, solid black line). However, the assimilation had a slight negative impact on the fit between the mean forecast and observed near-surface soil moisture. In contrast, assimilating the AMSR-E soil moisture (grey solid line)-improved the fit between the mean forecast and observed near-surface soil moisture, while degrading the fit between the modeled and observed screenlevel variables. This result is consistent with previous studies showing that adjusting model soil moisture to improve screen-level forecasts does not necessarily improve soil moisture (Douville et al, 2000; Drusch and Viterbo, 2007; -Seuffert et al 2004), and conversely improving the model soil moisture does not necessarily improve atmospheric forecasts (Seuffert et al 2004).

Consequently, in the foreseeable future it is unlikely that remotely sensed near-surface soil moisture will be used in NWP in place of screen-level observations. However, combining the assimilation of both observation types can reduce errors in both model soil moisture and lowlevel atmospheric forecasts. For example, when both data types were assimilated together(Fig. 20) (grey dashed line) in Fig. 20, the fit between the model and both observation types was improved, although the mean soil moisture improvements were very small (see also Seuffert et al, 2004).

Currently near-surface soil moisture observations are assimilated operationally at the UK Met Office (UKMO) and the European Centre for Medium Range Weather Forecasting 
1146 (ECMWF). While the development of soil moisture assimilation in NWP is motivated by the

1147

eventual use of L-band observations (e.g., SMOS and SMAP), both centers are currently assimilating Advanced Seatterometer (ASCAT) Surface Degree of Saturation (SDS) data (Bartalis et al, 2007), ansince this is currently the only_operationally-supported remotely sensed soil moisture product with global coverage. At -the UKMO the screen-level observation based soil moisture analysis was amended in July 2010, to also constrain the near-surface soil moisture by nudging it with ASCAT SDS data (Dharssi et al, 2011). Compared to nudging with only screen-level observations, adding the ASCAT data very slightly improved near-surface soil moisture forecasts over selected sites in the US, while also improving screen level temperature and relative humidity forecasts over the tropics and Australia (with neutral impact elsewhere).

At -ECMWF the NWP -land surface analysis was updated in November 2010, to an extended Kalman filter based scheme, enabling the assimilation of remotely sensed data (de Rosnay et al 2012, Drusch et al 2009). The ASCAT SDS are not used in their weather forecasting model, but are assimilated together with screen-level observations in an offline land surface analysis system. Including the ASCAT data in this system has had a neutral impact on near-surface soil moisture and screen-level forecasts (Albergel et al 2012b; de Rosnay et al, 2012).

The above examples highlight some challenges of land data assimilation specific to NWP applications. For example, the computation cost of the assimilation is a major limitation in NWP (de Rosnay et al 2012, Drusch et al 2009), hence the assimilation methods applied must be relatively simple. Further work is required to improve the land surface analysis schemes used in NWP, and in particular to propagate the surface soil moisture information into the root-zone (not currently achieved by the schemes in place at the UKMO or ECMWF). Additionally, Dharssi et al. (2011) and de Rosnay et al. (2012) identified the observation bias correction strategy, i.e.i.e., 
the method by which satellite derived surface soil moisture values are adjusted to be consistent with the model used for assimilation, as a likely cause of the limited impact of assimilating the ASCAT data. Bias correction of remotely sensed soil moisture is difficult in NWP, since the long data records required to estimate statistics of the model climatology are not available from NWP models, due to frequent model updates and the prohibitive cost of rerunning models.

However, the greatest challenge faced by soil moisture assimilation in NWP is that improving the model soil moisture may not immediately improve atmospheric forecasts, due to errors in the model physics. It is likely that the greatest contribution of using remotely sensed near-surface soil moisture observations in NWP will be in helping to identify and address these physics errors. Already, the availability of remotely sensed soil moisture and efforts to assimilate that data have stimulated improvements in modeling soil moisture processes. For example, in response to discrepancies between modeled and SMOS observed $\underline{T}_{\underline{B}}$ brightness temperatures, ECMWF recently improved their bare soil evaporation parameterization, resulting in improved model near-surface soil moisture and $\underline{T}_{\underline{B}}$ - brightness temperature (Albergel et al, 2012b). As soil moisture data is used more extensively in NWP models, this should also help to expose and eventually address other errors in the model surface flux processes.

\section{Ecological Modeling and Forecasting}

Ecological modeling is another area which could logically benefit from increased availability of large-scale soil moisture monitoring. Soil moisture is a key parameter in the control of plant growth, soil respiration, and distribution of plant functional types in terrestrial ecosystems (Blyth et al. 2010; Ren et al. 2008; Pan et al. 1998; Neilson 1995). Plant growth

(i.e.i.e., assimilation of $\mathrm{CO}_{2}$ through photosynthesis) is coupled with water loss through 
Field et al., 1995). Decomposition of soil organic carbon is also sensitive to soil moisture content via microbial activity and other processes (Ise and Moorcroft 2006; Xu et al. 2004; Orchard and Cook 1983). Furthermore, temporal and spatial availability of soil moisture content constrains distribution and properties of plant functional types (Bremond, Boom, and Favier 2012; Seneviratne et al. 2010; Gerten et al. 2004; Breshears and Barnes 1999).

A striking example of the interactions between vegetation and soil moisture conditions is provided by the Tiger Bush sites in the HAPEX-Sahel experiment. The Tiger Bush is made up of relatively long and narrow patches of vegetation approximately 40-m wide separated by nearly cemented patches of bare soil approximately $60-\mathrm{m}$ wide and these sites are characteristic of certain regions in the Sahel. One can note in the $>3-\mathrm{m}$ deep profile in Fig. 21 (monitored by neutron probe) that there is limited variation in soil moisture content and only in the upper $50 \mathrm{~cm}$ of the bare soil profile, while there are appreciable soil moisture changes even past $300-\mathrm{cm}$ in the vegetated strip. The result is that nearly all of the high intensity rainfall during the rainy season in this environment runs off the bare soil into the vegetated strip which thereby receives on the order of hundred percent $200 \%$ of the precipitation. Verhoef (1995) noted this effect and that the result was a well-watered vegetation strip adjacent to a very dry bare soil strip in this environment. Verhoef (1995) was able to show that in the generally hot and dry conditions of the Sahel, advective conditions for sensible heat flux from the bare soil resulted such that the evapotranspiration (ET) from the vegetated strip clearly exceeded the potential, or reference, ET rate (Verhoef et al., 1999; Verhoef and Allen, 2000). Carbon fluxes would obviously be affected by the heterogeneity in the Tiger Bush system, as well.

To better understand and predict ecosystem dynamics such as these, different classes of ecological models have been developed for various scales and emphases. For example, 
biogeography models such as MAPSS (Neilson, 1995) and BIOMEs (Prentice et al., 1992; Haxeltine and Prentice, 1996) focus on the distribution of species and ecosystems in space. Biogeochemistry models such as CENTURY/DAYCENT (Parton et al., 1987, 1998), RothC (Jenkinson and Coleman, 1994) and DNDC (Li et al., 1992) place emphasis on the carbon and nutrient cycles within ecosystems. Biophysics models based on soil-vegetation-atmosphere transfer (SVAT) schemes (SiB: Sellers et al. 1986; BATS: Dickinson et al. 1986) have been developed to support regional and global climate modeling to provide accurate information for the fluxes of water, radiation, heat and momentum between the atmosphere and the various land surfaces. Recently developed dynamic global vegetation models (DGVM)-such as LPJ (Sitch et al., 2003), IBIS (Foley et al., 1996) and MC1 (Bachelet et al., 2001), generally incorporate above classes of models and schemes to simulate dynamics of potential vegetation and its associated biogeochemical and hydrological cycles.

These models estimate soil moisture content or its proxy using different schemes such as the bucket method (Robock et al. 1995; Manabe 1969), the precipitation to potential evapotranspiration ratio method (Scheffer et al., 2005), and the water balance model (Law et al. 2002). Details of these and other schemes are discussed in Shao and Henderson-Sellers (1996) and Ren et al. (2008). These schemes often use simple algorithms to reduce computational demand and are less reliable compared to schemes used in hydrologic models [e.g.g the Richards equation (Richards, 1931)]. Also, especially in cases of large scale ecological models, a more realistic parameterization of soil moisture content at subgrid-scale as related to topography is often desirable (Gordon et al. 2004). Optimization of the degree of the simplification and the spatial resolution is necessary due to computational restrictions, but is difficult to judge due to 
1237 lack of adequate observational data with which to verify the performance of the models (Ren et 1238 al.2008).

Traditionally, ecological models have been tested through intercomparison studies such

1240 1241

1242

1243

1244

1245

1246

1247

1248

1249

1250

1251

as the Vegetation/Ecosystem Modeling and Analysis Project (VEMAP;VEMAP Members 1995), the Carbon Land Model Project (ELAMP; Randerson et al. 2009), the Project for Intercomparison of Land-surface Parameterization Schemes (PILPS;Henderson-Sellers et al. 1996; 1995), and the Global Soil Wetness Projects (GSWP/GSWP2;Dirmeyer et al. 2006; Dirmeyer 1999) because evaluating the model performance, especially at larger scales, has been difficult due to the incompleteness of observation data sets. However, these models are not independent because they have integrated the same theories and relied on similar data sets as they evolved (Reichstein et al. 2003). Therefore, while model intercomparison is an important task, extreme care must be exercised to derive any conclusions.

Future research advances in this area will require use of newly available observation data at suitable spatial and temporal scales -(Seneviratne et al. 2010). Observation data from largescale soil moisture monitoring in particular should be valuable to validate the simplification and scaling of ecological models. Wagner et al. (2003) found that modeled $\underline{0 \text { to } 50 \mathrm{~cm} \text { monthly }}$ average soil moisture from the Lund-Potsdam-Jena (LPJ) dynamic global vegetation model agreed "reasonably well" over tropical and temperate locations with values derived from satellite microwave scatterometer, yielding Pearson correlation coefficients $>0.6$. The agreement was poorer over drier and colder climatic regions. However, few studies have used large-scale soil moisture data to improve the structure or parameterizations of ecological models or to improve model predictions through data assimilation. 
Furthermore, the relationship between soil moisture and terrestrial ecosystem is dynamic and interdependent: soil moisture constrains the properties of the ecosystem as described earlier, which in turn, modifies hydrology through evapotranspiration, LAI, and surface roughness (Breshears and Barnes 1999). Newer generations of ecological models, especially dynamic global vegetation models, include these important feedback processes to simulate the effects of future climate change on natural vegetation and associated carbon and hydrologic cycles.

Validation of these models studies willmay reveal an increased need for data from large-scale soil moisture observations across various ecosystems and for continuous expansion of observation networks.

\section{Hydrologic Modeling and Forecasting}

One motivation underlying many large-scale soil moisture monitoring efforts is the desire to more accurately model and forecast watershed dynamics, especially streamflow and flood events. Pauwels et al. (2001) demonstrated the possibility of improved stream discharge estimates through assimilation of surface soil moisture estimates derived using data from the ESA satellites ERS1 and ERS2 into a land atmosphere transfer scheme. The study was limited to bare soil conditions and small catchments $\left(<20 \mathrm{~km}^{2}\right)$. The assimilation improved discharge estimates $20-50 \%$ in seven out of 12 cases considered, but degraded model accuracy by up to $10 \%$ in the remaining five cases. Francois et al. (2003) showed that assimilation of ERS1 SAR data into a simple two-layer land surface scheme through an extended Kalman filter approach improved the Nash-Sutcliffe efficiency (NSE) for streamflow from $70 \%$ to $85 \%$. Their study involved a larger catchment $\left(104 \mathrm{~km}^{2}\right)$ than that of Pauwels et al. (2001) and included vegetation cover. The sensitivity of simulated flow to soil moisture was highest when soil moisture itself 
1281 was high. The assimilation scheme was also able to correct for 5-10\% errors in the input data,

1282 e.g.2 potential evapotranspiration or precipitation.

More recent applications of large-scale soil moisture data for hydrologic modeling and

1284

1285

1286

1287

1288

1289

1290

1291

1292

1293

1294

1295

1296

1297

1298

1299

1300

1301

1302

1303

forecasting have focused on newer satellite remote sensing datasets. Brocca et al. (2010) used a simple nudging scheme to assimilate the ASCAT surface soil wetness index into a rainfallrunoff model for five catchments $\left(<700 \mathrm{~km}^{2}\right)$ in the Upper Tiber River basin in Italy.

Assimilation increased the NSE for streamflow prediction during flood events in all five catchments, with increases ranging from 2 to $17 \%$-(Fig. 22). In a subsequent study, root zone soil moistureRZSM was estimated from the ASCAT surface soil moisture data through application of an exponential filter, and both data types were then assimilated into a two-layer rainfall—runoff model using an ensemble Kalman filter approach (Brocca et al., 2012).

Assimilation of the root zone soil moistureRZSM estimates produced a clear improvement in discharge prediction for a $137 \mathrm{~km}^{2}$ catchment (NSE improved from $76 \%$ to $86 \%$ ), while assimilation of surface soil moisture had only a small effect.

Thus far only a few studies have evaluated methods for using soil moisture data to improve hydrologic forecasting in catchments of $>1000 \mathrm{~km}^{2}$. One example is the work of Meier et al. (2011) in which the ERS1 and ERS2 soil water index was used, along with rainfall data, to drive a conceptual rainfall—runoff model in an ensemble Kalman filter framework assimilating observed discharge every 10 days. The method was applied to three catchments in the Zambezi River basin in southern Africa. The catchments ranged in size from 95,300 to $281,000 \mathrm{~km}^{2}$. The catchment average soil water index correlated well with measured discharge when the data were shifted by a catchment-specific time lag. This time lag allowed $40-\mathrm{d}$ lead time streamflow forecasts with a NSE value of $85 \%$ for the largest watershed, but in a catchment with steep 
slopes and little soil water storage the lead time was as short as $10 \mathrm{~d}$. Gains in streamflow

forecast accuracy, especially during flood events, have even been demonstrated by using assimilating point soil moisture observations from a single location within a catchment of 1120

$\mathrm{km}^{2}$ together with streamflow data, suggesting that even sparse observations networks in large catchments can be quite useful (Fig. 22; Aubert et al., 2003)._assimilation process was dominated by streamflow assimilation when considering the entire period, but the effectiveness of the assimilation process was dominated by soil moisture $\underline{\text { assimilation during flood events. }}$

That large-scale soil moisture monitoring can benefit hydrologic modeling and forecasting is now well-established with gains in forecast efficiency of 10-20\% being typical; however, significant challenges and uncertainties remain. Most of the research to date in this area has focused on the use of satellite derived surface soil moisture products, with few studies using in situ soil moisture measurements within a data assimilation framework (Aubert et al., 2003; Chen et al., 2011). Thus, the world's growing in situ soil moisture monitoring infrastructure (Table 1) is a virtually unexplored resource in this context, and many opportunities exist to develop hydrologic forecasting tools which utilize that infrastructure.

A key challenge associated with assimilation of soil moisture data, regardless of the source, is to identify and overcome structural deficiencies in the hydrologic models themselves. For example, a data assimilation experiment using in situ soil moisture measurements in Oklahoma was generally unsuccessful in improving streamflow predictions from the widely used Soil and Water Assessment Tool (SWAT) model (Chen et al., 2011). The calibrated SWAT model significantly underestimated the vertical coupling of soil moisture between upper and lower soil layers, and the inadequate coupling was apparently a structural, rather than parametric, 
problem in the model. Thus, the ensemble Kalman filter assimilation approach was not effective in improving estimates of deep soil moisture or streamflow. This particular challenge of correctly representing linkages between soil moisture across two or more soil layers has been identified as a key concern in studies with other models as well (Brocca et al., 2012). Further research is needed to optimize the structure of SWAT and other hydrologic models in order to maximize the benefits from assimilating increasingly available large-scale soil moisture observations (Brocca et al., 2012).

Another challenge which has been encountered in this arena is uncertainty regarding proper characterization of model errors and observation errors within the assimilation procedure (Francois et al., 2003; Brocca et al., 2012). Statistical representations of model errors must often be made in a somewhat arbitrary or subjective fashion, and pre-existing biases in either the observations or the model can be particularly problematic (Chen et al., 2011; Brocca et al., 2012). Nevertheless, research in this area appears to be gaining momentum, and opportunities abound to advance hydrologic modeling and forecasting with the help of existing and emerging large-scale soil moisture datasets.

\section{PRIMARY CHALLENGES AND OPPORTUNITIES}

In this review, we have attempted to describe the state of the art in large-scale soil moisture monitoring and to identify some critical needs for research to optimize the use of increasingly available soil moisture data. We have considered: 1) emerging in situ and proximal sensing techniques, 2) dedicated soil moisture remote sensing missions, 3) soil moisture monitoring networks, and 4) applications of large-scale soil moisture measurements. The primary challenges and opportunities in these topic areas can be summarized as follows. For 
emerging in situ and proximal sensing techniques (e.g., COSMOS and GPS) empirical confirmations of theoretical predictions regarding the variable measurement depths are needed. Calibration procedures for these methods, as well as the DTS methods, need to be further refined and standardized with due accounting for site-specific factors such as soil and vegetation characteristics which influence instrument performance. Spatial and temporal heterogeneity in these site-specific factors must also be considered in some instances, creating additional challenges. Also, the community of expertise for these methods, that is the number of researchers with the capability to advance these technologies, needs to be expanded. Probably the largest share of scientific resources in this general topic area is currently devoted to the advancement of satellite remote sensing approaches for soil moisture monitoring. These investments are bearing fruit, but challenges and opportunities remain. One significant challenge is to further improve methods for estimating root zone soil moistureRZSM, the information we often need, using surface soil moisture observations, the information satellites provide. Progress has been made towards this goal, by using data assimilation into numerical models to retrieve root-zone soil moistureRZSM from near-surface observations. Continued İImprovements are also needed in downscaling relatively coarse resolution calibration and validation of -remotely-sensed soil moisture products to describe sub-footprint spatial variability which plays an important role in many applications. because the relatively coarse resolution of these products is not well matehed with most in situ observations. Coarse resolution, satellitederived soil moisture products are challenging to validate (Reichle et al., 2004), so continuing $\underline{\text { efforts to effectively use these products for modeling and forecasting will likely play an }}$ important role in their evaluation. Although not primarily a scientific challenge, more work is needed to reduce problems associated with RFI. Similarly, continuity of missions is a necessity 
1373 if remotely sensed soil moisture data are to be adopted for operational applications like 1374 numerical weather prediction.

1375 In contrast with remote sensing approaches, relatively few resources are currently 1376 devoted toward large-scale in situ soil moisture monitoring networks. Although the number of

1377

1378

1379

1380

1381

1382

1383 networks is growing steadily, the lack of standardization of procedures across networks is a significant challenge. There is a need for rigorous guidelines and standards to be developed and adopted worldwide for in situ soil moisture monitoring networks, similar to guidelines for measurement of other meteorological variables. Best practice standards for sensor selection, calibration, installation, validation, and maintenance are needed, as well as standards for site selection, data quality assurance and quality control, data delivery, metadata delivery, and data archives. The recent recognition of soil moisture as an "Essential Climate Variable" by the Global Climate Observing System, and the development of the International Soil Moisture NetworkISMN are positive steps in this direction, but much more is needed.

For both in situ networks and remote sensing approaches, sustainability is a significant challenge, perhaps underestimated. Societal and scientific needs for soil moisture data would seem to justify that our monitoring systems be designed to function without interruption for many decades. Current realities within science and society at large typically result in monitoring systems which are designed to function for only a few years. Researchers are rewarded for developing new systems and technologies, not for ensuring their long-term viability. Successful long-term operation of monitoring systems generally requires substantial state or federal support. Securing such long-term support for soil moisture monitoring systems is often difficult. Thus, determining effective pathways to transition monitoring systems from research mode to operational mode remains a key challenge. 
In closing, we again note the growing need to develop the science necessary to make effective use of the rising number of large-scale soil moisture datasets. One area where significant progress seems possible in the near term is the use of large-scale soil moisture data for drought monitoring. Already some progress has been made using in situ data for this purpose and approaches using remote sensing data seem sure to follow. Significant efforts have been devoted to the use of soil moisture observations within the area of numerical weather prediction. In general, assimilation of soil moisture data has resulted in only modest improvements in forecast skill. The primary problem is that the current model structures are not well suited for assimilation of these data, and the model physics may not be properly parameterized to allow for accurate soil moisture values. A smaller effort, but arguably greater progress, has been made in the assimilation of soil moisture data into models designed primarily for hydrologic prediction, especially rainfall—runoff models. Here gains in forecast efficiency of $10-20 \%$ are not uncommon. Nonetheless, as with numerical weather prediction, a key challenge is to identify or create models that are structured in a way that is optimal for assimilation of soil moisture data. To date little or no progress has been made in using large-scale soil moisture observations to improve the structure, parameters, or forecasts of ecological models, and perhaps surprisingly, the same can be said for crop models. These topic areas are ripe with eppertunity opportunities and challenges yet to be uncovered. Another frontier where the potential is great but the workers are few is the use of soil moisture observations in socio-economic modeling and forecasting to address issues such as drought impacts and food security (Simelton et al., 2012). We are optimistic that these challenges and opportunities can be addressed by improved communication and collaboration across the relevant disciplines. The international soil science community has much to contribute in this context. Hopefully this review will be a small step towards further 
engaging that community in advancing the science and practice of large-scale soil moisture monitoring for the sake of improved Earth system monitoring, modeling, and forecasting.

\section{REFERENCES}

Alavi, N., A.A. Berg, J.S. Warland, G. Parkin, D. Verseghy and P. Bartlett. 2010. Evaluating the Impact of Assimilating Soil Moisture Variability Data on Latent Heat Flux Estimation in a Land Surface Model. Canadian Water Resources Journal 35: 157-172. doi:10.4296/cwrj3502157.

Al Bitar, A., D. Leroux, Y.H. Kerr, O. Merlin, P. Richaume, A. Sahoo, and E.F. Wood. 2012. Evaluation of SMOS soil moisture products over continental US using the SCAN/SNOTEL network. IEEE Trans. Geosci. Remote Sensing 50:1572-1586.

Albergel C., G. Balsamo, P. de Rosnay, J. Muñoz-Sabater, and S. Boussetta. 2012b. A bare ground evaporation revision in the ECMWF land-surface scheme: evaluation of its impact using ground soil moisture and satellite microwave data. Hydrol. Earth Syst. Sci. 16:36073620.

Albergel, C., P. de Rosnay, C. Gruhier, J. Munoz-Sabater, S. Hasenauer, L. Isaksen, Y. Kerr, and W. Wagner. 2012a. Evaluation of remotely sensed and modeled soil moisture products using global ground-based in situ observations. Remote Sens. Environ. 118:215-226.

Albergel, C., C. Rüdiger, D. Carrer, J. Calvet, N. Fritz, V. Naeimi, Z. Bartalis and S. Hasenauer. 2009. An evaluation of ASCAT surface soil moisture products with in-situ observations in Southwestern France. Hyrdol. Earth Syst. Sci. 13: 115. 
Albergel, C., E. Zakharova, J.-C. Calvet, M. Zribi, M. Pardé, J.-P. Wigneron, N. Novello, Y. Kerr, A. Mialon and N.-e.-D. Fritz. 2011. A first assessment of the SMOS data in southwestern France using in situ and airborne soil moisture estimates: The CAROLS airborne campaign. Remote Sensing of Environment 115: 2718-2728. doi:http://dx.doi.org/10.1016/j.rse.2011.06.012.

Allen, R.G., L.S. Pereira, D. Raes, and M. Smith. 1998. Crop evapotranspiration: Guidelines for computing crop water requirements, Vol. FAO Irrigation and Drainage Paper No. 56. Rome.

Anderson, W., B. Zaitchik, C. Hain, M. Anderson, M. Yilmaz, J. Mecikalski and L. Schultz. 2012. Towards an integrated soil moisture drought monitor for East Africa. Hydrol. Earth Syst. Sci. Discuss 9: 4587-4631.

André, J- C., J- P. Goutorbe, A. Perrier, F. Becker, P. Bessemoulin, P. Bougeault, Y. Brunet, W. Brutsaert, T. Carlson, R. Cuenca, J. Gash, J. Gelpe, P. Hilderbrand, J-P. Lagouarde, C. Lloyd, L. Mahrt, P. Mascart, C. Mazaudier, J. Noilhan, C. Ottlé, M. Payen, T. Phulpin, R. Stull, J. Shuttleworth, T. Schmugge, O. Taconet, C. Tarrieu, R-M. Thepenier, C.

Valencogne, D. Vidal-Madjar and A. Weill. 1988. Evaporation Over Land-Surfaces: First Results from HAPEX-MOBILHY Special Observing Period. Annales Geophysicae, Vol. 6, No. 5. pp. 477 - 492.

André, J-C., J-P. Goutorbe and A. Perrier. 1986. HAPEX-MOBILY: A hydrologic atmospheric experiment for the study of water budget and evaporation flux at the climatic scale. Bulletin of the American Meteorological Society, vol. 67, pp. 138-144.

Aubert, D., C. Loumagne, and L. Oudin. 2003. Sequential assimilation of soil moisture and streamflow data in a conceptual rainfall-runoff model. J. Hydrol. 280:145-161. 
Bachelet, D., J.M. Lenihan, C. Daly, R.P. Neilson, D.S. Ojima, and W.J. Parton. 2001. MC1: a dynamic vegetation model for estimating the distribution of vegetation and associated carbon, nutrients, and water-technical documentation. Version 1.0.

Baker, J.M., and R.R. Allmaras. 1990. System for automating and multiplexing soil moisture measurement by time-domain reflectometry. Soil Sci. Soc. Am. J. 54:1-6.

Baldocchi, D., Falge, E., Gu, L., Olson, R., Hollinger, D., Running, S., Anthoni, P., Bernhofer, C., Davis, K., Evans, R., Fuentes, J., Goldstein, A., Katul, G., Law, B., Lee, X., Malhi, Y., Meyers, T., Munger, W., Oechel, W., Paw, K. T., Pilegaard, K., Schmid, H. P., Valentini, R., Verma, S., Vesala, T., Wilson, K., and Wofsy, S.: FLUXNET: A New Tool to Study the Temporal and Spatial Variability of Ecosystem-Scale Carbon Dioxide, Water Vapor, and Energy Flux Densities, Bull. Am. met. Soc., 82, 2415-2434, doi:10.1175/1520-0477, 2001.

Bartalis, Z., Wagner, W., Naeimi, V., Hasenauer, S., Scipal, K., Bonekamp, H., Figa, J. and Anderson, C. 2007. Initial soil moisture retrievals from the METOP-A Advanced Scatterometer (ASCAT), Geophysical Research Letters, 34, L20401

Basara, J.B., and K.C. Crawford. 2002. Linear relationships between root-zone soil moisture and atmospheric processes in the planetary boundary layer. J. Geophys. Res. 107:4274.

Best, M., C. Jones, I. Dharssi, and R. Quaggin. 2007. A physically based soil moisture nudging scheme for the global model. MetOffice Technical Note.

Best, M. and Maisey, P. 2002. A physically based soil moisture nudging scheme, Hadley Centre Technical Note 35, 22 pp., Met Office Hadley Centre, Exeter, UK.

Bircher, S., J.E. Balling, N. Skou, and Y.H. Kerr. 2012. Validation of SMOS brightness temperatures during the HOBE airborne campaign, western Denmark. IEEE Trans. Geosci. 
Remote Sensing 50:1468-1482.

Blonquist, J.M., S.B. Jones, and D.A. Robinson. 2005. Standardizing characterization of electromagnetic water content sensors: Part 2. Evaluation of seven sensing systems. Vadose Zone J. 4:1059-1069.

Blyth, E., D. B. Clark, R. Ellis, C. Huntingford, S. Los, M. Pryor, M. Best, and S. Sitch. 2010. A Comprehensive Set of Benchmark Tests for a Land Surface Model of Simultaneous Fluxes of Water and Carbon at Both the Global and Seasonal Scale. Geoscientific Model Development Discussions 3 (4) (October 26): 1829-1859. doi:10.5194/gmdd-3-1829-2010.

Bolten, J.D., W.T. Crow, Z. Xiwu, T.J. Jackson, and C.A. Reynolds. 2010. Evaluating the utility of remotely sensed soil moisture retrievals for operational agricultural drought monitoring. IEEE J. of Selected Topics in Applied Earth Observations and Remote Sensing 3:57-66.10.1109/jstars.2009.2037163.

Bremond, Laurent, Arnoud Boom, and Charly Favier. 2012. Neotropical C3/C4 Grass Distributions - Present, Past and Future. Global Change Biology 18 (7): 2324-2334. doi:10.1111/j.1365-2486.2012.02690.x.

Breshears, David D., and Fairley J. Barnes. 1999. Interrelationships Between Plant Functional Types and Soil Moisture Heterogeneity for Semiarid Landscapes Within the Grassland/forest Continuum: a Unified Conceptual Model. Landscape Ecology 14 (5): 465-478. doi:10.1023/A:1008040327508.

Bristow, K.L., G.S. Campbell, and K. Calissendorff. 1993. Test of a heat-pulse probe for measuring changes in soil water content. Soil Sci. Soc. Am. J. 57:930-934.

Brocca, L., Hasenauer, S., Lacava, T., Melone, F., Moramarco, T., Wagner, W., Dorigo, W., Matgen, P., Martínez-Fernández, J., llorens, P., Latron, J., martin, C., and Bittelli, M.: Soil 
moisture estimation through ASCAT and AMSR-E sensors: An intercomparison and validation study across Europe, Remote Sensing Envir., 115, 3390-3408, 10.1016/j.rse.2011.08.003, 2011.

Brocca, L., F. Melone, T. Moramarco, W. Wagner, V. Naeimi, Z. Bartalis, and S. Hasenauer. 2010. Improving runoff prediction through the assimilation of the ascat soil moisture product. Hyrdol. Earth Syst. Sci. 14:1881-1893.

Brocca, L., T. Moramarco, F. Melone, W. Wagner, S. Hasenauer, and S. Hahn. 2012. Assimilation of surface- and root-zone ascat soil moisture products into rainfall-runoff modeling. Geoscience and Remote Sensing, IEEE Transactions on 50:2542-2555.

Brock F.V., Crawford K.C., Elliott R.L., Cuperus G.W., Stadler S.J., Johnson H.L., Eilts M.D. 1995. The Oklahoma Mesonet: A technical Overview. Journal of Atmospheric and Oceanic Technology 12:5-19.

Calvet, J. C., Fritz, N., Froissard, F., Suquia, D., Petitpa, A., and Piguet, B. 2007. In situ soil moisture observations for the CAL/VAL of SMOS: The SMOSMANIA network, International Geoscience and Remote Sensing Symposium, 2007. IGARSS, Barcelona, Spain, p. 1196-1199.

Campbell, G.S., C. Calissendorff, and J.H. Williams. 1991. Probe for measuring soil specific heat using a heat-pulse method. Soil Sci. Soc. Am. J. 55:291-293.

Carroll, T.R. 1981. Airborne soil moisture measurement using natural terrestrial gamma radiation. Soil Sci. 132:358-366.

Carslaw, H.S., and J.C. Jaeger. 1959. Conduction of heat in solids. Second ed. Oxford University Press, Oxford.

Chang, A.T.C., S.G. Atwater, V.V. Salomonson, J.E. Estes, D.S. Simonett, and M.L. Bryan. 
1980. L-band radar sensing of soil moisture. Geoscience and Remote Sensing, IEEE Transactions on GE-18:303-310.

Chen, F., W.T. Crow, P.J. Starks, and D.N. Moriasi. 2011. Improving hydrologic predictions of a catchment model via assimilation of surface soil moisture. Advances in Water Resources $34: 526-536$.

Chen, F. and J. Dudhia. 2001. Coupling an advanced land surface hydrology model with the Penn State-NCAR MM5 modeling system. Part I: Model implementation and sensitivity. Monthly Weather Review, Vol. 129, pp. 569-585.

Chew, C., E. Small, K. Larson, and V. Zavorotny. in press. Effects of Near-Surface Soil Moisture on GPS SNR Data: Development of a Retrieval Algorithm for Volumetric Soil Moisture, IEEE Trans. Geosci. Remote Sens.

\section{Collow, T.W., A. Robock, J.B. Basara and B.G. Illston. 2012. Evaluation of SMOS retrievals} of soil moisture over the central United States with currently available in situ observations. Journal of Geophysical Research: Atmospheres 117: D09113. doi:10.1029/2011jd017095.

Curran, P.J. 1978. A photographic method for the recording of polarised visible light for soil surface moisture indications. Remote Sensing of Environment 7:305-322.

Crow, W.T., A.A. Berg, M.H. Cosh, A. Loew, B.P. Mohanty, R. Panciera, P. de Rosnay, D. Ryu, and J.P. Walker. 2012. Upscaling sparse ground-based soil moisture observations for the validation of coarse-resolution satellite soil moisture products. Reviews of Geophysics 50:RG2002 DOI: 10.1029/2011RG000372.-

Das, N.N., D. Entekhabi and E.G. Njoku. 2011. An Algorithm for Merging SMAP Radiometer and Radar Data for High-Resolution Soil-Moisture Retrieval. Geoscience and Remote Sensing, IEEE Transactions on 49: 1504-1512. doi:10.1109/TGRS.2010.2089526. 
de Rosnay P., M. Drusch, D. Vasiljevic, G. Balsamo, C. Albergel and L. Isaksen. 2012. A simplified Extended Kalman Filter for the global operational soil moisture analysis at ECMWF, in press, Q. J. R. Meteorol. Soc.

de Rosnay, P., C. Gruhier, F. Timouk, F. Baup, E. Mougin, P. Hiernaux, L. Kergoat, and V.

LeDantec. 2009. Multi-scale soil moisture measurements at the Gourma Meso-scale Site in Mali. J. Hydrol. 375:241-252.

Denning, A.S., R. Oren, D. McGuire, C. Sabine, S. Doney, K. Paustian, M. Torn, L. Dilling, L. Heath, and P. Tans. 2005. Science implementation strategy for the north american carbon program. US Global Change Research Program.

Desilets, D. and Zreda, M., 2001. On scaling cosmogenic nuclide production rates for altitude and latitude using cosmic-ray measurements. Earth and Planetary Science Letters, 193, $213-225$.

Desilets, D. and Zreda, M., 2003. Spatial and temporal distribution of secondary cosmic-ray nucleon intensities and applications to in-situ cosmogenic dating. Earth and Planetary Science Letters, 206, 21-42.

Desilets, D., Zreda, M. and Ferre, T., 2010. Nature's neutron probe: Land-surface hydrology at an elusive scale with cosmic rays. Water Resources Research, 46, W11505.

Desilets, D., Zreda, M. and Prabu, T., 2006. Extended scaling factors for in situ cosmogenic nuclides: New measurements at low latitude. Earth and Planetary Science Letters, 246, $265-276$.

Dharssi, I. Bovis, K., Macpherson, B. and C. Jones: Operational assimilation of ASCAT surface soil wetness at the Met Office, Hydrol. Earth Syst. Sci., 15, 2729-2746, 2011

Dickey, F.M., C. King, J.C. Holtzman, and R.K. Moore. 1974. Moisture dependency of radar 
backscatter from irrigated and non-irrigated fields at $400 \mathrm{Mhz}$ and $13.3 \mathrm{Ghz}$. Geoscience Electronics, IEEE Transactions on 12:19-22.

Dickinson, R.E., A. Henderson-Sellers, P.J. Kennedy, and M.F. Wilson. 1986. BiospherAtmosphere Transfer Scheme (BATS) for the NCAR CCM. National Center for Atmospheric Research, Boulder, Colorado.

Dirmeyer, P. 1999. Assessing GCM Sensitivity to Soil Wetness Using GSWP Data. J Meteorol Soc Jpn 77 (1B): 367-385.

Dirmeyer, Paul A., Xiang Gao, Mei Zhao, Zhichang Guo, Taikan Oki, and Naota Hanasaki. 2006. GSWP-2 $\square$ : Multimodel analysis and implications for our perception of the land surface. Bulletin of the American Meteorological Society 87 (10): 1381-1397.

Dobriyal, P., A. Qureshi, R. Badola, and S.A. Hussain. 2012. A review of the methods available for estimating soil moisture and its implications for water resource management. J. Hydrol. 458-459:110-117.

Dorigo, W. A., Wagner, W., Hohensinn, R., Hahn, S., Paulik, C., Xaver, A., Gruber, A., Drusch, M., Mecklenburg, S., van Oevelen, P., Robock, A., and Jackson, T.: The International Soil Moisture Network: a data hosting facility for global in situ soil moisture measurements, Hydrol. Earth Syst. Sci., 15, 1675-1698, 10.5194/hess-15-1675-2011, $2011 b$.

Dorigo, W. A., Xaver, A., Vreugdenhil, M., Gruber, A., Hegyiová, A., Sanchis-Dufau, A. D., Wagner, W., and Drusch, M. 2013. Global automated quality control of in situ soil moisture data from the International Soil Moisture Network. Vadose Zone Journal. doi:10.2136/vzj2012.0097.

Dorigo, W., Van Oevelen, P., Wagner, W., Drusch, M., Mecklenburg, S., Robock, A., and 
Jackson, T.: A New International Network for in Situ Soil Moisture Data, EOS

Transactions, American Geophysical Union, 92, 141-142, $2011 \mathrm{a}$.

Douville, H., Viterbo, P., Mahfouf, J.-F. and Beljaars, A. 2000. Evaluation of the optimum interpolation and nudging techniques for soil moisture analysis using FIFE data, Monthly Weather Review, 128, 1733-1756.

Draper, C., Mahfouf, J.-F. and Walker, J. 2011. Root-zone soil moisture from the assimilation of screen-level variables and remotely sensed soil moisture, Journal of Geophysical Research, 116, D02127.

Drusch, M. and Viterbo, P. 2007. Assimilation of screen-level variables in ECMWF's Integrated Forecast System: A study on the impact on the forecast quality and analyzed soil moisture, Monthly Weather Review, 135, 300-314.

Drusch, M., Scipal, K., de Rosnay, P., Balsamo, G., Andersson, E., Bougeault, P. and Viterbo, P. 2009. Towards a Kalman Filter based soil moisture analysis system for the operational ECMWF Integrated Forecast System, Geophysical Research Letters, 36, L10401.

Ek, M.B. and R. H. Cuenca. 1994. Variation in Soil Parameters: Implications for Modeling Surface Fluxes and Atmospheric Boundary-Layer Development. Boundary-Layer Meteorology, Vol. 70, pp. 369 - 383.

Ek, M. B. and A. A. M. Holstag. 2004. Influence of soil moisture on boundary layer cloud development. Journal of Hydrometeorology, Vol. 5, pp. 86-99.

Ek, M.B. and L. Mahrt. 1994. Daytime evolution of relative humidity at the boundary-layer top. Monthly Weather Review, Vol. 122, pp. 2709-2721.

Ek, M. B., K. E. Mitchell, Y. Lin, E. Rogers, P. Grummann, V. Koren, G. Gayno, and J. D. Tarpley. 2003. Implementation of Noah land surface model advances in the National 
Centers for Environmental Prediction operational mesoscale Eta model. Journal of Geophysical Research, Vol. 108, 8851, doi:10.1029/2002JD003296.

Entekhabi, D., E.G. Njoku, P.E. O'Neill, K.H. Kellogg, W.T. Crow, W.N. Edelstein, J.K. Entin, S.D. Goodman, T.J. Jackson, and J. Johnson. 2010. The soil moisture active passive (SMAP) mission. Proceedings of the IEEE 98:704-716.

Escorihuela, M.J., A. Chanzy, J.P. Wigneron, and Y.H. Kerr. 2010. Effective soil moisture sampling depth of L-band radiometry: A case study. Remote Sens. Environ. 114:995-1001.

Evett, S.R. 2001. Exploits and endeavors in soil water management and conservation using nuclear techniques. International Symposium on Nuclear Techniques in Integrated Plant Nutrient, Water, and Soil Management. Vienna, Austria. 16-20 October 2000.

Field, C. B., R. B. Jackson, and H. A. Mooney. 1995. Stomatal Responses to Increased CO2: Implications from the Plant to the Global Scale. Plant, Cell \& Environment 18 (10): 1214 1225. doi:10.1111/j.1365-3040.1995.tb00630.x.

Foley, J.A., I.C. Prentice, N. Ramankutty, S. Levis, D. Pollard, S. Sitch, and A. Haxeltine. 1996. An integrated biosphere model of land surface processes, terrestrial carbon balance, and vegetation dynamics. Global Biogeochemical Cycles. 10(4): 603-628.

Francois, C., A. Quesney, and C. Ottlé. 2003. Sequential assimilation of ers-1 SAR data into a coupled land surface-hydrological model using an extended kalman filter. Journal of Hydrometeorology 4:473-487.

Franz, T.E., M. Zreda, R. Rosolem and T.P.A. Ferre. 2012. Field Validation of a Cosmic-Ray Neutron Sensor Using a Distributed Sensor Network. Vadose Zone J. 11: doi:10.2136/vzj2012.0046.

Franz, T.E., Zreda, M., Rosolem, R. and Ferre, T.P.A., 2013. A universal calibration function 
for determination of soil moisture with cosmic-ray neutrons. Hydrology and Earth System Sciences, 17:453-460.

Fredlund, D.G., and D.K.H. Wong. 1989. Calibration of thermal conductivity sensors for measuring soil suction. Geotechnical Testing J. 12:188-194.

Friedlingstein et al. 2006. Climate-Carbon Cycle Feedback Analysis: Results from the C4MIP Model Intercomparison. Journal of Climate, Vol. 19: pp. 3337-3353.

Gardner, W., and D. Kirkham. 1952. Determination of soil moisture by neutron scattering. Soil Sci. 73:391-402.

GCOS: Implementation Plan for the Global Observing System for Climate in support of the UNFCCC - 2010 Update, World Meteorological Organization, 2010.

Georgiadou, Y., and A. Kleusberg 1988, On carrier signal multipath effects in relative GPS positioning, Manuscr. Geod., 13, 172- 179.

Gerten, Dieter, Sibyll Schaphoff, Uwe Haberlandt, Wolfgang Lucht, and Stephen Sitch. 2004. Terrestrial Vegetation and Water Balance-hydrological Evaluation of a Dynamic Global Vegetation Model. Journal of Hydrology 286 (1-4) (January 30): 249-270. doi:10.1016/j.jhydrol.2003.09.029.

Gil-Rodríguez, M., L. Rodríguez-Sinobas, J. Benítez-Buelga, and R. Sánchez-Calvo. in press. Application of active heat pulse method with fiber optic temperature sensing for estimation of wetting bulbs and water distribution in drip emitters. Agricultural Water Management Gordon, W. S., J. S. Famiglietti, N. L. Fowler, T. G. F. Kittel, and K. A. Hibbard. 2004. Validation of simulated runoff from six terrestrial ecosystem models: Results from VEMAP. Ecological Applications 14:(2)(April1):527-545. doi:10.1890/02-5287.

Goutoule, J. M. 1995. MIRAS spaceborne instrument and its airborne demonstrator. 
Proceedings of the Consultative Meeting on Soil Moisture and Ocean Salinity (SMOS), ESA WPP-87, ESTEC, Nordwijk, Netherlands, April 20-21.

Gruber, A., Dorigo, W., Zwieback, S., Xaver, A., and Wagner, W. 2013. Characterizing coarse-scale representativeness of in situ soil moisture measurements from the International Soil Moisture Network. Vadose Zone Journal. 12: - doi:10.2136/vzj2012.0170

Guttman, N.B. 1999. Accepting the standardized precipitation index: A calculation algorithm. Journal of the American Water Resources Association 35:311-322.

Haxeltine, A., and I.C. Prentice. 1996. BIOME3: An equilibrium terrestrial biosphere model based on ecophysiological constraints, resource availability, and competition among plant functional types. Global Biogeochemical Cycles. 10(4): 693-709.

Hallikainen, M., F. Ulaby, M. Dobson, M. El-Rayes, and L. Wu, Microwave Dielectric Behavior of Wet Soil—Part I: Empirical Models and Experimental Observations, IEEE Trans. Geosci. Remote Sens., vol. 23, no. 1, pp. 25-34, Jan. 1985.

Heitman, J.L., J.M. Basinger, G.J. Kluitenberg, J.M. Ham, J.M. Frank, and P.L. Barnes. 2003. Field evaluation of the dual-probe heat-pulse method for measuring soil water content. Vadose Zone J. 2:552-560.

Henderson-Sellers, A., A. J. Pitman, P. K. Love, P. Irannejad, and T. H. Chen. 1995. The project for intercomparison of land surface parameterization schemes (PILPS): phases 2 and 3. Bulletin of the American Meteorological Society 76 (4): 489-503.

Henderson-Sellers, A., K. McGuffie, and A. J. Pitman. 1996. The Project for Intercomparison of Land-surface Parametrization Schemes (PILPS): 1992 to 1995. Climate Dynamics 12 (12): 849-859. doi:10.1007/s003820050147.

Hess, H. 2001. Assimilation of screen-level observations by variational soil moisture analysis, 
Meteorology and Atmospheric Physics, 77, 145:154.

Hoeben, R., and P.A. Troch. 2000. Assimilation of active microwave observation data for soil moisture profile estimation. Water Resour. Res. 36:2805-2819.

Hoeffner, M., T. Lebel and B. Monteny (editors). 1996. Interactions surface continental/atmosphere: L'Expérience HAPEX-Sahel, OSTROM Éditions, Paris, 763 pp.

Hollinger, S.E., and S.A. Isard. 1994. A soil moisture climatology of illinois. Journal of Climate 7:822-833.

Hoogenboom, G., 1993. The Georgia automated environmental monitoring network. Southeastern Climate Review 4 (1), 12-18.

Hubbard, K. G., J. You, V. Sridhar, E. Hunt, S. Korner, and G. Roebke. 2009. Near-surface soil-water monitoring for water resources management on a wide-area basis in the Great Plains. Great Plains Res. 19:45-54.

Hunt, E.D., K.G. Hubbard, D.A. Wilhite, T.J. Arkebauer, and A.L. Dutcher. 2009. The development and evaluation of a soil moisture index. International Journal of Climatology 29:747-759.

Illston B.G., Basara J., Fischer D.K., Elliott R.L., Fiebrich C., Crawford K.C., Humes K.S., Hunt E., 2008, Mesoscale monitoring of soil moisture across a statewide network. J. Atmospheric and Oceanic Technology 25:167-182.

Ise, Takeshi, and Paul R. Moorcroft. 2006. The Global-scale Temperature and Moisture Dependencies of Soil Organic Carbon Decomposition: An Analysis Using a Mechanistic Decomposition Model. Biogeochemistry 80 (3): 217-231. doi:10.1007/s10533-006-9019-5. Jackson T.J., Cosh M.H., Bindlish R., Starks P.J., Bosch D.D., Seyfried M.S., Goodrich D.C., Moran M.S., Du J. 2010. Validation of Advanced Microwave Scanning Radiometer Soil 
Moisture Products. IEEE Transactions of Geoscience and Remote Sensing 48:4256-4272.

Jackson, T.J., and T.J. Schmugge. 1989. Passive microwave remote-sensing system for soilmoisture - some supporting research. IEEE Transactions on Geoscience and Remote Sensing 27:225-235.

Jackson, T.J., and T.J. Schmugge. 1991. Vegetation effects on the microwave emission of soils. Remote Sensing of Environment 36:203-212.

Jackson, T.J., R. Bindlish, M.H. Cosh, T.J. Zhao, P.J. Starks, D.D. Bosch, M. Seyfried, M.S. Moran, D.C. Goodrich, Y.H. Kerr, and D. Leroux. 2012. Validation of soil moisture and ocean salinity (SMOS) soil moisture over watershed networks in the U.S. IEEE Trans. Geosci. Remote Sensing 50:1530-1543.

Jacquette, E., A. Al Bitar, A. Mialon, Y. Kerr, A. Quesney, F. Cabot, and P. Richaume. 2010. SMOS CATDS level 3 global products over land. In C. M. U. Neale and A. Maltese, eds. In Remote sensing for Agriculture, Ecosystems, and Hydrology xii, Vol. 7824.

Jenkinson, D.S., and K. Coleman. 1994. Calculating the annual input of organic matter to soil from measurements of total organic carbon and radiocarbon. European Journal of Soil Science. 45: 167-174.

Kaleschke, L., X. Tian-Kunze, N. Maaß, M. Mäkynen, and M. Drusch. 2012. Sea ice thickness retrieval from SMOS brightness temperatures during the arctic freeze-up period. Geophysical Research Letters 39:L05501.

Katzberg, S., O. Torres, M. Grant, D. Masters, Utilizing calibrated GPS reflected signals to estimate soil reflectivity and dielectric constant: Results from SMEX02, Geosci. Remote Sens., vol. 49, no. 1, pp. 71-84, Jan. 2005. 
Keller, M., Schimel, D. S., Hargrove, W. W., and Hoffman, F. M., 2008, A continental strategy for the National Ecological Observatory Network, Frontiers in Ecology, 6, 282287

Kerr, Y.H. 2007. Soil moisture from space: Where are we? Hydrogeol. J. 15:117-120.

Kerr, Y.H., P. Waldteufel, P. Richaume, J.P. Wigneron, P. Ferrazzoli, A. Mahmoodi, A. A1

Bitar, F. Cabot, C. Gruhier and S.E. Juglea. 2012. The SMOS soil moisture retrieval algorithm. Geoscience and Remote Sensing, IEEE Transactions on 50: 1384-1403.

Kerr, Y.H., P. Waldteufel, J.P. Wigneron, S. Delwart, F. Cabot, J. Boutin, M.J. Escorihuela, J. Font, N. Reul, C. Gruhier, S.E. Juglea, M.R. Drinkwater, A. Hahne, M. Martin-Neira, and S. Mecklenburg. 2010. The SMOS mission: New tool for monitoring key elements of the global water cycle. Proc. IEEE 98:666-687.

Kerr, Y.H., P. Waldteufel, J.-P. Wigneron, J.-M. Martinuzzi, J. Font, and M. Berger. 2001. Soil moisture retrieval from space: The soil moisture and ocean salinity (SMOS) mission. IEEE Trans. Geosci. Rem. Sens. 39:1729-1735.

Kerr, Y.H., P. Waldteufel, J.P. Wigneron, S. Delwart, F. Cabot, J. Boutin, M.J. Escerihuela, J. Font, N. Reul, C. Gruhier, S.E. Juglea, M.R. Drinkwater, A. Hahne, M. Martin-Neira, and S. Mecklenburg. 2010. The SMOS mission: New tool for monitering key elements of the global water cycle. Proc. IEEE 98:666-687.

Kerr, Y.H., P. Waldteufel, P. Richaume, J.P. Wigneren, P. Ferrazzoli, A. Mahmoødi, A. A1 Bitar, F. Cabot, C. Gruhier, S.E. Juglea, D. Leroux, A. Mialon, and S. Delwart. 2012. The SMOS soil moisture retrieval algorithm. IEEE Trans. Geosei. Remote Sensing 50:1384 1403.

Knoll, G.F., 2000. Radiation detection and measurement. Wiley, New York, 802 pp. 
Kumar, Mukesh, Gopal Bhatt, Christopher Duffy. 2010. The Role of Physical, Numerical and Data Coupling in a Mesoscale Watershed Model (PIHM). http://www.pihm.psu.edu/tab_publication.html

Lagerloef, G.S.E. 2001. Satellite measurements of salinity. p. 2511-2516. In S. T. J. Steele, and K. Turekian, ed. In Encyclopedia of Ocean Sciences. Academic Press, London.

Larson, K. M., Braun, J. J., Small, E. E., Zavorotny, V. U., Gutmann, E. D., and Bilich, A. L., 2010. GPS Multipath and its relation to near-surface soil moisture content, IEEE Journal of Selected Topics in Applied Earth Observations and Remote Sensing, 3, 1, 91-99.

Larson, K.M., E.E. Small, E.D. Gutmann, A.L. Bilich, J.J. Braun, and V.U. Zavorotny. 2008. Use of GPS receivers as a soil moisture network for water cycle studies. Geophys. Res. Lett. 35:L24405.

Larson, K.M., E. E. Small, E. Gutmann, A. Bilich, P. Axelrad, and J. Braun, Using GPS multipath to measure soil moisture fluctuations: initial results, GPS Solutions, vol. 12(3), pp. 173-177, 2008.

Law, B.E, E Falge, L Gu, D.D Baldocchi, P Bakwin, P Berbigier, K Davis, et al. 2002.

Environmental Controls over Carbon Dioxide and Water Vapor Exchange of Terrestrial Vegetation. Agricultural and Forest Meteorology, 113 (1-4): 97-120. doi:10.1016/S01681923(02)00104-1.

Le Houérou, H.N. 1996. Climate change, drought and desertification. Journal of Arid Environments 34:133-185.

Levine, D. 1988. Synthetic aperture microwave radiometer. Laboratory for Oceans 1: 237-238. Le- $\vee \underline{v}$ ine, D.M., A.J. Griffis, C.T. Swift, and T.J. Jackson. 1994. ESTAR: A synthetic aperture microwave radiometer for remote sensing applications. Proc. IEEE 82 
Le $\vee_{v}$ vine, D.M., M. Kao, A.B. Tanner, C.T. Swift, and A. Griffis. 1990. Initial results in the development of a synthetic aperture microwave radiometer. IEEE Trans. Geosci. Remote Sens.:614-619.

Leroux, D. J., Y. H. Kerr, R. A. M. de Jeu and A. Mialon 2012. Simplified algorithm for SMOS: Adaptation of the land parameter retrieval model. EGU General assembly 2012, Wien Austria.

Li, B. and R. Avissar. 1994. The impact of spatial variability of land-surface characteristics on land-surface heat fluxes. Journal of Climate 7: 527-537.

Li, C., S. Frolking, and T.A. Frolking. 1992. A model of nitrous oxide evolution from soil driven by rainfall events: 1 . Model structure and sensitivity. Journal of Geophysical Research: Atmospheres. 97(D9): 9759-9776.

Lowe, S.T., J. L. LaBrecque, C. Zuffada, L. J. Romans, L. E. Young, and G. A. Hajj, 37, 1, doi:10.1029/2000RS002539, 2002

Magagi, R.D., and Y.H. Kerr. 1997a. Retrieval of soil moisture and vegetation characteristics by use of ERS-1 wind scatterometer over arid and semi-arid areas. J. Hydrol. 189:361-384. Magagi, R.D., and Y.H. Kerr. 1997b. Characterization of surface parameters over arid and semi-arid areas by use of ERS-1 windscatterometer. Remote Sensing Reviews 15:133-155.

Magagi, R.D., and Y.H. Kerr. 2001. Estimating surface soil moisture and soil roughness from ERS-1 winscatterometer data over semi-arid area: Use of the co-polarisation ratio. Remote Sens. Environ.:432-445.

Mahfouf, J.-F. 1991. Analysis of soil moisture from near-surface parameters: A feasibility study, Journal of Applied Meteorology, 30, 1534-1547.

Mahfouf, J.-F., Bergaoui, K., Draper, C., Bouyssel, C., Taillefer, F. and Taseva, L. 2009. A 
comparison of two off-line soil analysis schemes for assimilation of screen-level observations, Journal of Geophysical Research, 114, D08105.

Mahrt, L. and H-L. Pan. 1984. A two-layer model of soil hydrology, Boundary-Layer Meteorology, Vol. 29, pp. 1-20.

Manabe, Syukuro. 1969. Climate and the Ocean Circulation. Monthly Weather Review 97: 739. doi: 10.1175/1520-0493.

McPherson, R.A., C.A. Fiebrich, K.C. Crawford, J.R. Kilby, D.L. Grimsley, J.E. Martinez, J.B. Basara, B.G. Illston, D.A. Morris, K.A. Kloesel, A.D. Melvin, H. Shrivastava, J.M. Wolfinbarger, J.P. Bostic, D.B. Demko, R.L. Elliott, S.J. Stadler, J.D. Carlson, and A.J. Sutherland. 2007. Statewide monitoring of the mesoscale environment: A technical update on the Oklahoma mesonet. J. Atmos. Ocean. Tech. 24:301-321.

Mecklenburg, S., M. Drusch, Y.H. Kerr, J. Font, M. Martin-Neira, S. Delwart, G. Buenadicha, N. Reul, E. Daganzo-Eusebio, R. Oliva, and R. Crapolicchio. 2012. Esa's soil moisture and ocean salinity mission: Mission performance and operations. IEEE Trans. Geosci. Remote Sensing 50:1354-1366.

Meier, P., A. Frömelt, and W. Kinzelbach. 2011. Hydrological real-time modelling in the zambezi river basin using satellite-based soil moisture and rainfall data. Hyrdol. Earth Syst. Sci. 15:999-1008.

Merlin, O., A. Al Bitar, J.P. Walker, and Y. Kerr. 2010. An improved algorithm for disaggregating microwave-derived soil moisture based on red, near-infrared and thermalinfrared data. Remote Sens. Environ. 114:2305-2316.

Merlin, O., A.G. Chehbouni, Y.H. Kerr, E.G. Njoku, and D. Entekhabi. 2005. A combined modeling and multi-spectral/multi-resolution remote sensing approach for disaggregation 
of surface soil moisture: Application to SMOS configuration IEEE Trans. Geosc. Remote Sens. 43:2036-2050.

Merlin, O., C. Rudiger, A. Al Bitar, P. Richaume, J.P. Walker, and Y.H. Kerr. 2012.

Disaggregation of SMOS soil moisture in southeastern Australia. IEEE Trans. Geosci. Remote Sensing 50:1556-1571.

Mishra, A.K., and V.P. Singh. 2010. A review of drought concepts. J. Hydrol. 391:202-216.

Moghaddam, M. 2009. Polarimetric SAR Phenomenology and Inversion Techniques for Vegetated Terrain, in SAGE Remote Sensing Handbook, T. Warner, Ed., Sage Publications, London.

Moghaddam, M., S. Saatchi, and R. Cuenca. 2000. Estimating subcanopy soil moisture with radar. J. Geophysical Research - Atmospheres, Vol. 105, No. D11, pp. 14899-14911.

Monna, W. A. A. and J. G. van der Vliet. 1987. Facilities for research and weather observations on the 213-m tower at Cabauw and at remote locations. KNMI Scientific Report WP-87-5, Royal Netherlands Meteorological Institute (KNMI), De Bilt, Netherlands.

Montaldo, N., J.D. Albertson, M. Mancini, and G. Kiely. 2001. Robust simulation of root zone soil moisture with assimilation of surface soil moisture data. Water Resour. Res. 37:28892900.

Moorcroft, P. R, G. C. Hurtt, S. W. Pacala. 2001. A method for scaling vegetation dynamics: the ecosystem demography model (ED), Ecological Monographs, 71, 557-585.

Moran, M.S., D.C. Hymer, J. Qi, and Y. Kerr. 1998. Radar imagery for precision crop and soil management. Modern Agriculture 2:21-23.

Moran, M.S., D.C. Hymer, J.G. Qi, and Y. Kerr. 2002. Comparison of ERS-2 SAR and 
LANDSAT TM imagery for monitoring agricultural crop and soil conditions. Remote Sens. Environ. 79:243-252.

Mozny, M., M. Trnka, Z. Zalud, P. Hlavinka, J. Nekovar, V. Potop, and M. Virag. 2012. Use of a soil moisture network for drought monitoring in the Czech Republic. Theoretical and Applied Climatology 107:99-111.

Narasimhan, B., and R. Srinivasan. 2005. Development and evaluation of soil moisture deficit index (SMDI) and evapotranspiration deficit index (ETDI) for agricultural drought monitoring. Agr. Forest Meteorol. 133:69-88.

Neilson, Ronald P. 1995. A Model for Predicting Continental-Scale Vegetation Distribution and Water Balance. Ecological Applications 5 (2) (May 1): 362-385. doi: $10.2307 / 1942028$.

\section{Njoku, E.G., T.J. Jackson, V. Lakshmi, T.K. Chan and S.V. Nghiem. 2003. Soil moisture} retrieval from AMSR-E. Geoscience and Remote Sensing, IEEE Transactions on 41: 215$\underline{229 .}$

NRC. 2007. Earth Science and Applications from Space: National Imperatives for the Next Decade and Beyond. Washington DC: National Academies Press.

Ochsner, T.E., R. Horton, and T. Ren. 2003. Use of the dual-probe heat-pulse technique to monitor soil water content in the vadose zone. Vadose Zone J. 2:572-579.

Oliva, R., E. Daganzo, Y. Kerr, S. Mecklenburg, S. Nieto, P. Richaume, and C. Gruhier. 2012. SMOS RF interference scenario: Status and actions taken to improve the RFI environment in the 1400-1427 Mhz passive band. IEEE Geosci. Remote Sens. 50:1427-1439.

Orchard, Valerie A., and F.J. Cook. 1983. Relationship Between Soil Respiration and Soil Moisture. Soil Biology and Biochemistry 15 (4): 447-453. doi:10.1016/0038- 
0717(83)90010-X.

Owe, M., R. de Jeu, and T. Holmes. 2008. Multisensor historical climatology of satellitederived global land surface moisture. Journal of Geophysical Research 113:F01002.

Owe, M., R. A. M. de Jeu, and J. P. Walker. 2001. A methodology for surface soil moisture and vegetation optical depth retrieval using the microwave polarization difference index, IEEE Trans. Geosci. Remote Sens., 39, 1643-1654, doi:10.1109/36.942542.

Palecki, M.A., and P.Ya. Groisman, 2011. Observing climate at high elevations using United States Climate Reference Network Approaches. J. Hydrometeor. 12, 1137-1143, doi:10.1175/2011JHM1335.1.

Palmer, W.C. 1965. Meteorological drought. Research Paper No. 45. U.S. Weather Bureau, Washington, DC.

Pan, H-L. and L. Mahrt. 1987. Interaction between soil hydrology and boundary-layer development, Boundary-Layer Meteorology, Vol. 38, pp. 185-202.

Pan, Y., J.M. Melillo, A.D. McGuire, D.W. Kicklighter, L.F. Pitelka, K. Hibbard, L.L. Pierce, S.W. Running, D.S. Ojima, and W.J. Parton. 1998. Modeled responses of terrestrial ecosystems to elevated atmospheric $\mathrm{CO} 2$ : A comparison of simulations by the biogeochemistry models of the vegetation/ecosystem modeling and analysis project (VEMAP). Oecologia 114:389-404.

Parton, W.J., M. Hartman, D. Ojima, and D. Schimel. 1998. DAYCENT and its land surface submodel: description and testing. Global and Planetary Change. 19(1-4): 35-48.

Parton, W.J., D.S. Schimel, C.V. Cole, and D.S. Ojima. 1987. Analysis of Factors Controlling Soil Organic Matter Levels in Great Plains Grasslands. Soil Science Society of America Journal. 51(5): 1173. 
Parrens, M., E. Zakharova, S. Lafont, J.-C. Calvet, Y. Kerr, W. Wagner and J.-P. Wigneron. 2012. Comparing soil moisture retrievals from SMOS and ASCAT over France. Hyrdol. Earth Syst. Sci. 16: 423-440.

Pauwels, V.R.N., R. Hoeben, N.E.C. Verhoest, and F.P. De Troch. 2001. The importance of the spatial patterns of remotely sensed soil moisture in the improvement of discharge predictions for small-scale basins through data assimilation. J. Hydrol. 251:88-102.

Pauwels, V. R., H. Lievens, N. E. Verhoest, G. De Lannoy, D. Plaza Guingla, M. J. van den Berg, Y. Kerr, A. Al Bitar, O. Merlin, F. Cabot, S. Gascoin, E. Wood, M. Pan, A. Sahoo, J. Walker, G. Dumedah and M. Drusch 2012. Assimilation of SMOS data into a coupled land surface and radiative transfer model for improving surface water management. AGU Chapman Conference on Remote Sensing of the Terrestrial Water Cycle, Kona, Hawaii, US, AGU.

Peel, M. C., B.L. Finlayson, B. L., and T.A. McMahon. 2007, T. A... Updated world map of the Köppen-Geiger climate classification, ${ }_{-}$.Hydrol. Earth Syst. Sci,.,_11:, 1633-1644. doi:, 410.5194/hess-11-1633-2007, 2007.

Peled, E., E. Dutra, P. Viterbo, and A. Angert. 2010. Technical note: Comparing and ranking soil-moisture indices performance over europe, through remote-sensing of vegetation. Hydrology and Earth System Sciences Discussions 6:6247-6264.

Phene, C.J., G.J. Hoffman, and S.L. Rawlins. 1971. Measuring soil matric potential in situ by sensing heat dissipation within a porous body: I. Theory and sensor construction1. Soil Sci. Soc. Am. J. 35:27-33.

Piles, M., A. Camps, M. Vall-Llossera, I. Corbella, R. Panciera, C. Rudiger, Y.H. Kerr and J. Walker. 2011. Downscaling SMOS-derived soil moisture using MODIS visible/infrared 
data. Geoscience and Remote Sensing, IEEE Transactions on 49: 3156-3166.

Pratt, D.A., and C.D. Ellyett. 1979. The thermal inertia approach to mapping of soil moisture and geology. Remote Sensing of Environment 8:151-168.

Prentice, I., W. Cramer, S. Harrison, R. Leemans, R. Monserud, and A. Solomon. 1992. A global biome model based on plant physiology and dominance, soil properties and climate. Journal Of Biogeography. 19: 117-134.

Qu, Yizhong and Christopher J. Duffy. 2007. A semidiscrete finite volume formulation for multiprocess watershed simulation. Water Resources Research, Vol. 43, pp. 1 - 18 .

Rahmoune, R., P. Ferrazoli, Y.H. Kerr, and P. Richaume. 2012. Analysis of SMOS signatures over forests and application of 12 algorithm. IEEE Geosci. Remote Sens. in press

Randerson, James T., Forrest M. Hoffman, Peter E. Thornton, Natalie M. Mahowald, Keith Lindsay, Yen-Huei Lee, Cynthia D. Nevison, et al. 2009. Systematic Assessment of Terrestrial Biogeochemistry in Coupled Climate-carbon Models. Global Change Biology 15 (10): 2462-2484. doi:10.1111/j.1365-2486.2009.01912.x.

Reece, C.F. 1996. Evaluation of a line heat dissipation sensor for measuring soil matric potential. Soil Sci. Soc. Am. J. 60:1022-1028.

Reichle, R.H., W.T. Crow, R.D. Koster, J.S. Kimball and G.J.M. De Lannoy. 2012. SMAP $\underline{\text { Level } 4 \text { Surface and Root Zone Soil Moisture (L4 SM) Data Product Algorithm }}$ Theoretical Basis Document. Global Modeling and Assimilation Office. NASA Goddard Space Flight Center. Greenbelt, MD. http://smap.jpl.nasa.gov/files/smap2/L4_SM_InitRel_v1.pdf. Accessed June 11, 2013. Reichle, R.H., R.D. Koster, J. Dong and A.A. Berg. 2004. Global Soil Moisture from Satellite Observations, Land Surface Models, and Ground Data: Implications for Data Assimilation. 
Journal of Hydrometeorology 5: 430-442. doi:10.1175/1525-7541

Reichstein, Markus, Ana Rey, Annette Freibauer, John Tenhunen, Riccardo Valentini, Joao

Banza, Pere Casals, et al. 2003. Modeling temporal and large-scale spatial variability of soil respiration from soil water availability, temperature and vegetation productivity indices. Global Biogeochemical Cycles 17 (4) (November 22): 1104.

doi:10.1029/2003GB002035.

Ren, D., L. M. Leslie, and D. J. Karoly. 2008. Sensitivity of an Ecological Model to Soil Moisture Simulations from Two Different Hydrological Models. Meteorology and Atmospheric Physics 100 (1): 87-99. doi:10.1007/s00703-008-0297-4.

Richards, L. A. 1931. Capillary conduction of liquids through porous mediums. Physics 1, 318-333.

Rivera Villarreyes, C.A., Baroni, G. and Oswald, S.E., 2011. Integral quantification of seasonal soil moisture changes in farmland by cosmic-ray neutrons. Hydrology and Earth System Sciences 15, 3843-3859.

Robinson, D.A., C.S. Campbell, J.W. Hopmans, B.K. Hornbuckle, S.B. Jones, R. Knight, F. Ogden, J. Selker, and O. Wendroth. 2008. Soil moisture measurement for ecological and hydrological watershed-scale observatories: A review. Vadose Zone J. 7:358-389.

Robock, A., K. Ya Vinnikov, C. A. Schlosser, N. A. Speranskaya, and Y. Xue. 1995. Use of midlatitude soil moisture and meteorological observations to validate soil moisture simulations with biosphere and bucket models. Journal of Climate 8 (1): 15-35.

Robock, A., K.Y. Vinnikov, G. Srinivasan, J.K. Entin, S.E. Hollinger, N.A. Speranskaya, S. Liu, and A. Namkhai. 2000. The global soil moisture data bank. Bulletin of the American Meteorological Society 81:1281-1299. 
Robock, A., Mu, M., Vinnikov, K., Trofimova, I. V., and Adamenko, T. I.: Forty-five years of observed soil moisture in the Ukraine: No summer desiccation (yet), Geophys. Res. Lett., 32, 1-5, 10.1029/2004GL021914, 2005.

Rodell, M., Houser, P.R., Jambor, U., Gottschalck, J., Mitchell, K., Meng, C.-J., Arsenault, K., Cosgrove, B., Radakovich, J., Bosilovich, M., Entin, J.K., Walker, J.P., Lohmann, D., \& Toll, D. 2004. The Global Land Data Assimilation System. Bulletin of the American Meteorological Society, 85: 381-394.

Rodriguez-Alvarez, N., X. Bosch-Lluis, A. Camps, M. Vall-Ilossera, E. Valencia, J.F. Marchan-Hernandez, and I. Ramos-Perez. 2009. Soil Moisture Retrieval Using GNSS-R Techniques: Experimental Results Over a Bare Soil Field, IEEE Trans. Geosci. Remote Sens., vol. 47, no. 11 , pp. 3616-3624.

Rodriguez-Alvarez, N., X. Bosch-Lluis, A. Camps, A. Aguasca, M. Vall-llossera, E. Valencia, I. Ramos-Perez, and H. Park. 2011a. Review of crop growth and soil moisture monitoring from a ground-based instrument implementing the interference pattern GNSS-R technique. Radio Sci. 46:RS0C03.10.1029/2011rs004680.

Rodriguez-Alvarez, N., A. Camps, M. Vall-Ilossera, X. Bosch-Lluis, A. Monerris, I. RamosPerez, E. Valencia, J.F. Marchan-Hernandez, J. Martinez-Fernandez, G. BaronciniTurricchia, C. Pérez-Gutiérrez, and N. Sánchez. 2011b. Land Geophysical Parameters Retrieval Using Interference Patten GNSS-R Technique. IEEE Trans. Geosci. Remote Sens. 49: 71-84.

Rosolem, R., Shuttleworth, W.J., Zreda, M., Franz, T.E., Zeng, X. and Kurc, S.A., 2012. The effect of atmospheric water vapor on the cosmic-ray soil moisture signal. Journal of Hydrometeorology (in revisions). 
Sayde, C., C. Gregory, M. Gil-Rodriguez, N. Tufillaro, S. Tyler, N. van de Giesen, M. English, R. Cuenca, and J.S. Selker. 2010. Feasibility of soil moisture monitoring with heated fiber optics. Water Resour. Res. 46:W06201.

Schaap, M.G., F.J. Leij, and M.T. van Genuchten. 2001. Rosetta: A computer program for estimating soil hydraulic parameters with hierarchical pedotransfer functions. J. Hydrol. 251:163-176.

Schaefer, G.L., M.H. Cosh, and T.J. Jackson. 2007. The USDA Natural Resources Conservation Service Soil Climate Analysis Network (SCAN). J. Atmos. Ocean. Tech. 24:2073-2077.

Scheffer, M., M. Holmgren, V. Brovkin, and M. Claussen. 2005. Synergy between small- and large-scale feedbacks of vegetation on the water cycle. Global Change Biology. 11(7): $1003-1012$.

Schmugge, T., P. Gloersen, T. Wilheit, and F. Geiger. 1974. Remote sensing of soil moisture with microwave radiometers. J. Geophys. Res. 79:317-323.

Schmugge, T., and T. Jackson. 1994. Mapping surface soil moisture with microwave radiometers. Meteorol Atmos Phys 54:213-223.

Schneider, J. M., Fisher, D. K., Elliott, R. L., Brown, G. O., and Bahrmann, C. P., 2003, Spatiotemporal variations in soil water: First results from the ARM SGP CART Network, J. Hydrometeorology, 4, 106-120.

Schroeder, J. L., W. S. Burgett, K. B. Haynie, I. Sonmez, G. D. Skwira, A. L. Doggett, J. W. Lipe, 2005: The West Texas Mesonet: A Technical Overview. J. Atmos. Oceanic Technol., $22,211-222$.

Schwank, M., J.P. Wigneron, E. Lopez-Baeza, I. Volksch, C. Matzler, and Y.H. Kerr. 2012. L- 
band radiative properties of vine vegetation at the MELBEX III SMOS Cal/Val Site. IEEE Trans. Geosci. Remote Sensing 50:1587-1601.

Scott, R. W., E. C. Krug, S. L. Burch, C. R. Mitdarfer, and P. F. Nelson. 2010. Investigations of Soil Moisture Under Sod in of East-Central Illinois. Illinois State Water Survey Report of Investigation 119. Champaign, Illinois. $138 \mathrm{p}$.

\section{$\underline{\text { Scott, B.L., T.E. Ochsner, B.G. Illston, C.A. Fiebrich, J.B. Basara and A.J. Sutherland. in }}$} review. New soil property database improves Oklahoma Mesonet soil moisture estimates.

\section{J. Atmos. Ocean. Tech.}

Selker, J.S., L. Thevenaz, H. Huwald, A. Mallet, W. Luxemburg, N. van de Giesen, M. Stejskal, J. Zeman, M. Westhoff, and M.B. Parlange. 2006. Distributed fiber-optic temperature sensing for hydrologic systems. Water Resour. Res. 42:W12202.

Sellers, P., R. Dickinson, D. Randall, A. Betts, F. Hall, J. Berry, G. Collatz, A. Denning, H. Mooney, and C. Nobre. 1997. Modeling the exchanges of energy, water, and carbon between continents and the atmosphere. Science 275:502-509.

Sellers, P.J., Y. Mintz, Y.C. Sud, and A. Dalcher. 1986. A Simple Biosphere Model (SIB) for Use within General Circulation Models. Journal of the Atmospheric Sciences. 43(6): 505531.

Seneviratne, Sonia I., Thierry Corti, Edouard L. Davin, Martin Hirschi, Eric B. Jaeger, Irene Lehner, Boris Orlowsky, and Adriaan J. Teuling. 2010. Investigating Soil Moistureclimate Interactions in a Changing Climate: A Review. Earth-Science Reviews 99 (3-4) (May): 125-161. doi:10.1016/j.earscirev.2010.02.004.

Seuffert, G., Wilker, H., Viterbo, P., Drusch, M. and Mahfouf, J.-F. 2004. The usage of screenlevel parameters and microwave brightness temperature for soil moisture analysis, Journal 
of Hydrometeorology, 5, 516\{531.

Shao, Yaping, and A. Henderson-Sellers. 1996. Modeling soil moisture $\square$ : A project for intercomparison of land surface parameterization schemes phase 2(b) $\square$ : GEWEX Continental-Scale International Project (GCIP). Journal of geophysical research 101 (D3): $7227-7250$.

Simelton, E., E.G. Fraser, M. Termansen, T. Benton, S. Gosling, A. South, N. Arnell, A. Challinor, A. Dougill, and P. Forster. 2012. The socioeconomics of food crop production and climate change vulnerability: A global scale quantitative analysis of how grain crops are sensitive to drought. Food Sec. 4:163-179.

Simpson, J.A., 2000. The cosmic ray nucleonic component: the invention and scientific uses of the neutron monitor. Space Science Reviews 93, 11-32.

Sitch, S., B. Smith, I.C. Prentice, A. Arneth, A. Bondeau, W. Cramer, J.O. Kaplan, S. Levis, W. Lucht, M.T. Sykes, K. Thonicke, and S. Venevsky. 2003. Evaluation of ecosystem dynamics, plant geography and terrestrial carbon cycling in the LPJ dynamic global vegetation model. Global Change Biology. 9(2): 161-185.

Small, E.E., K.M. Larson, and J.J. Braun. 2010. Sensing vegetation growth with reflected gps signals. Geophysical Research Letters 37:L12401.

Smith, A. B., Walker, J. P., Western, A. W., Young, R. I., Ellett, K. M., Pipunic, R. C., Grayson, R. B., Siriwardena, L., Chiew, F. H. S., and Richter, H. 2012. The Murrumbidgee soil moisture monitoring network data set, Water Resour. Res., 48, W07701, $10.1029 / 2012 \mathrm{wr} 011976$.

Song, Y., M.B. Kirkham, J.M. Ham, and G.J. Kluitenberg. 1999. Dual probe heat pulse technique for measuring soil water content and sunflower water uptake. Soil tillage res 
$50: 345-348$.

Sridhar, V., K.G. Hubbard, J. You, and E.D. Hunt. 2008. Development of the soil moisture index to quantify agricultural drought and its user friendliness in severity-area-duration assessment. Journal of Hydrometeorology 9:660-676.

Steele-Dunne, S.C., M.M. Rutten, D.M. Krzeminska, M. Hausner, S.W. Tyler, J. Selker, T.A. Bogaard, and N.C. van de Giesen. 2010. Feasibility of soil moisture estimation using passive distributed temperature sensing. Water Resour. Res. 46:W03534.

Striegl, A.M., and S.P. Loheide II. 2012. Heated distributed temperature sensing for field scale soil moisture monitoring. Ground Water 50:340-347.

Su, Z., Wen, J., Dente, L., van der Velde, R., Wang, L., Ma, Y., Yang, K., and Hu, Z. 2011.

The Tibetan Plateau observatory of plateau scale soil moisture and soil temperature (TibetObs) for quantifying uncertainties in coarse resolution satellite and model products,

Hydrol. Earth Syst. Sci., 15, 2303-2316, 10.5194/hess-15-2303-2011.

Sutinen, R., P. Hänninen and A. Venäläinen. 2008. Effect of mild winter events on soil water content beneath snowpack. Cold Regions Science and Technology 51: 56-67. doi:http://dx.doi.org/10.1016/j.coldregions.2007.05.014.

Suyker, A.E., S.B. Verma and G.G. Burba. 2003. Interannual variability in net CO2 exchange of a native tallgrass prairie. Global Change Biol. 9: 255-265. doi:10.1046/j.13652486.2003.00567.x.

$\underline{\text { Svoboda, M., D. LeComte, M. Hayes, R. Heim, K. Gleason, J. Angel, B. Rippey, R. Tinker, M. }}$ Palecki, D. Stooksbury, D. Miskus and S. Stephens. 2002. The Drought Monitor. Bulletin of the American Meteorological Society 83: 1181-1190.

Tarara, J.M., and J.M. Ham. 1997. Measuring soil water content in the laboratory and field 
with dual-probe heat-capacity sensors. Agron. J. 89:535-542.

Topp, G.C. 2006. TDR reflections: My thoughts and experiences on TDR. Proc. TDR 2006. Purdue University, West Lafayette, Indiana, USA. Sept. 2006.

Topp, G.C., J.L. Davis, and A.P. Annan. 1980. Electomagnetic determination of soil water content: Measurements in coaxial transmission lines. Water Resour. Res. 16:574-582.

Torres, G.M., R.P. Lollato, and T.E. Ochsner. 2013. Comparison of drought probability assessments based on atmospheric water deficit and soil water deficit. Agron. J.

Tyler, S.W., J.S. Selker, M.B. Hausner, C.E. Hatch, T. Torgersen, C.E. Thodal, and S.G. Schladow. 2009. Environmental temperature sensing using raman spectra dts fiber-optic methods. Water Resour. Res. 45

Ulaby, F.T., M.C. Dobson, and D.R. Brunfeldt. 1983. Improvement of moisture estimation accuracy of vegetation-covered soil by combined active/passive microwave remote sensing. Geoscience and Remote Sensing, IEEE Transactions on GE-21:300-307.

VEMAP Members. 1995. Vegetation/Ecosystem Modeling and Analysis Project:Comparing Biogeography and Biogeochemistry Models in a Continental-scale Study of Terrestrial Ecosystem Responses to Climate Change and CO2 Doubling. Global Biogeochemical Cycles 9:407. doi:10.1029/95GB02746.

Verheof, A. 1995. Surface energy balance of shrub vegetation in the Sahel. Ph.D. dissertation, Wageningen University, Netherlands, $247 \mathrm{pp}$.

Verhoef, A. and Allen, S. J. 2000. A SVAT scheme describing energy and CO2 fluxes for multi-component vegetation: calibration and test for a Sahelian savannah. Ecological Modelling, Vol. 127, pp. 245-267.

Verhoef, A., Allen, S. J. and Lloyd, C. R. 1999. Seasonal variation of surface energy balance 
over two Sahelian surfaces. International Journal of Climatology, Vol. 19, pp. 1267-1277.

Vinnikov, K.Y., A. Robock, S. Qiu, and J.K. Entin. 1999. Optimal design of surface networks for observation of soil moisture. J. Geophys. Res. 104:19743-19749.

Wagner, W., G. Bloschl, P. Pampaloni, J.C. Calvet, B. Bizzarri, J.P. Wigneron, and Y. Kerr. 2007. Operational readiness of microwave remote sensing of soil moisture for hydrologic applications. Nord. Hydrol. 38:1-20.

Wagner, W., S. Hahn, R. Kidd, T. Melzer, Z. Bartalis, S. Hasenauer, J. Figa-Saldaña, P. de Rosnay, A. Jann, S. Schneider, J. Komma, G. Kubu, K. Brugger, C. Aubrecht, J. Züger, U. Gangkofner, S. Kienberger, L. Brocca, Y. Wang, G. Blöschl, J. Eitzinger, K. Steinnocher, P. Zeil and F. Rubel. 2013. The ASCAT Soil Moisture Product: A Review of its

Specifications, Validation Results, and Emerging Applications. Meteorologische Zeitschrift 22: 5-33. doi:10.1127/0941-2948/2013/0399.

Wagner, W., G. Lemoine, and H. Rott. 1999. A method for estimating soil moisture from ERS scatterometer and soil data. Remote Sens. Environ.70:191-207.

Wagner, W., K. Scipal, C. Pathe, D. Gerten, W. Lucht, and B. Rudolf. 2003. Evaluation of the agreement between the first global remotely sensed soil moisture data with model and precipitation data. J. Geophys. Res 108:4611.

Weinan Pan, R. P. Boyles, J. G. White, and J. L. Heitman. 2012. Characterizing Soil Physical Properties for Soil Moisture Monitoring with the North Carolina Environment and Climate Observing Network, Journal of Atmospheric and Oceanic Technology, July 2012, Vol. 29, No. 7 : pp. 933-943 (doi: 10.1175/JTECH-D-11-00104.1)

Weiss, J.D. 2003. Using fiber optics to detect moisture intrusion into a landfill cap consisting of a vegetative soil barrier. Journal of the Air \& Waste Management Association 53:1130- 
1148.

Western, A.W., and G. Blöschl. 1999. On the spatial scaling of soil moisture. J. Hydrol. 217:203-224.

Xu, Liukang, Dennis D. Baldocchi, and Jianwu Tang. 2004. How soil moisture, rain pulses, and growth alter the response of ecosystem respiration to temperature. Global Biogeochemical Cycles 18 (4) (October 5): GB4002. doi:10.1029/2004GB002281.

Yang, Hao, Karl Auerswald, Yongfei Bai, and Xingguo Han. 2011. Complementarity in water sources among dominant species in typical steppe ecosystems of Inner Mongolia, China. Plant and soil 340 (1-2): 303-313.

Yang, K., T. Koike, I. Kaihotsu, and J. Qin. 2009. Validation of a dual-pass microwave land data assimilation system for estimating surface soil moisture in semiarid regions. Journal of Hydrometeorology 10:780-793.10.1175/2008jhm1065.

Zacharias, S., H. Bogena, L. Samaniego, M. Mauder, R. Fuß, T. Pütz, M. Frenzel, M.

Schwank, C. Baessler, and K. Butterbach-Bahl. 2011. A network of terrestrial environmental observatories in Germany. Vadose Zone J. 10:955-973.

Zavorotny, V., K. Larson, J. Braun, E. Small, E. Gutmann, and A. Bilich, A Physical Model for GPS Multipath Caused by Land Reflections: Toward Bare Soil Moisture Retrievals, IEEE J. Sel. Topics Appl. Earth Obs. Remote Sens., vol. 3, no. 1, pp. 100-110, Mar. 2010.

Zhao, L., K. Yang, J. Qin, Y. Chen, W. Tang, C. Montzka, H. Wu, C. Lin, M. Han, and H. Vereecken. in press. Spatiotemporal analysis of soil moisture observations within a tibetan mesoscale area and its implication to regional soil moisture measurements. J.

Hydrol.http://dx.doi.org/10.1016/j.jhydrol.2012.12.033.

Zreda, M., D. Desilets, T.P.A. Ferré, and R.L. Scott. 2008. Measuring soil moisture content 
non-invasively at intermediate spatial scale using cosmic-ray neutrons. Geophysical Research Letters 35:10.1029/2008GL035655.

Zreda, M., W. J. Shuttleworth, X. Zeng, C. Zweck, D. Desilets, T. Franz, and R. Rosolem. 2012. COSMOS: the COsmic-ray Soil Moisture Observing System. Hydrology and Earth System Sciences, Vol. 16, pp. 4079-4099.

Zreda, M. and 9 others, 2011. Cosmic-ray neutrons, an innovative method for measuring areaaverage soil moisture. GEWEX News 21(3), 6-10.

Zweck, C., Zreda, M. and Desilets, D.. 2011. Empirical confirmation of the sub-kilometer footprint of cosmic-ray soil moisture probes. Geophysical Research Abstracts 13, EGU2011-13393. 
1425 Table 1. Partial list of large-scale $\left(>100^{2} \mathrm{~km}^{2}\right)$ in situ soil moisture monitoring networks ordered

1426 from largest to smallest in areal extent. The areas are enumerated by $\mathrm{XX}^{2}$ to indicate the length

1427 of one side of a square of the given area.

\begin{tabular}{|c|c|c|c|c|c|}
\hline Network Name & $\begin{array}{l}\text { Country or } \\
\text { State }\end{array}$ & $\begin{array}{l}\text { Site } \\
\text { no. }\end{array}$ & Extent & Density & Reference \\
\hline & & & $\mathrm{km}^{2}$ & $\mathrm{~km}^{2} \mathrm{st}^{-1}$ & \\
\hline \multicolumn{6}{|l|}{ Insłide the U.S.US } \\
\hline Soil Climate Analysis Network & USA & 180 & $3100^{2}$ & $230^{2 a}$ & Schaefer et al. (2007) \\
\hline Climate Reference Network & USA & 114 & $3100^{2}$ & $290^{2}$ & Palecki and Groisman (2011) \\
\hline Cosmic Ray Soil Moisture Observing System & USA & 67 & $3100^{2}$ & $380^{2}$ & Zreda et al. (2012) \\
\hline Plate Boundary Observatory Network & Western US & 59 & $1800^{2}$ & $240^{2}$ & Larson et al. (2008) \\
\hline Automated Weather Data Network & Nebraska & 53 & $450^{2}$ & $62^{2}$ & Hubbard et al. (2009) \\
\hline Oklahoma Mesonet & Oklahoma & 108 & $430^{2}$ & $41^{2}$ & Illston et al. (2008) \\
\hline Automated Environmental Monitoring Network & Georgia & 81 & $390^{2}$ & $44^{2}$ & Hoogenboom (1993) \\
\hline Water \& Atmospheric Resources Monitoring Program & Illinois & 19 & $390^{2}$ & $89^{2}$ & Scott et al. (2010) \\
\hline Environment and Climate Observing Network & N. Carolina & 37 & $370^{2}$ & $61^{2}$ & Weinan et al. (2012) \\
\hline West Texas Mesonet & Texas & 53 & $300^{2}$ & $41^{2}$ & Schroeder et al. (2005) \\
\hline $\begin{array}{l}\text { ARM-SGP Extended Facilities } \\
\text { Outside the U.S.US }\end{array}$ & $\mathrm{OK} / \mathrm{KS}$ & 13 & $150^{2}$ & $42^{2}$ & Schneider et al. (2003) \\
\hline Tibet-Obs & China & 46 & $1600^{2}$ & $230^{2}$ & Su et al. (2011) \\
\hline GT|K Geological Survey of Finland & Finland & $\underline{23}$ & $\underline{580^{2}}$ & $\underline{121^{2}}$ & $\underline{\text { Sutinen et al. (2008) }}$ \\
\hline OzNet & Australia & $\overline{38}$ & $290^{2}$ & $47^{2}$ & Smith et al. (2012) \\
\hline SMOSMANIA & France & 21 & $200^{2}$ & $44^{2}$ & Calvet et al. (2007) \\
\hline Gourma Mesoscale Site & Mali & 10 & $170^{2}$ & $55^{2}$ & de Rosnay et al. (2009) \\
\hline Automatic Stations for Soil Hydrology & Mongolia & 12 & $140^{2}$ & $40^{2}$ & Yang et al. (2009) \\
\hline Central Tibetan Plateau SMTMN ${ }^{\mathrm{c}}$ & China & 50 & $100^{2}$ & $14^{2}$ & Zhao et al. (2013) \\
\hline Umbria Region Hydro-meteorological Network & Italy & 15 & $100^{2}$ & $26^{2}$ & www.cfumbria.it \\
\hline
\end{tabular}


1431 Table 2. Selected large-scale hydrologic-atmospheric-remote sensing experiments.

\begin{tabular}{lllll}
\hline Experiment & Lead Agency & Location & Climatic Regime & Observation Period \\
\hline HAPEX-MOBILHY & Mété - France & Southwest France & Temperate Forest & Summer, 1986 \\
HAPEX-Sahel & Météo - France & Niger & Tropical Arid & Summer, 1992 \\
BOREAS & NASA & Canada & Boreal Forest & Spr./Fall 1994,1996 \\
IHOP & NSF & KS, OK, TX & Continental & 2002 \\
HYMeX & GEWEX & Europe & Mediterranean & $2010-2020$ (LOP) \\
CZO & NSF & 6 sites & Varies & $2011-2015$ (EOP) \\
AirMOSS & NASA & 7 sites & Varies & $2011-2015$
\end{tabular}

1432 LOP-Long-term observation period

1433 EOP - Enhanced observation period

1434

1435

1436

1437 


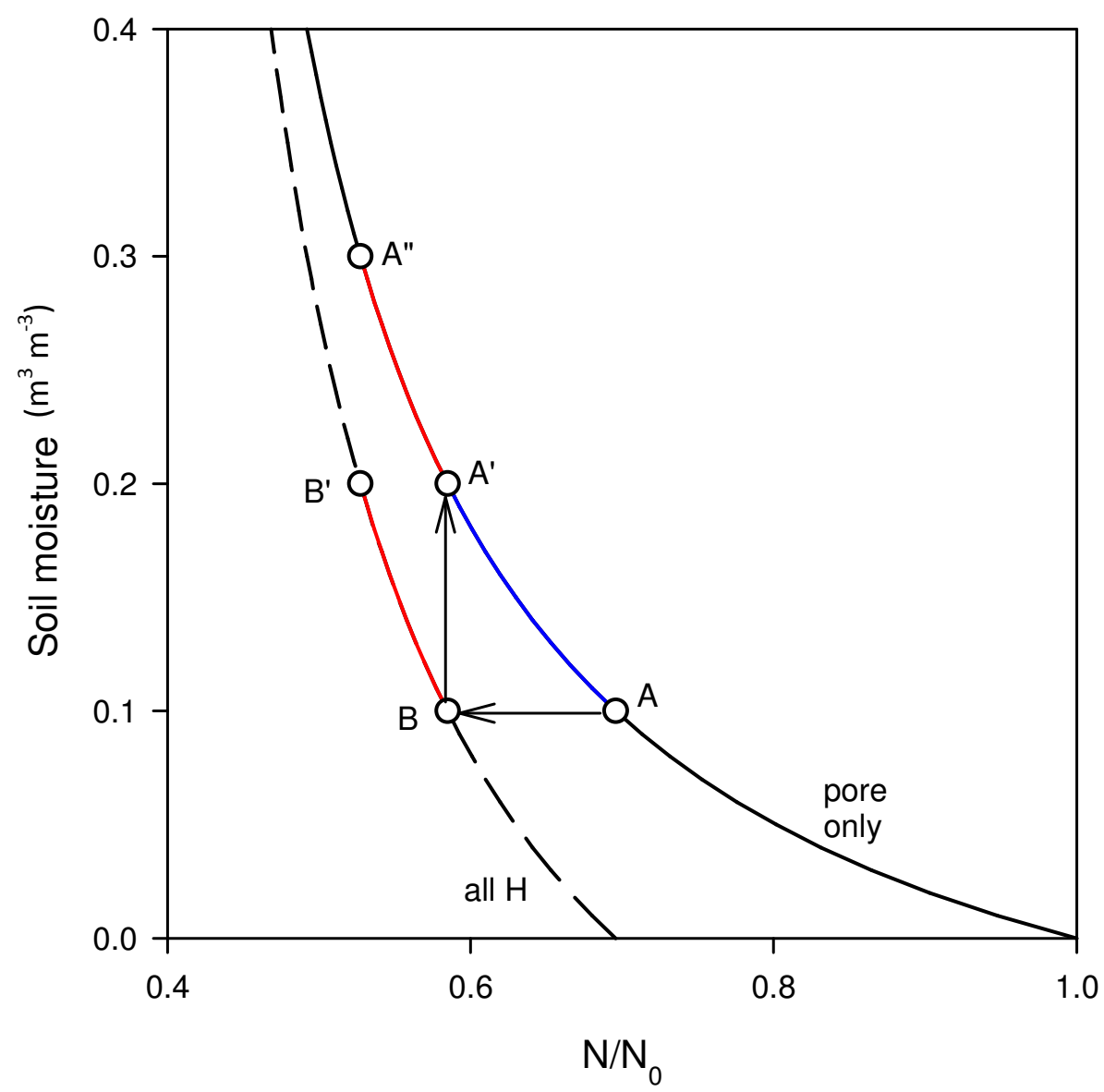

12 Fig. 1. Response function for cosmic-ray probe for soils with pore water only (solid black line)

13 and those with pore water and other water, such as lattice and organic matter (dashed black line).

$14 N$ is the mesaured neutron intensity, and $N_{0}$ is a calibration parameter representing the neutron

15 intensity above dry soil. The presence of other water shifts the line horizontally from point A to

$16 \mathrm{~B}$ and $\mathrm{A}^{\prime}$ to $\mathrm{B}^{\prime}$, and the new line is steeper than the original line for the same moisture range (B-

17 B' vs. A-A'). Section B-B' can be placed on the original line by translating it up to fall on

18 section A'-A', Thus, accounting for additional (non-pore) water does not require a new response

19 function, but merely a translation along the original function by the amount equal to that non-

20 pore water component. 


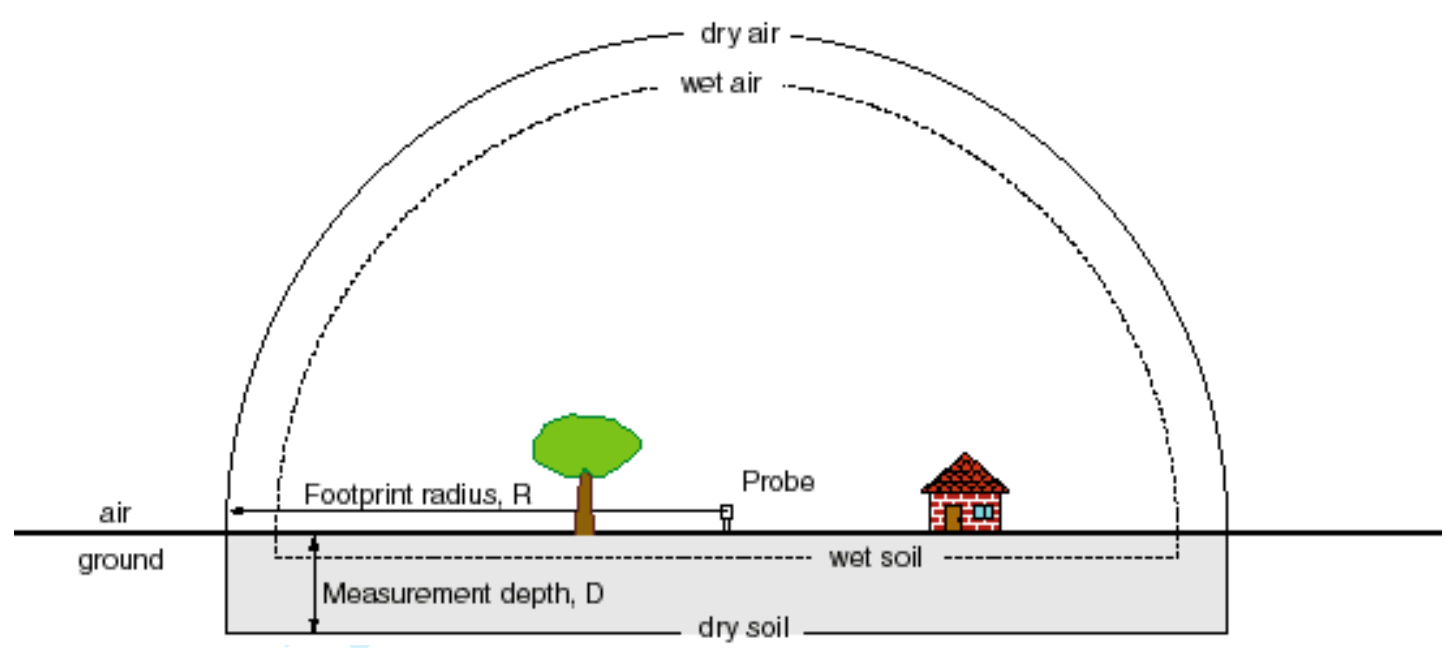

21 Fig. 2. Sensing volume of the cosmic-ray probe comprises a hemisphere in air (of radius R) and a

22 cylinder in soil (of height D). All hydrogen within the sensing volume is reflected in the

23 measured neutron intensity. The horizontal footprint, $\mathrm{R}$, depends on air properties: mainly

24 density and water vapor content. The vertical footprint depends on soil properties: mainly bulk

25 density and total hydrogen content (pore water, lattice water, organic matter water). 


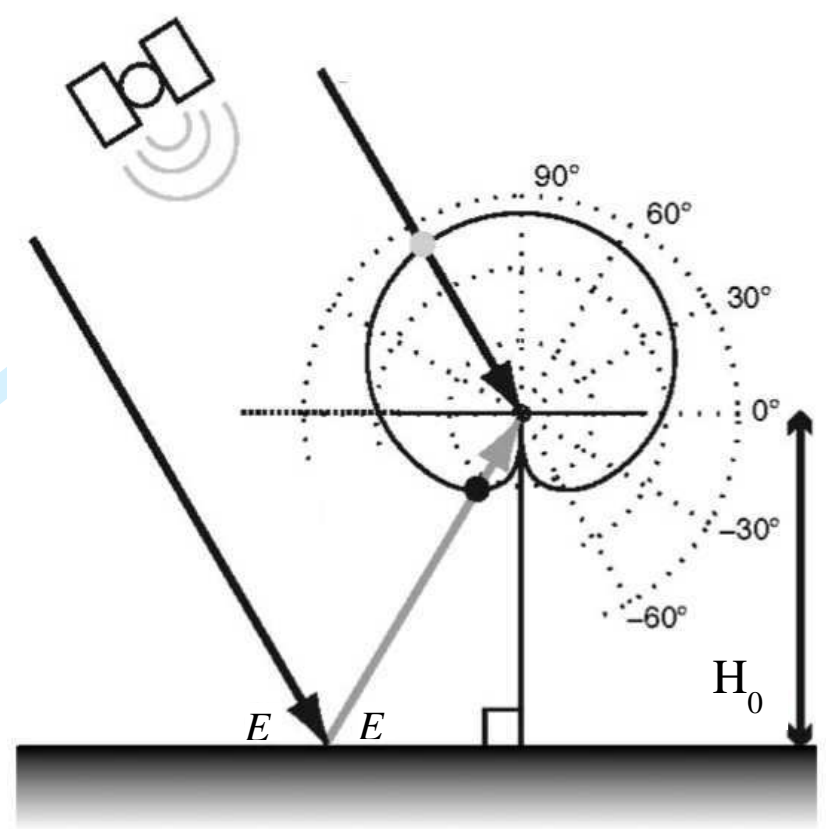

29 Fig. 3. Geometry of a multipath signal, for antenna height $\left(H_{0}\right)$ and satellite elevation angle $(E)$. Black lines represent the direct signal transmitted from the satellite. The gray line is the reflected

31 signal from the ground. The solid line represents the gain pattern of the antenna. Dashed circles

32 indicate relative power levels of the gain pattern. (Reproduced from Larson et al., 2008) 


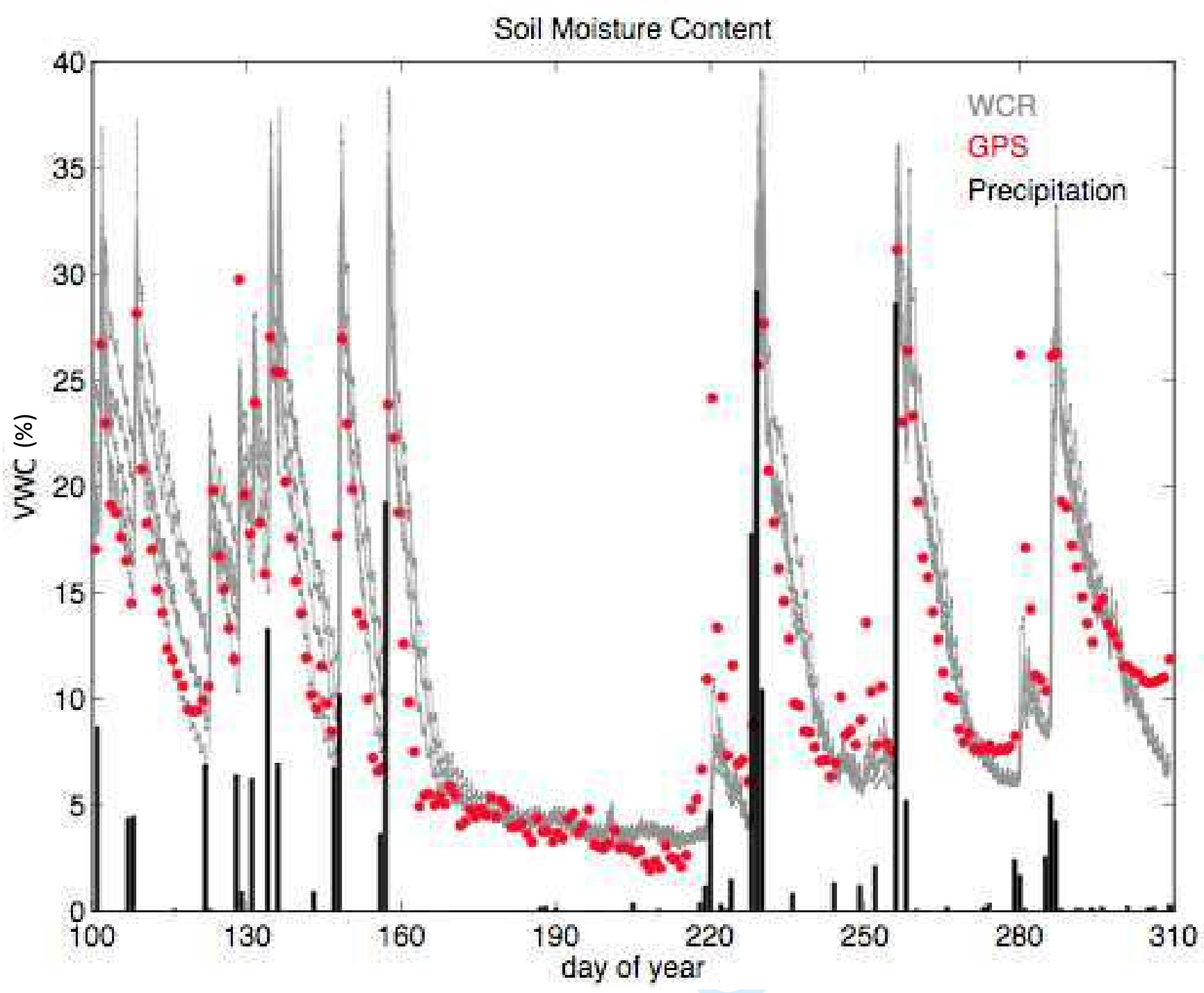

34

35

36 Fig. 4. Soil volumetric water content (VWC, \%) measured by five water content reflectometers

37 at $2.5 \mathrm{~cm}$ depth (grey lines), soil water content estimated by GPS-Interferometric Reflectometry

38 (circles), and daily precipitation totals (bars) from a site near Marshall, CO, United States.

39 (Adapted from Larson et al., 2010).

40 
(a)

(c)

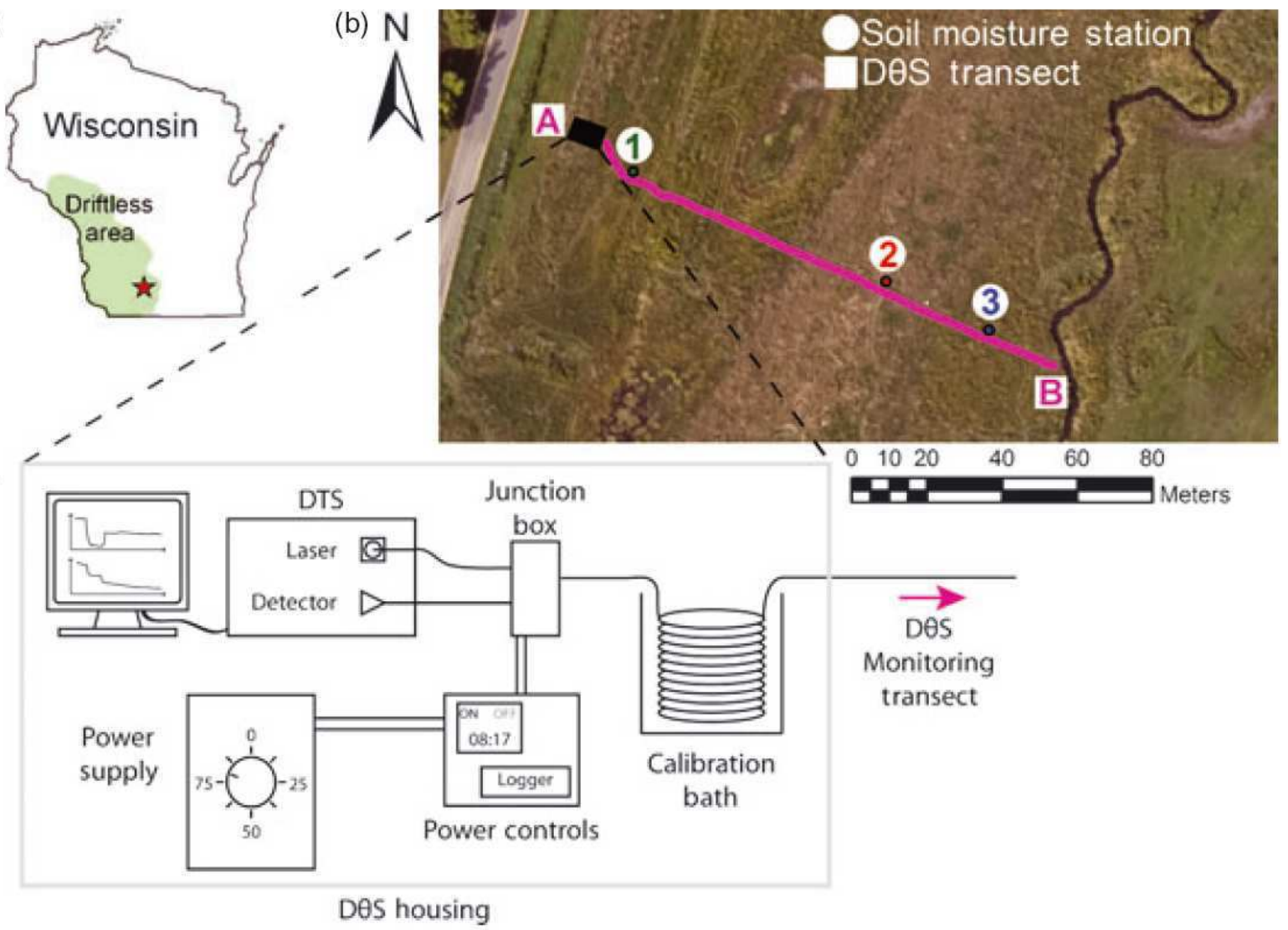

42 Fig. 5. Location of study site used by Striegl and Loheide (2012) (a), aerial photo of active DTS

43 transect with three independent soil moisture monitoring stations (b), and schematic diagram of

44 active DTS system components (c). Reproduced from Striegl and Loheide (2012). 


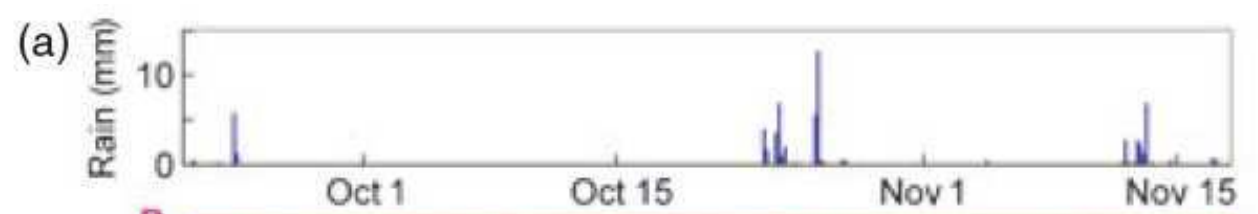

(1)
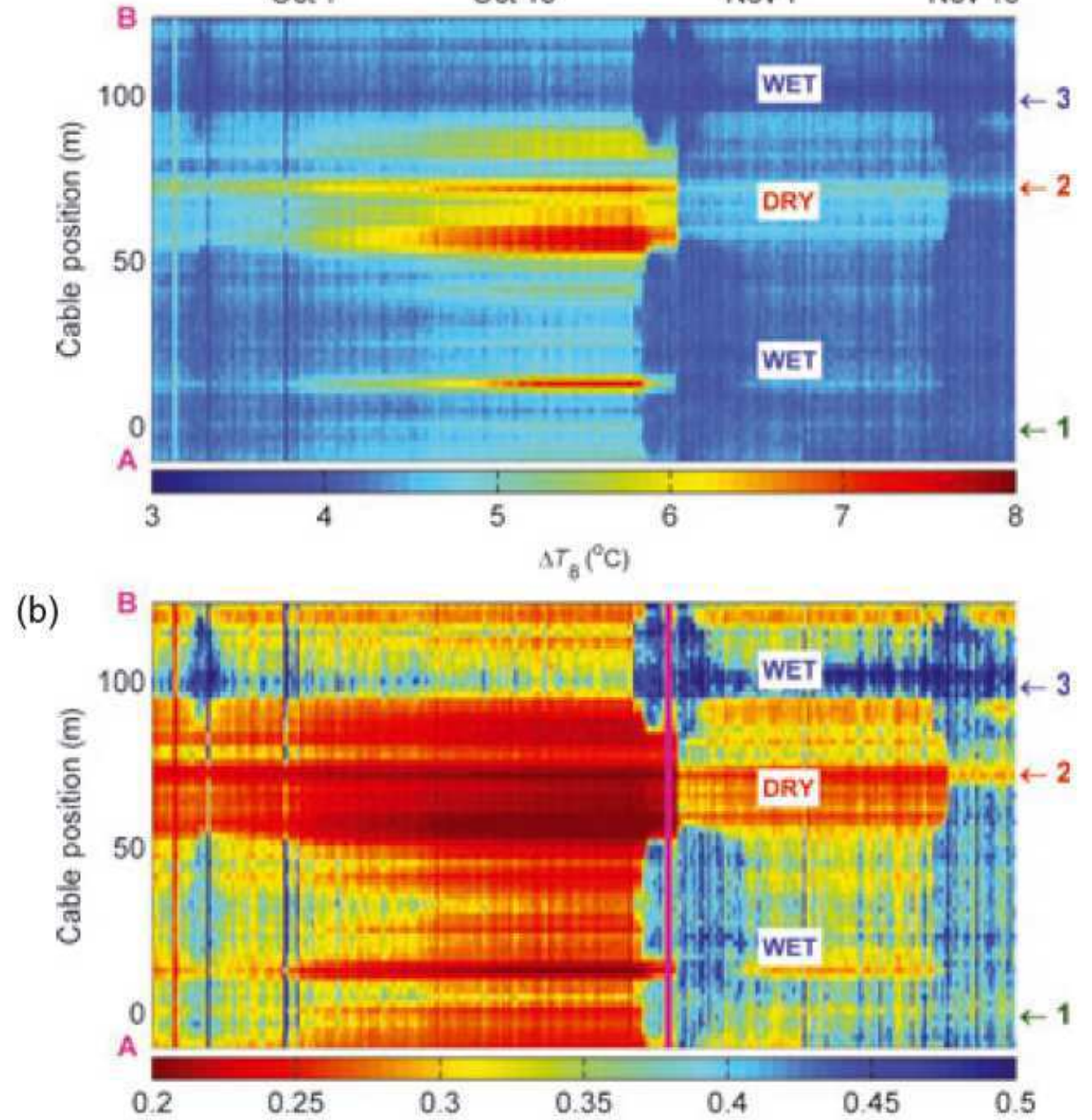

(c)

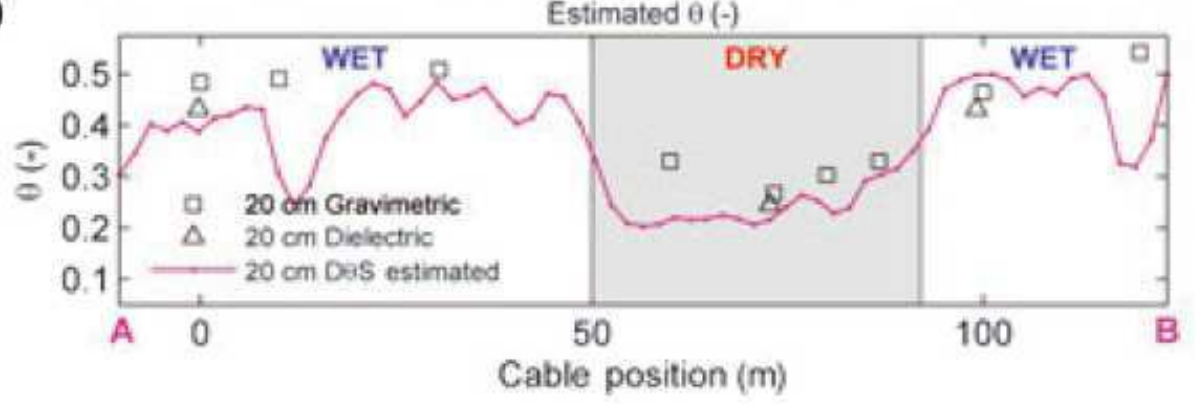

68 Fig. 6. Time series (x-axis) of four hour rainfall totals and DTS measured average temperature

69 rise eight minutes after heating began for each 2-m interval along the 130-m cable transect (a),

70 time series of estimated soil moisture values based on the active DTS data from each 2-m

71 interval along the cable (b), and a plot of active DTS soil moisture estimates and independent

72 soil moistuture estimates versus cable position on 25 Oct. 2010 at 16:00 (c). 
76

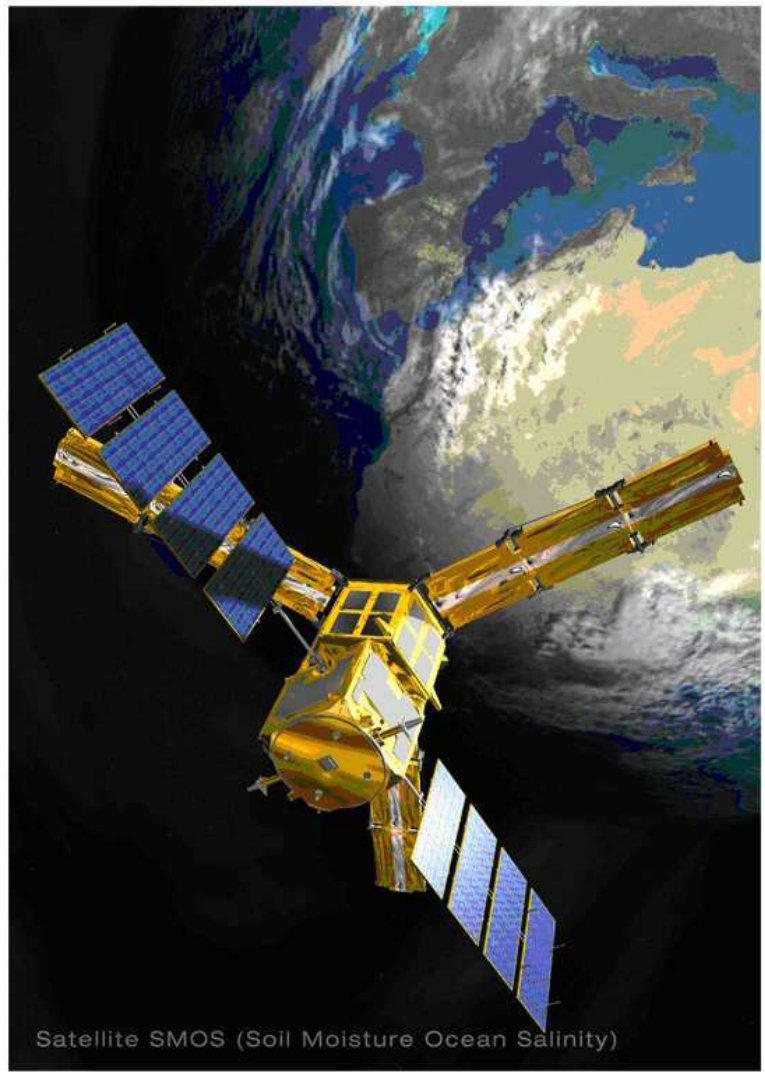

77 Fig. 7. Artist's view of the Soil Moisture and Ocean Salinity (SMOS) satellite (Courtesy of 78 Cesbio- Mira).

79 
80

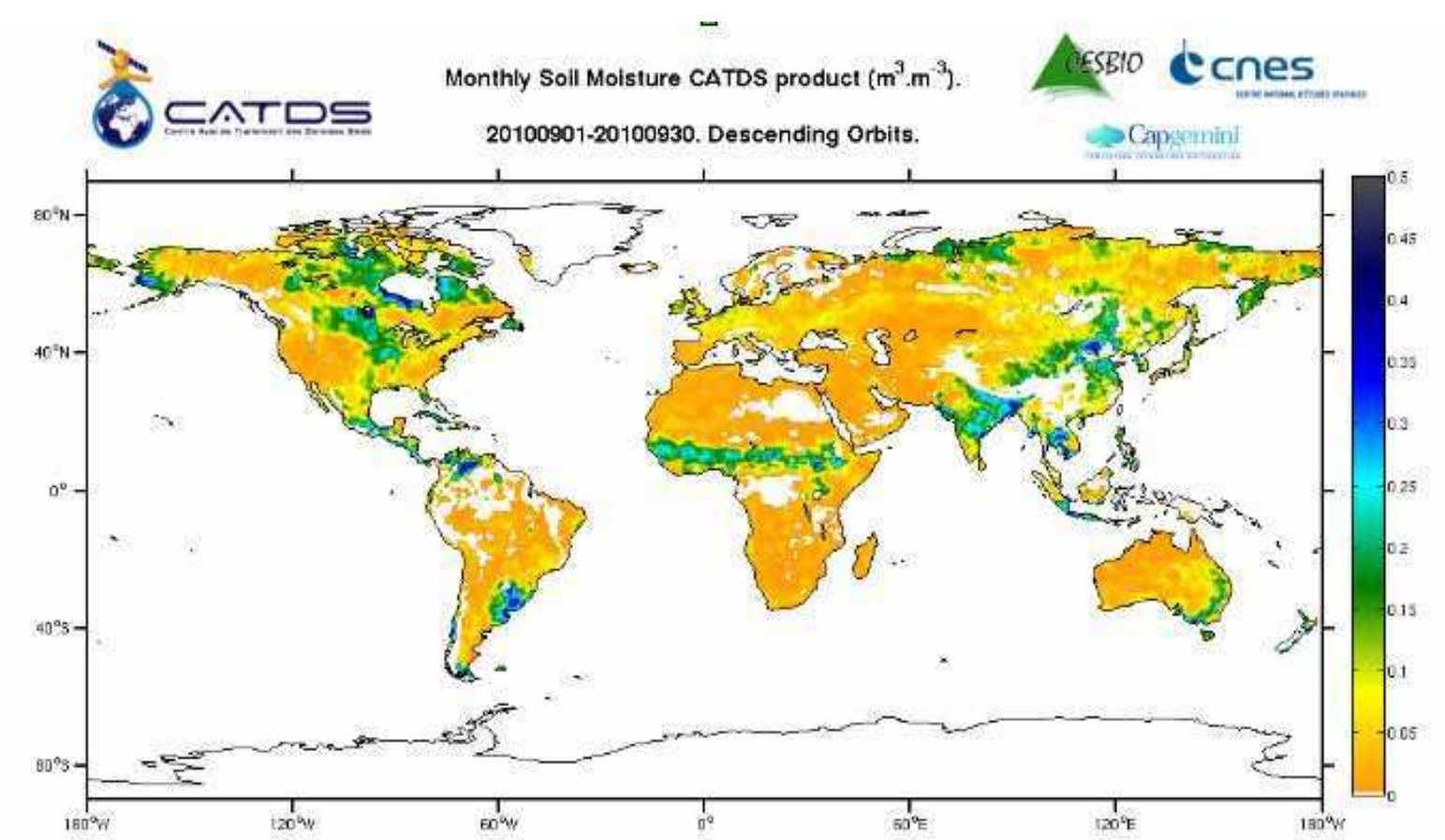

81

82 Fig. 8. Monthly soil moisture product (September 2010) expressed in $\mathrm{m}^{3} \mathrm{~m}^{-3}$. Note the wet

83 patches in Argentina or the receding Intertropical Convergence Zone influence in Sahel. Where

84 topography is too steep, RFI too important, vegetation too dense (tropical rain forest) or soils are

85 frozen /covered by snow, the retrievals are either not attempted or not represented.

86

87 


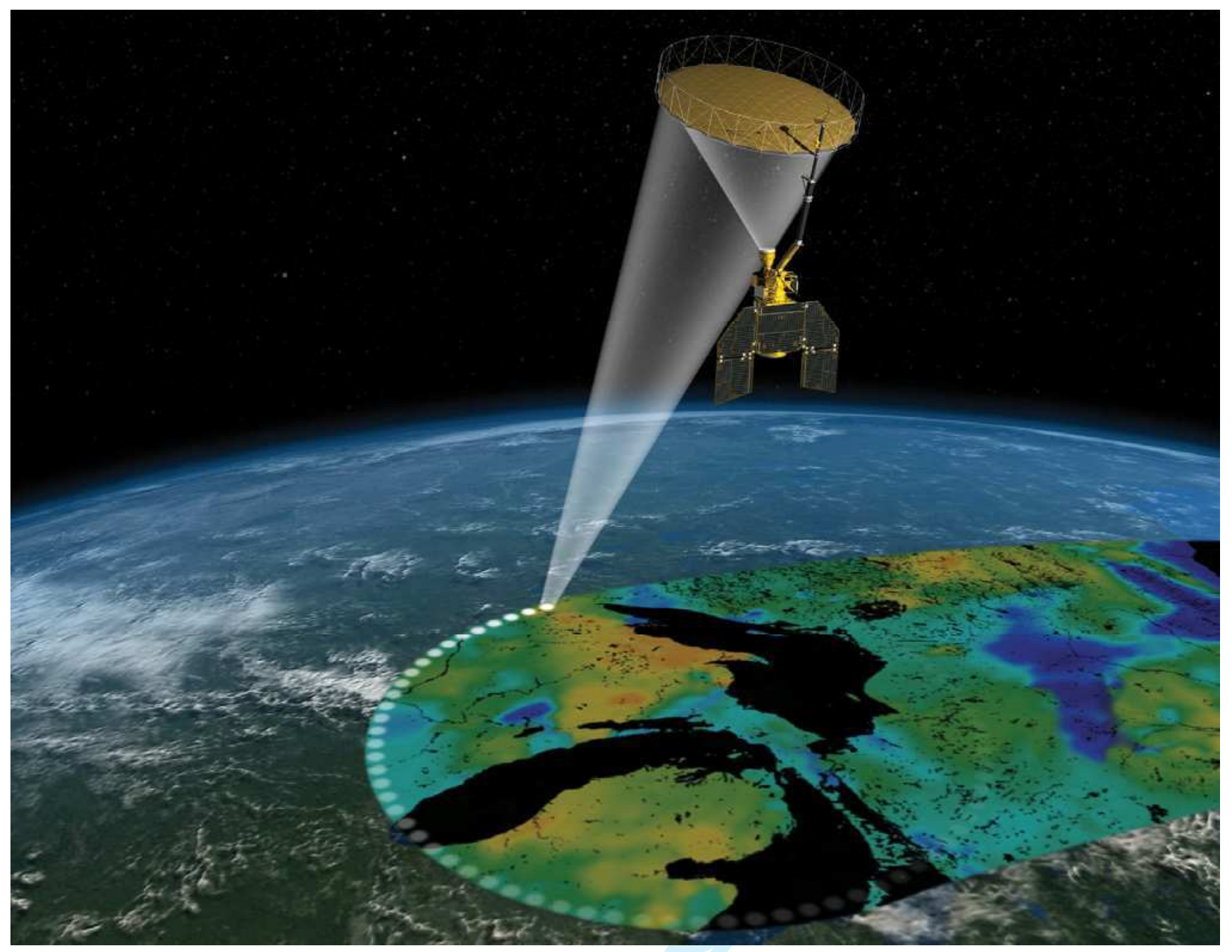

89 Fig. 9. Artist's view of the Soil Moisture Active Passive satellite. 


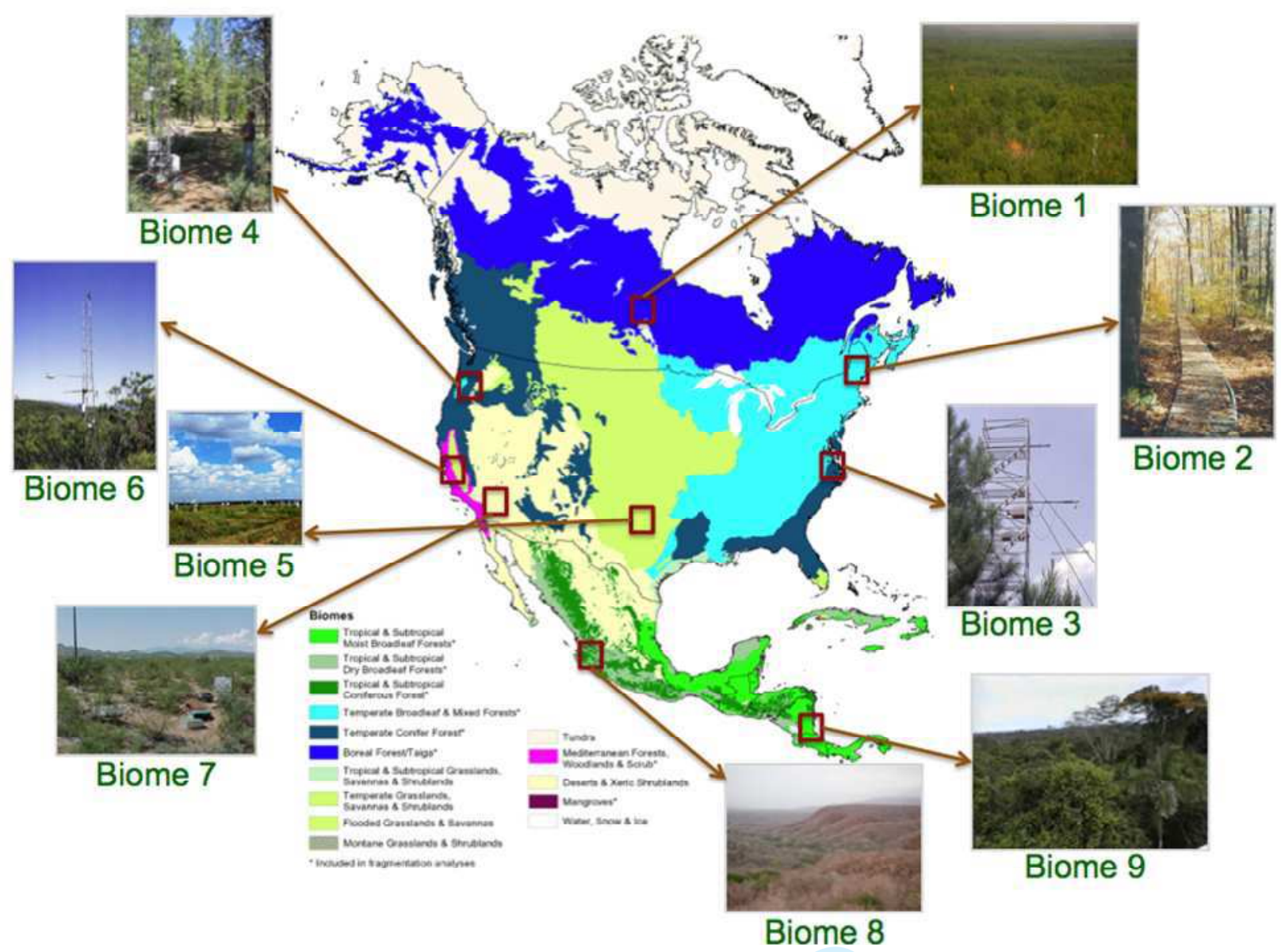

93 Fig. 10. Nine AirMOSS flux sites covering major distribution of vegetation types in North

94 American biomes.

95 


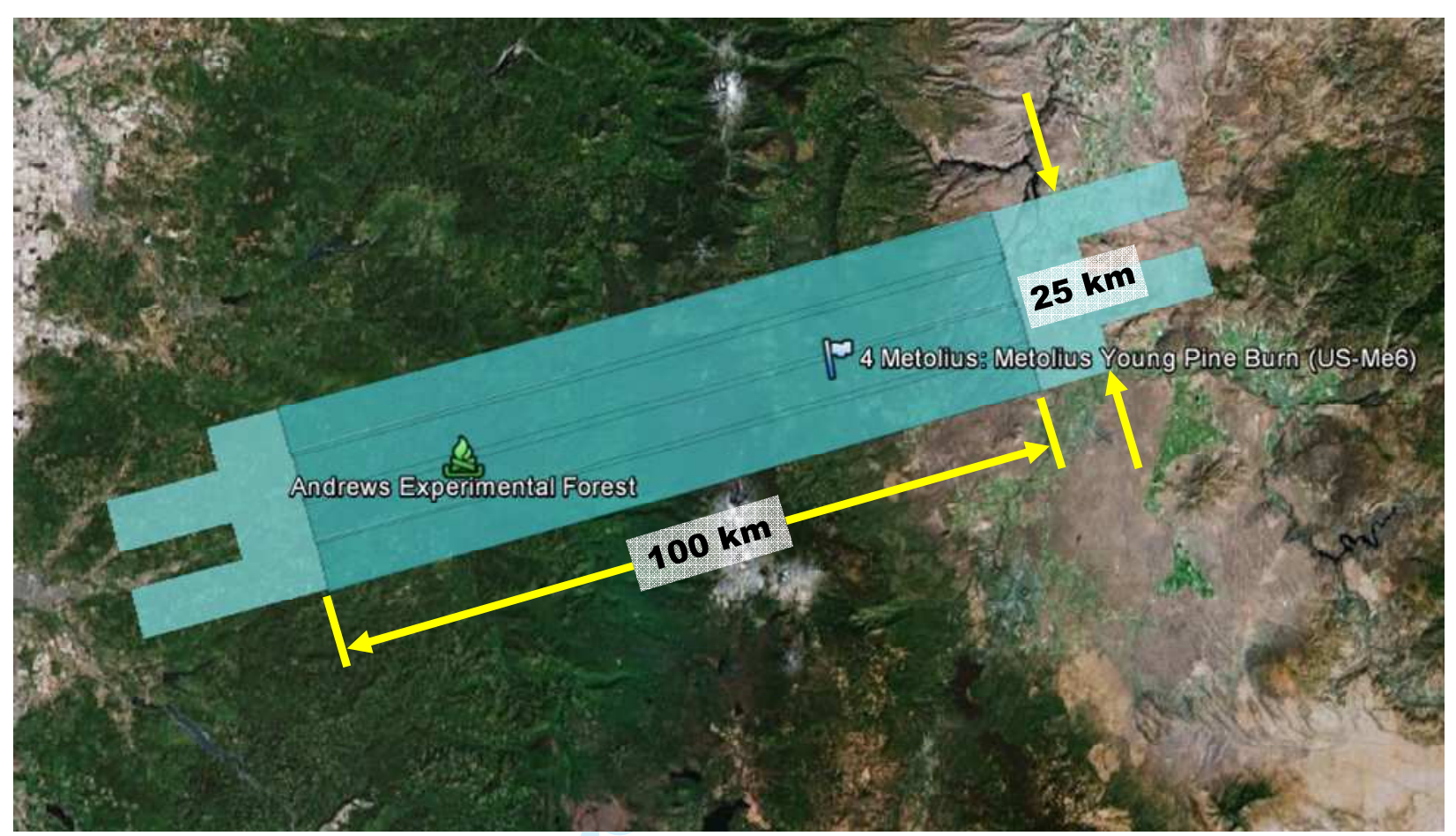

97

98 Fig. 11. AirMOSS flight path made up of four flight lines, Metolius flux site, Cascade

99 Mountains, Oregon. 


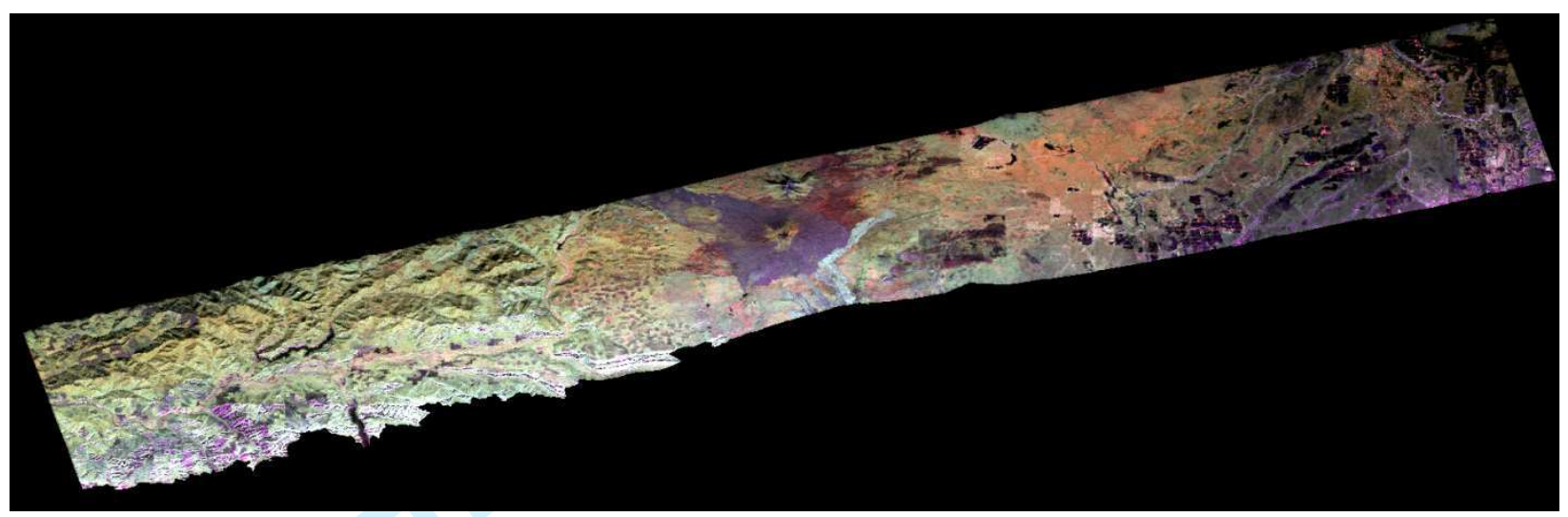

103 Fig. 12. AirMOSS three band $(\mathrm{Red}=\mathrm{HH}$, Green $=\mathrm{HV}$, Blue $=\mathrm{VV}$ where $\mathrm{H}$ is horizontal 104 polarization and $\mathrm{V}$ is vertical polarization) raw data image showing the spatial variation of soil 105 moisture over the Metolius flux site, Cascade Mountains, Oregon along with soil roughness and 106 vegetation effects which have not yet been removed. Volcanic feature in center of image is 107 Black Butte cinder cone. 


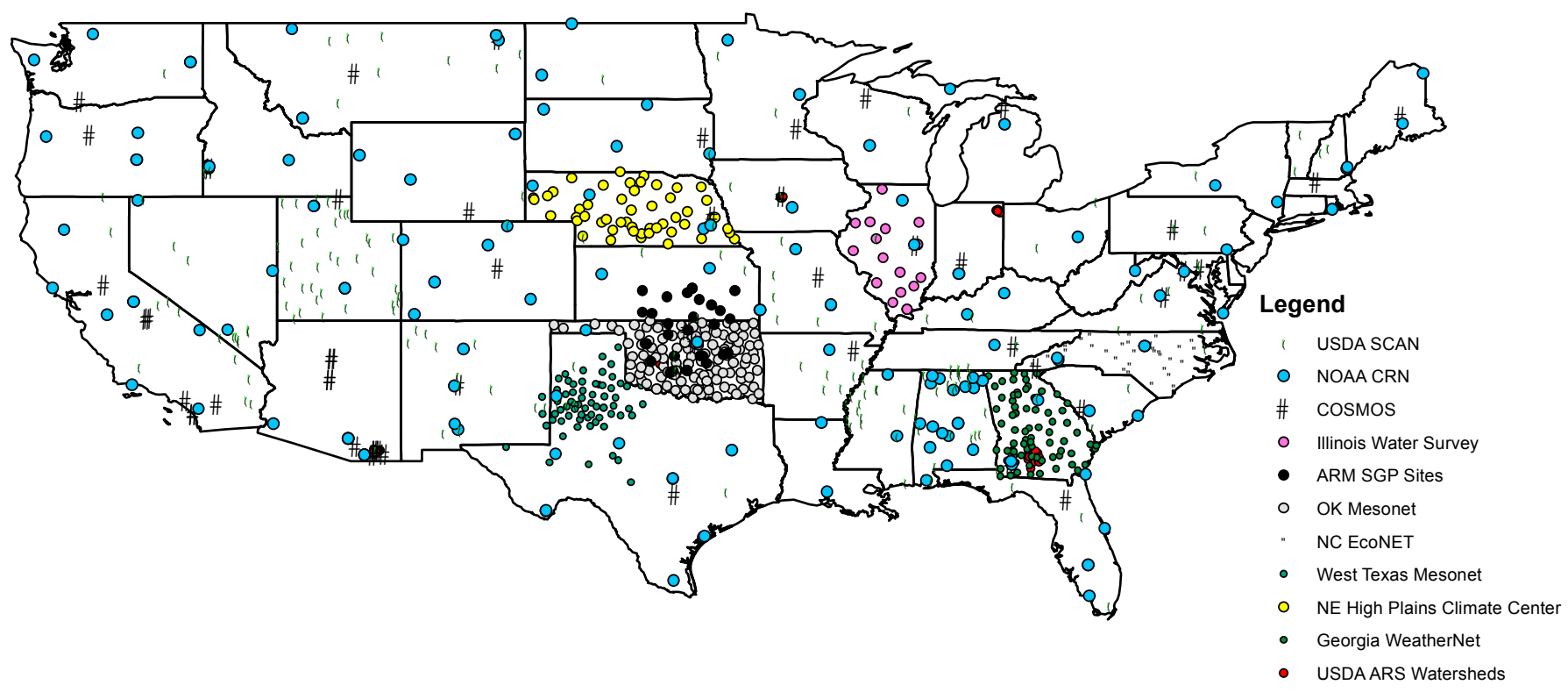

121

122 Fig. 13. In situ soil moisture monitoring sites across the Continental U.S. 


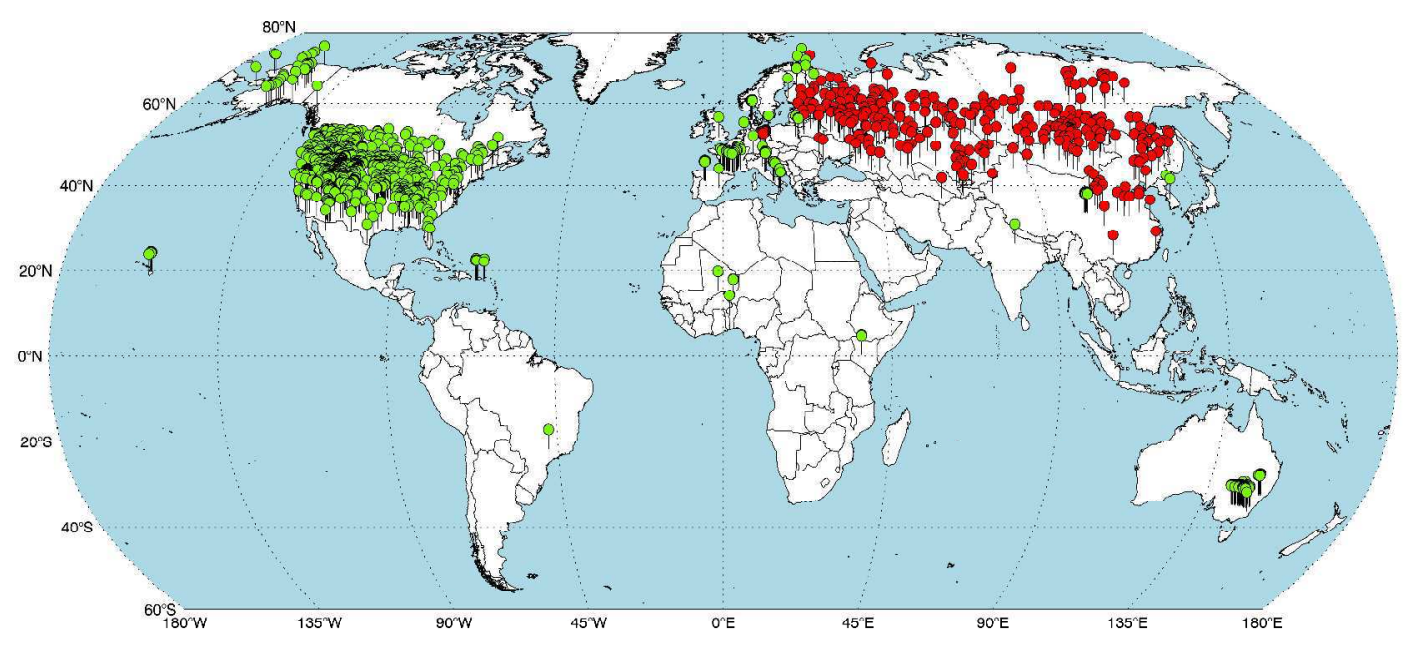

124

125

126 Fig. 14. Overview of soil moisture stations currently contained in the International Soil Moisture

127 Network (ISMN). Green dots show the stations that are still measuring soil moisture, red dots the 128 stations that were imported from the Global Soil Moisture Data Bank. 


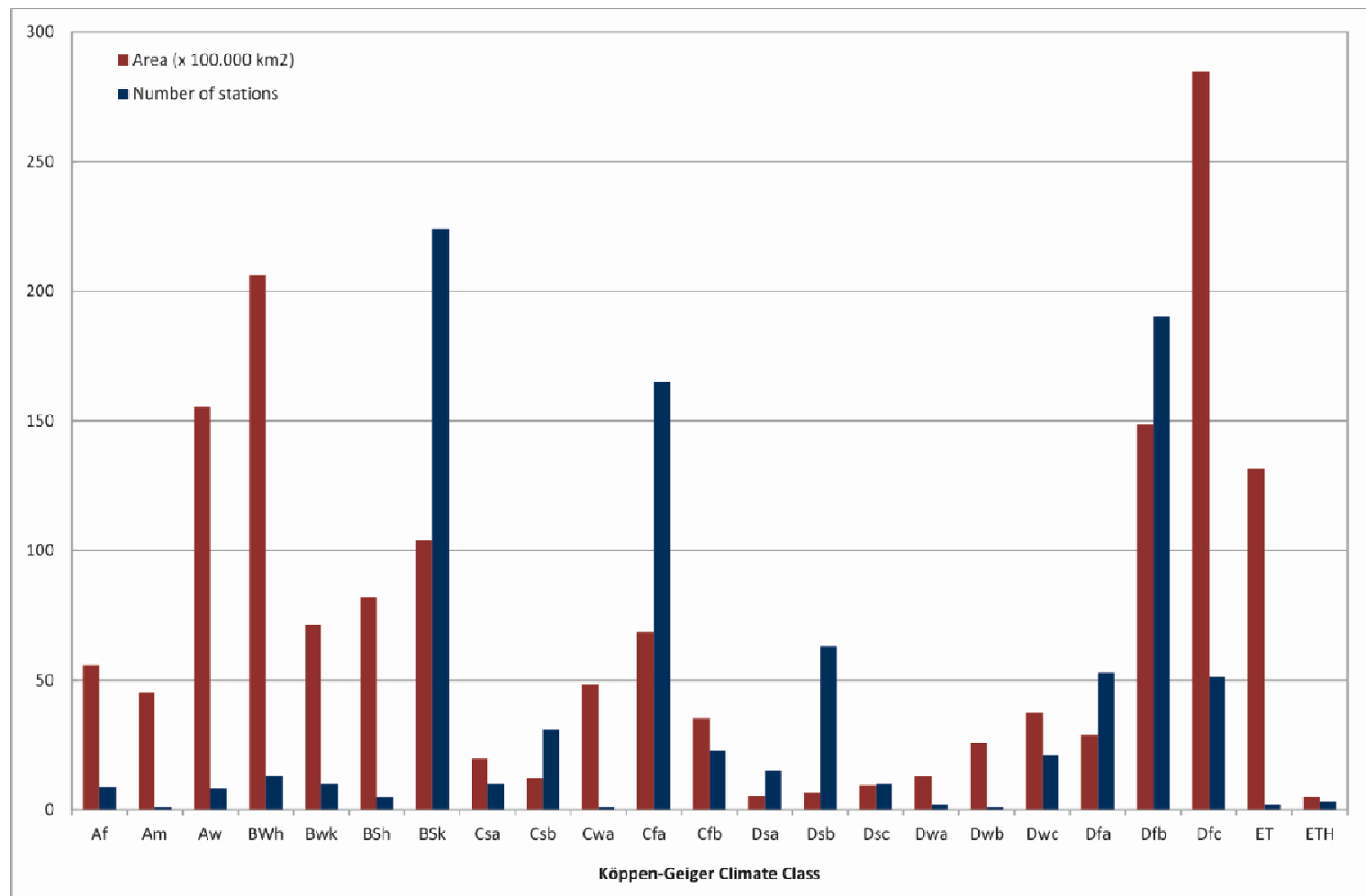

132 Fig. 15. Number of stations found within and area covered by the different Köppen Geiger classes after Peel et al. (2007). For the class legend we refer to the original publication. 


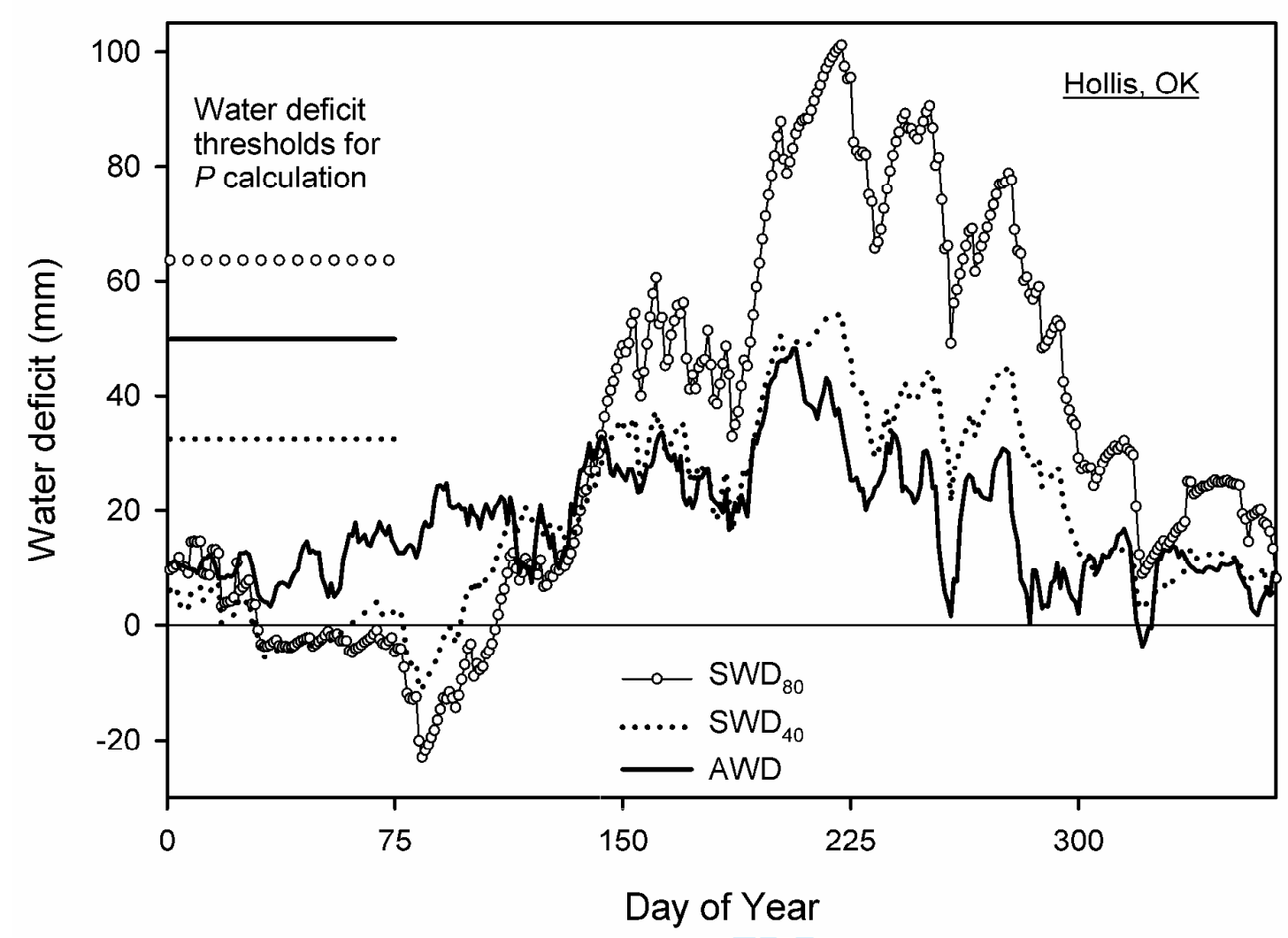

135 Fig. 16. Water deficit estimation by the atmospheric water deficit (AWD) method and soil water 136 deficit methods for the 0 - to $40-\left(\mathrm{SWD}_{40}\right)$ and 0 - to $80-\mathrm{cm}$ depths $\left(\mathrm{SWD}_{80}\right)$, with corresponding 137 water deficit thresholds. Averages of 15 yr for Hollis, OK. (Reproduced from Torres et al., 138 2013). 


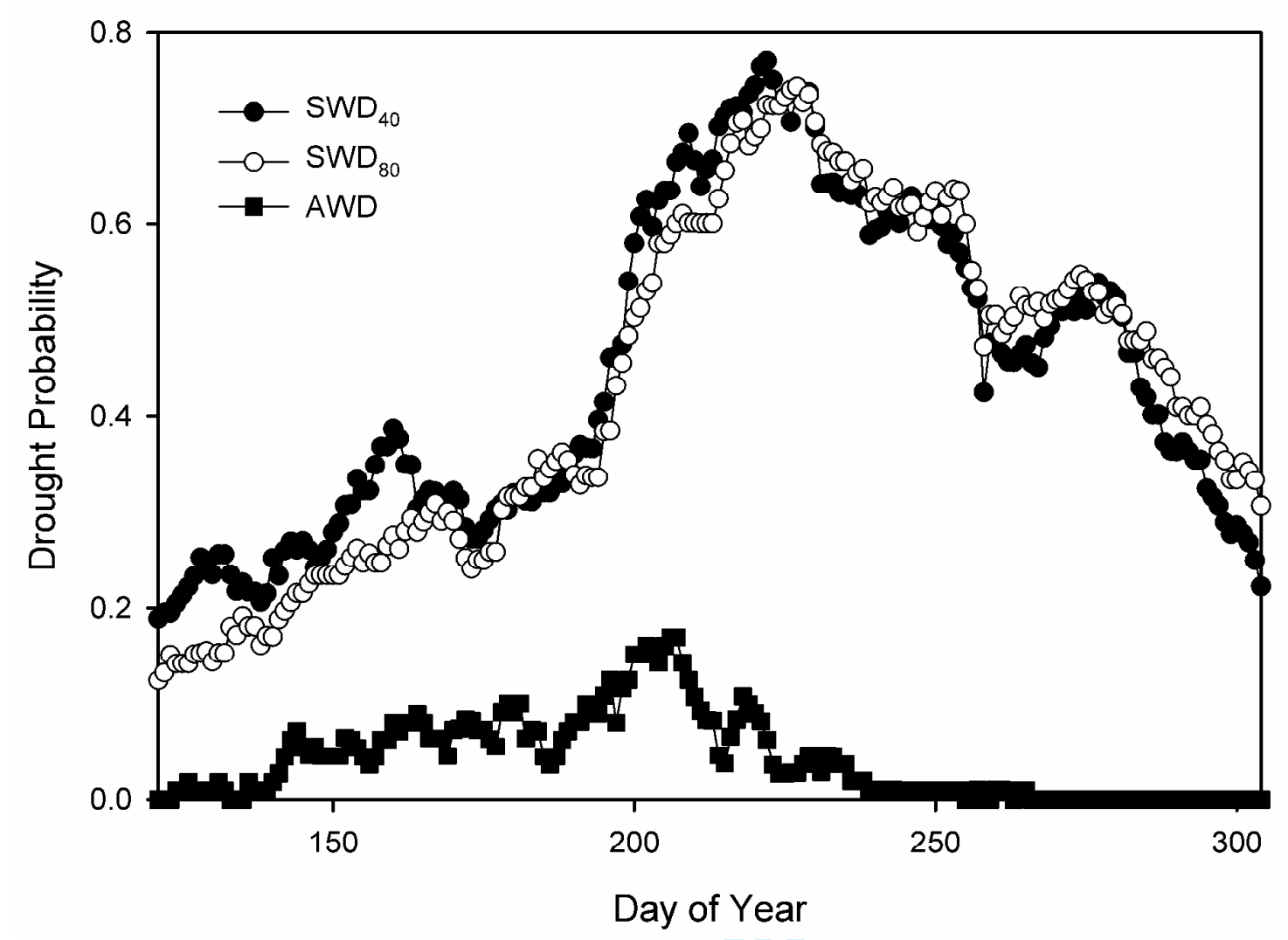

140 Fig. 17. Drought probabilities estimated by the AWD method and SWD methods for the 0- to 40-

$141\left(\mathrm{SWD}_{40}\right)$ and 0- to $80-\mathrm{cm}$ depths $\left(\mathrm{SWD}_{80}\right)$. Average for $15 \mathrm{yr}$ and eight sites in Oklahoma for

142 May 1 through October 31. (Reproduced from Torres et al., 2013). 


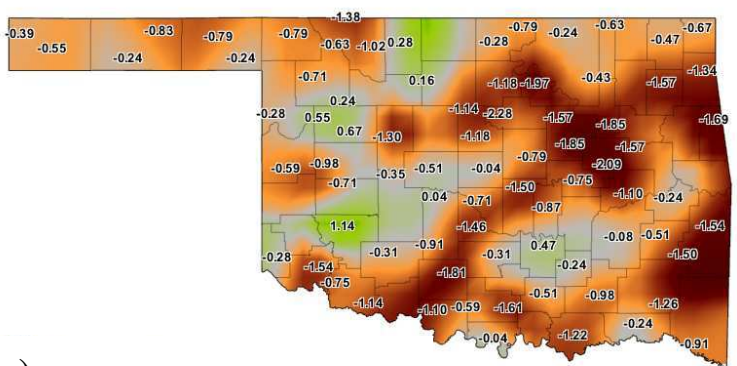

a)

147

148

149

150

151

c)

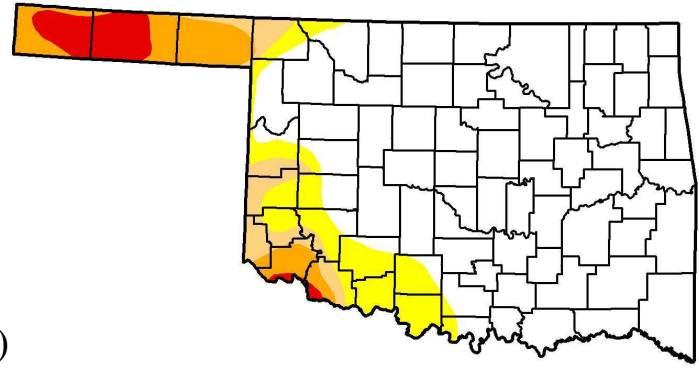

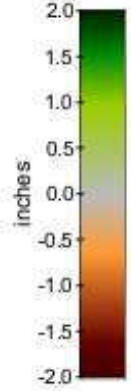

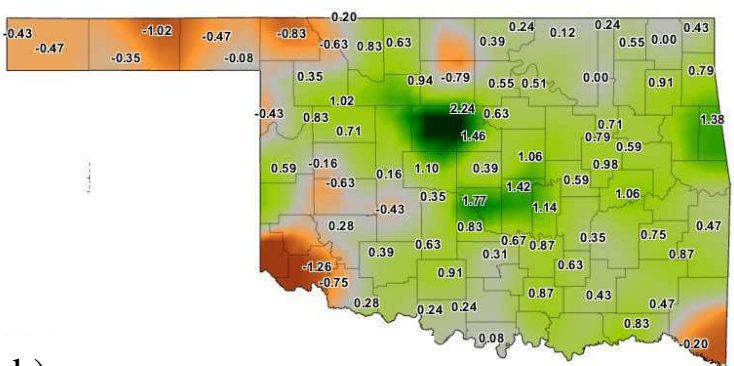

b)

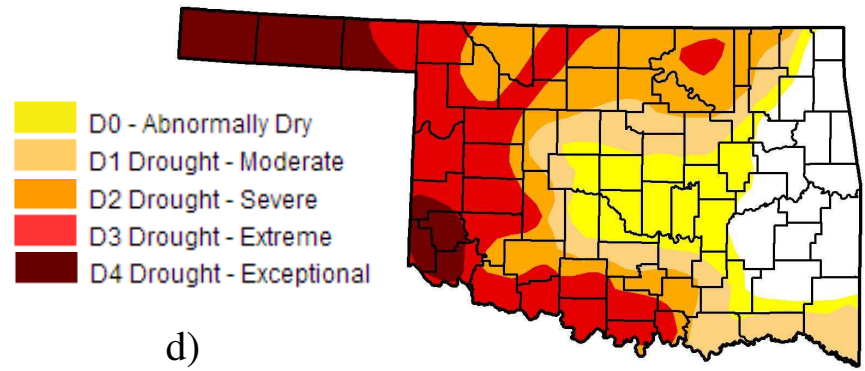

Fig. 18. Departure from average plant available water $(\mathrm{PAW})$ for the $0-16$ inch $(40 \mathrm{~cm})$ soil

154 layer across Oklahoma for May 2012 (a) and May 2013 (b). US Drought Monitor maps for

155 Oklahoma for May 15, 2012 (c) and May 14, 2013 (d). The PAW maps were adapted from the

156 Oklahoma Mesonet Long-Term Averages Maps

157 (http://www.mesonet.org/index.php/weather/mesonet_averages_maps). The Drought Monitor

158 maps were adapted from the US Drought Monitor Archives

159 (http://droughtmonitor.unl.edu/archive.html). 


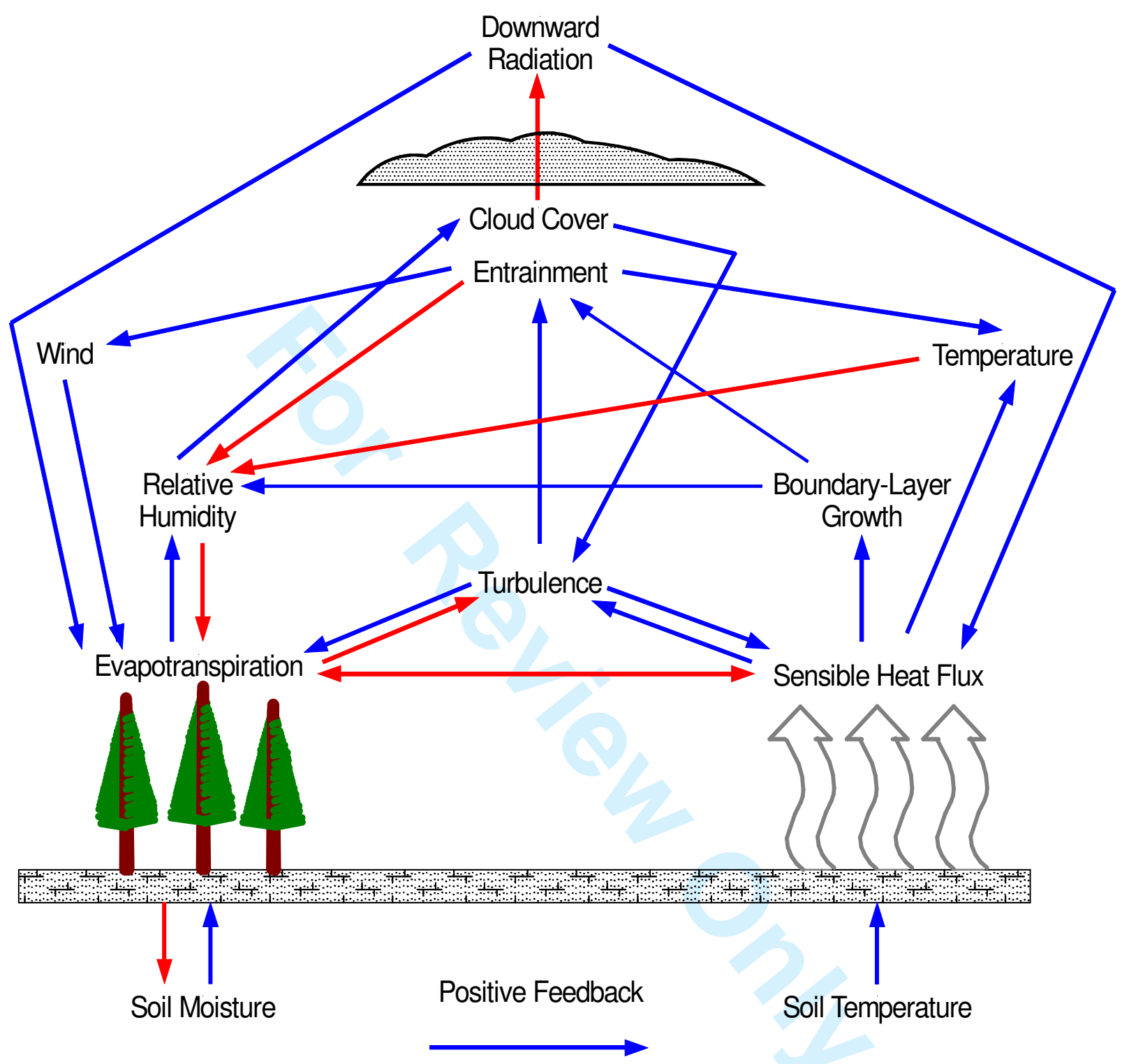

Negative Feedback

163 Fig. 19. Schematic of principle atmospheric boundary layer interactions with the land surface

164 conditions (modified from Ek and Mahrt, 1994 and Ek, 2005). Note that two consecutive

165 negative feedbacks result in a positive feedback. 

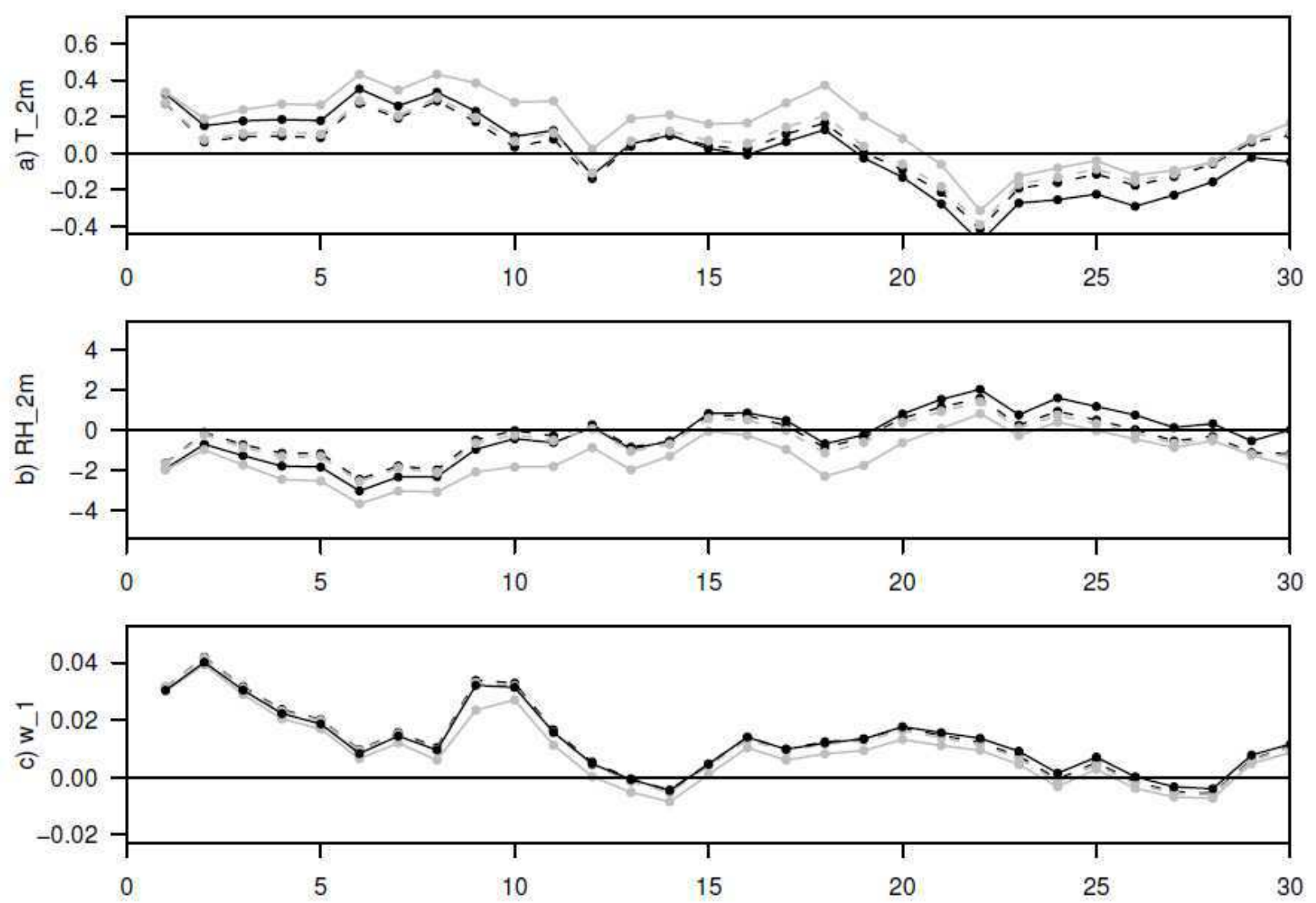

169 Fig. 20. Daily mean for each day in July 2006, averaged over Europe, of the observation minus

170 6-hour forecast of a) screen-level temperature (K), b) screen-level relative humidity (\%), and c)

171 near-surface soil moisture $\left(\mathrm{m}^{3} \mathrm{~m}^{-3}\right)$, from i) no assimilation (black, solid), and assimilation of ii)

172 screen-level temperature and relative humidity (black, dashed), iii) AMSR-E near-surface soil

173 moisture (grey, solid), and iv) both (grey, dashed) experiments. The assimilation was performed

174 with an EKF using Météo -France's ISBA land surface model. 

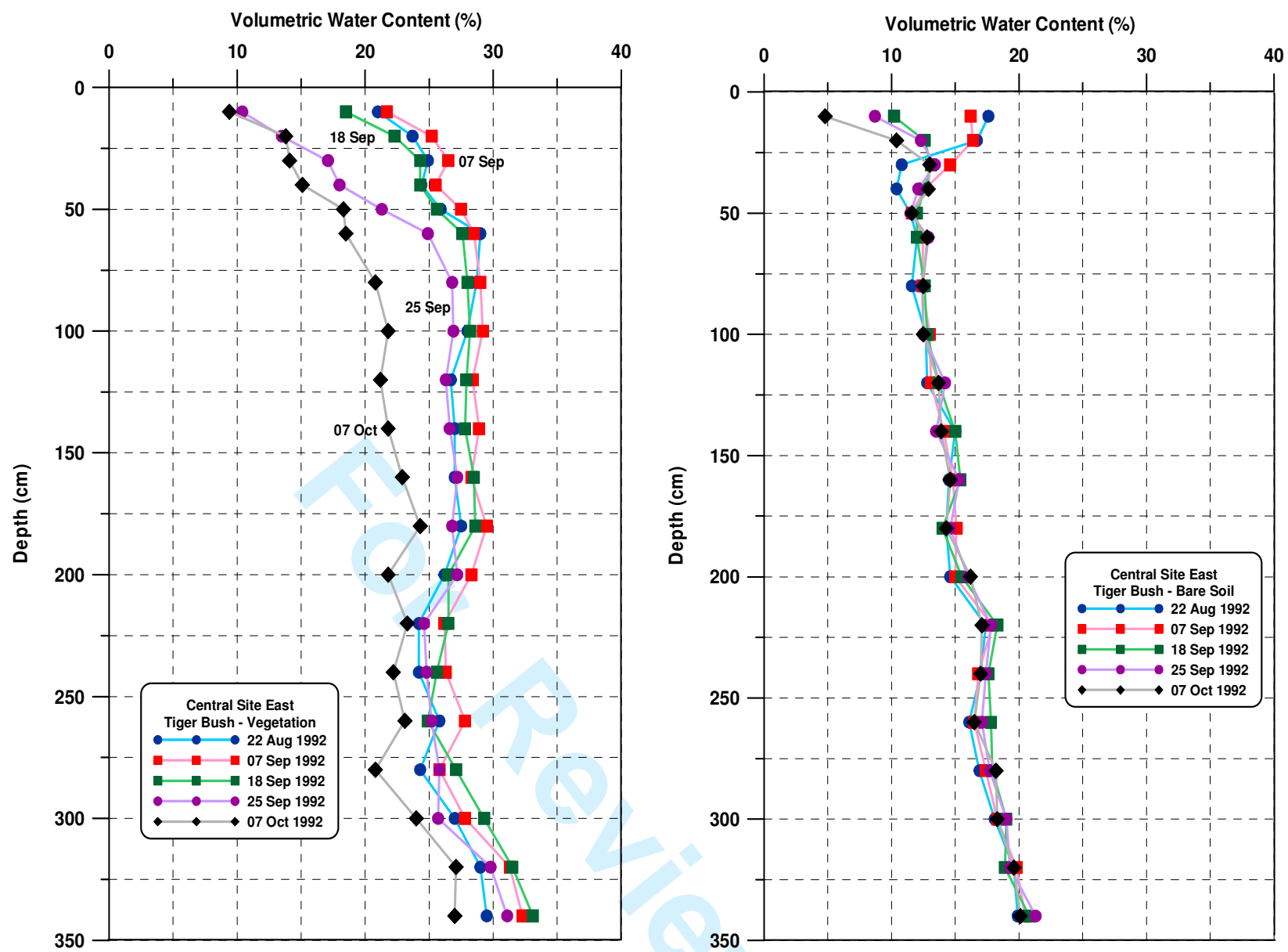

177 Fig. 21. Contrasting soil water depletion profiles from Central Site East-Tiger Bush, HAPEX-

178 Sahel project a) vegetated section and b) bare soil section (modified from Cuenca et al., 1996). 


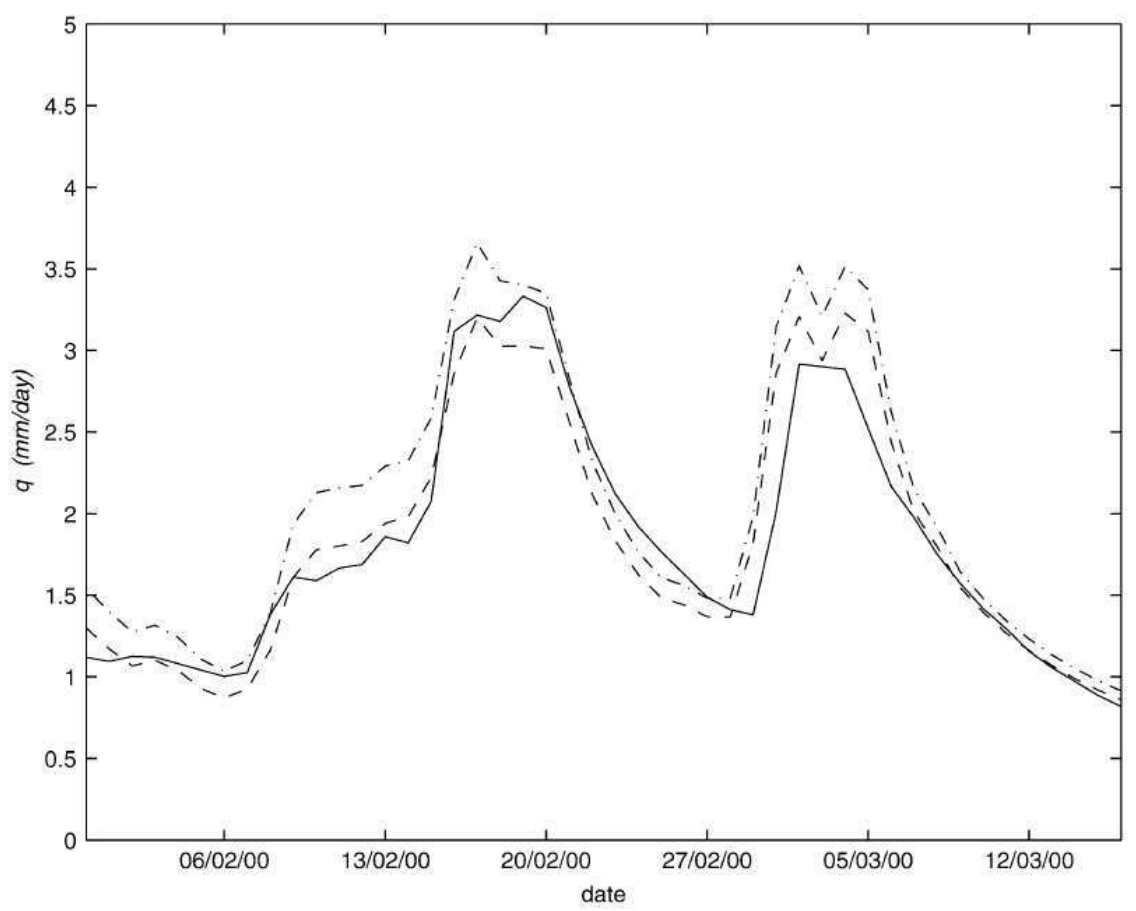

183

184 Fig. 22. Time series of streamflow $(q)$ at the outlet of the Serein catchment in the Seine river 185 basin in France for 1 Feb. 2000 to 15 March 2000. Solid line indicates measured streamflow, 186 dash dotted line indicates 1-day streamflow forecast without data assimilation, and dashed line 187 indicated 1-day streamflow forecast with assimilation of streamflow and in situ soil moisture 188 data. (Reproduced from Aubert et al., 2003). 